WHOI $-78-45$

\title{
SPACE AND TIME SCALES OF MESOSCALE MOTION IN THE WESTERN NORTH ATLANTIC
}

\section{by}

\author{
James G. Richman \\ Carl Wunsch \\ Nelson G. Hogg
}

\begin{abstract}
WOODS HOLE OCEANOGRAPHIC INSTITUTION Woods Hole, Massachusetts 02543
\end{abstract}

\author{
August 1978
}

\section{TECHNICAL REPORT}

Prepared for the Office of Naval Research under Contracts N00014-66-C-0241; NR 083-004, N00014-74-C-0262; NR 083-004 and N00014-76-C-0197; NR 083-400; and for the National Science Foundation under Grants GX-29054, GX-29034, OCE 75-03962 and IDO-82534.

Reproduction in whole or in part is permitted for any purpose of the United States Government. In citing this report in a bibliogrophy, the reference given should be to "Reviews of Geophysics and space Physics, Vol. 15, No. 4, November 1977, pp. 385-420". Approved for public release; distribution unlimited. 


\title{
Space and Time Scales of Mesoscale Motion in the Western North Atlantic
}

\author{
JAMES G. RICHMAN ${ }^{1}$ \\ Joint Program in Oceanography, Massachusetts Institute of Technology, Cambridge, Massachusetts 02139
}

Woods Hole Oceanographic Institution, Woods Hole, Massachusetts 02543

CARL WUNSCH

Department of Earth and Planetary Sciences, Massachusetts Institute of Technology, Cambridge, Massachusetts 02139

NeLson G. HogG

Woods Hole Oceanographic Institution, Woods Hole, Massachusetts 02543

\begin{abstract}
From moored data, primarily temperature, of the Mid-Ocean Dynamics Experiment (Mode I) and its successor experiments we find a statistical description of the mesoscale variability. In the Mode I area itself the spectral characteristics of the thermocline and the deep water are different. The thermocline is conveniently described as being made up of three spectral bands: a 'low-frequency' band dominated by zonal velocity fluctuations, an 'eddy-containing' band in which the velocity field is nearly isotropic, and a 'high-frequency' band consistent with models of geostrophic turbulence. In the deep water the zonal dominance at low frequencies is not apparent, and there is enhanced energy at periods of 20-50 days. Vertical structure scales with WKBJ approximation in the high-frequency band but not in the lower frequencies, where low vertical modes dominate the motion. Linear models do not adequately describe the data in the Mode I region. Differences between rough and smooth topography regions are clearly seen only at $1500 \mathrm{~m}$, where there is a loss of energy consistent with a reduced barotropic motion. Other differences, while apparently real, are small. It is found, consistent with the results of Schmitz (1976a), that the Mode I region is atypical of the midocean in that large changes of energy level are found elsewhere. A region due east of Mode I has slightly reduced kinetic energy levels in the main thermocline, but deep energy levels are much lower. Potential energy is less variable than kinetic; in the eastern region the frequency spectra change structure slightly. Linear models may be more adequate there. With more than 2 years of data, no statistically significant heat flux was found in the Mode I area, except for a weak zonal flux in the deep water. There is no direct evidence for baroclinic instability as a significant mechanism of eddy generation; the Gulf Stream is a possible, if unconfirmed, source.
\end{abstract}

\section{INTRODUCTION}

The Mid-Ocean Dynamics Experiment I (Mode I) was a cooperative effort on the part of many institutions and a large number of individual investigators to explore the nature of the variability of the oceanic interior at periods of days to months. Major goals of Mode I were to deduce whether the presumed variability field in the open sea occurred on definable time and space scales (and hence might be called 'eddylike'), to determine the energy levels of the variability relative to the energy of the mean circulation in a particular area, and to examine the zero-order dynamics of the variability field. In addition, there were a host of secondary objectives and experiments made possible by the presence in one area of a great many diverse measurement systems and ships. In the longer run the goals of Mode I and successor experiments are to understand the role of the variability field in the momentum, energy, and heat budgets of the general ocean circulation.

A number of authors have pointed out the analogy between the oceanic variability problem and similar problems in the atmosphere. One may regard the low Reynolds number discussions of the oceanic general circulation that were developed in the 1950's and 1960's [e.g., Stommel, 1965] as descriptions of the ocean climate. Indeed, they are analogous to the Hadley circulation of the atmosphere [Lorenz, 1969]. The variability, or eddy field, in the ocean might then be analogous to the

\footnotetext{
${ }^{1}$ Now at Department of Oceanography, Dalhousie University, Halifax, Nova Scotia, Canada.

Copyright (C) 1977 by the American Geophysical Union.

Paper number 7R0589.
}

weather systems, superimposed upon the climatic background. In the meteorological case it is well known that while kinematic distinctions may be made between the mean background climatic circulation and weather, or eddy, systems, a dynamical separation cannot be made and there is a complex interplay and flow of energies between the 'climatic' mean and eddies. In the ocean, one of the purposes of Mode I and like experiments is to deduce the degree to which a similar kinematic division is valid and whether a dynamical separation is possible.

However, the ocean presents a fundamentally more difficult observational problem than the atmosphere. The oceanic variability problem is important down to much smaller horizontal scales, but the periods, on the contrary, are much longer (we will become more specific below). The Mode I experiment was placed in an area (see Figure 1) that was dictated largely by logistical and instrumental considerations, but it was hoped that it would turn out to be not untypical of open ocean conditions. Typicality, of course, cannot be determined by an isolated experiment, and little prior information about the region was available. At the same time, the duration of the experiment was required, for logistical and instrumental reasons, to be no longer than 4 months. There was considerable evidence [e.g., Wunsch, 1972] that this period was too short to define the energy-containing part of the variability field. For these reasons the intensive Mode I field program was followed by a number of additional measurements of two major types. The first consisted of the so-called post-Mode experiment, which maintained a number of moored instruments (and Sofar floats [see Freeland et al., 1975]) within the Mode I area to improve the statistical reliability of the experiment and to 


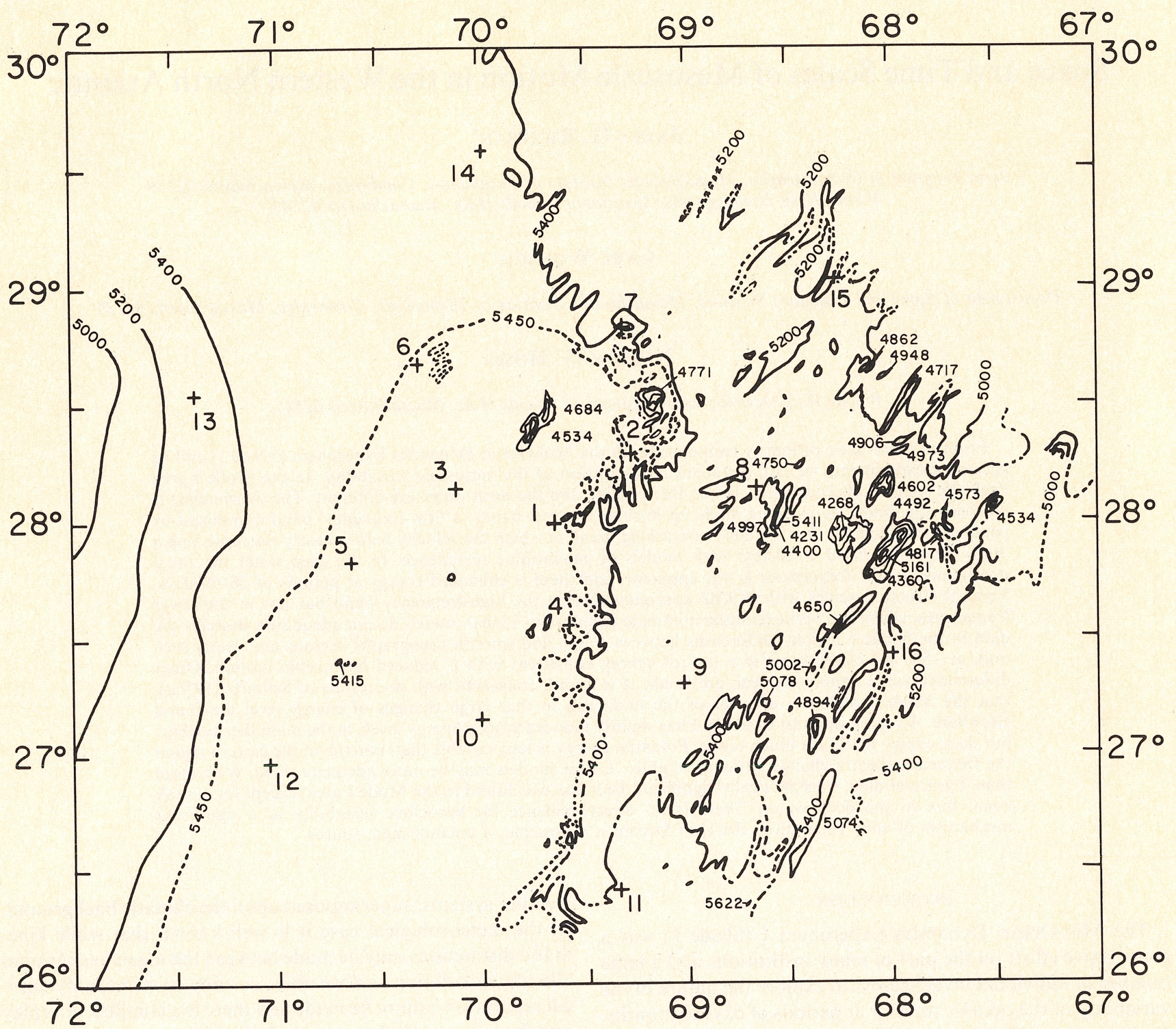

Fig. 1. Topography of the Mode I region, showing locations of Mode I moorings [after Bush, 1976]. Post-Mode site moorings were located at positions 1 and 8 .

investigate temporal stationarity. The second, sequel experiment has been dubbed Polymode and is continuing. But in its early stages, from which information is now available, a major goal was to understand the degree to which the Mode I area could be regarded as being typical of the ocean as a whole.

We will describe in some detail the results of the Mode I experiment and discuss the extent to which those results are likely to be representative of the average conditions in that area and in the ocean as a whole. We take this opportunity to point out that simply because of the very long time scales of the phenomenon, progress in this subject is likely to be slow in comparison to that in some other branches of physical oceanography. To date, a considerable literature has been published on the results of Mode I, and we will take the opportunity to review some of it. We have regarded the 'gray literature,' such as the Mode 'Hot-Line News,' as being mostly ephemeral. A semipopular account of Mode I may be found in the spring 1976 issue of Oceanus.

\section{EXPERIMENT}

The information available about the ocean eddy field prior to Mode I has been summarized by Gould et al. [1974] and will not be reproduced here except to say that some notion of dominant time and spatial scales at a few depths below the thermocline was available. (The shorthand term 'eddy' for the more general term 'variability field' is one that we find convenient. No prejudice concerning the dynamics of the variability is intended.) On the basis of the earlier information a moored array of 16 Woods Hole Oceanographic Institution (WHOI) subsurface moorings was placed in the area shown in Figure 1 on spatial scales consistent with the prior information. This array, our principal concern, was embedded in a larger field of instrumentation, to which we will refer as it becomes appropriate.

For reasons discussed by Gould et al. [1974], all of the moorings were of the subsurface type, reaching to a nominal level of $500 \mathrm{~m}$ below the surface. The instrumentation available was 80 current meters, of which 66 were AMF vectoraveraging current meters (VACM's) and the remainder, Geodyne 850 models. There were also 60 temperature/ pressure (T/P) recorders [Wunsch and Dahlen, 1974]. Standard WHOI mooring techniques and instrumentation have been described by Fofonoff and Webster [1971]. The T/P recorders were developed specifically for Mode I, and as they are a 
TABLE 1a. Deployment and Recovery Times and Positions for the Various Mode Moorings

\begin{tabular}{|c|c|c|c|c|c|c|c|}
\hline \multirow[b]{2}{*}{ Mode } & \multirow[b]{2}{*}{$\begin{array}{c}\text { WHOI } \\
\text { No. }\end{array}$} & \multicolumn{3}{|c|}{ Launch Data } & \multicolumn{3}{|c|}{ Recovery Data } \\
\hline & & $\begin{array}{l}\text { Date, } \\
1972\end{array}$ & $\begin{array}{l}\text { Time, } \\
\text { UT }\end{array}$ & $\begin{array}{c}\text { Geographic } \\
\text { Position }\end{array}$ & $\begin{array}{l}\text { Date, } \\
1973\end{array}$ & $\begin{array}{l}\text { Time, } \\
\text { UT }\end{array}$ & $\begin{array}{l}\text { Geographic } \\
\text { Position }\end{array}$ \\
\hline 1 & WH 481 & March 10 & 2358 & $27^{\circ} 59.8^{\prime} \mathrm{N}$ & July 4 & 1552 & $\begin{array}{l}27^{\circ} 58.0^{\prime} \mathrm{N} \\
69^{\circ} 416^{\prime} \mathrm{W}\end{array}$ \\
\hline 2 & WH 500 & April 4 & 0436 & $\begin{array}{l}69^{\circ} 39.0^{\prime} \mathrm{W} \\
28^{\circ} 17.0^{\prime} \mathrm{N} \\
69^{\circ} 16.3^{\prime} \mathrm{W}\end{array}$ & June 27 & 0829 & $\begin{array}{l}69^{\circ} 41.6^{\prime} \mathrm{W} \\
28^{\circ} 16.5^{\prime} \mathrm{N} \\
69^{\circ} 16.7^{\prime} \mathrm{W}\end{array}$ \\
\hline 3 & WH 499 & April 3 & 1641 & $\begin{array}{l}28^{\circ} 08.98^{\prime} \mathrm{N} \\
70^{\circ} 08.1^{\prime} \mathrm{W}\end{array}$ & June 28 & 0305 & $\begin{array}{l}28^{\circ} 09.0^{\prime} \mathrm{N} \\
70^{\circ} 08.1^{\prime} \mathrm{W}\end{array}$ \\
\hline 4 & WH 498 & April 3 & 0623 & $\begin{array}{l}27^{\circ} 33.1^{\prime} \mathrm{N} \\
69^{\circ} 34.1^{\prime} \mathrm{W}\end{array}$ & June 28 & 1138 & $\begin{array}{l}27^{\circ} 33.1^{\prime} \mathrm{N} \\
69^{\circ} 34.1^{\prime} \mathrm{W}\end{array}$ \\
\hline 5 & WH 494 & April 1 & 0807 & $\begin{array}{l}27^{\circ} 49.8^{\prime} \mathrm{N} \\
70^{\circ} 39.8^{\prime} \mathrm{W}\end{array}$ & June 29 & 2219 & $\begin{array}{l}27^{\circ} 49.3^{\prime} \mathrm{N} \\
70^{\circ} 39.9^{\prime} \mathrm{W}\end{array}$ \\
\hline 6 & WH 493 & March 31 & 1815 & $\begin{array}{l}28^{\circ} 42.0^{\prime} \mathrm{N} \\
70^{\circ} 15.8^{\prime} \mathrm{W}\end{array}$ & June 30 & 0514 & $\begin{array}{l}28^{\circ} 41.8^{\prime} \mathrm{N} \\
70^{\circ} 16.2^{\prime} \mathrm{W}\end{array}$ \\
\hline 7 & WH 501 & April 4 & 1200 & $\begin{array}{l}28^{\circ} 50.1^{\prime} \mathrm{N} \\
69^{\circ} 18.0^{\prime} \mathrm{W}\end{array}$ & June 30 & 1730 & $\begin{array}{l}28^{\circ} 50.5^{\prime} \mathrm{N} \\
69^{\circ} 19.0^{\prime} \mathrm{W}\end{array}$ \\
\hline 8 & WH 482 & March 12 & 0131 & $\begin{array}{l}28^{\circ} 09.3^{\prime} \mathrm{N} \\
68^{\circ} 39.3^{\prime} \mathrm{W}\end{array}$ & June 26 & 0940 & $\begin{array}{l}28^{\circ} 09.3^{\prime} \mathrm{N} \\
68^{\circ} 38.5^{\prime} \mathrm{W}\end{array}$ \\
\hline 9 & WH 497 & April 2 & 1641 & $\begin{array}{l}27^{\circ} 18.0^{\prime} \mathrm{N} \\
69^{\circ} 01.0^{\prime} \mathrm{W}\end{array}$ & June 28 & 2336 & $\begin{array}{l}28^{\circ} 18.4^{\prime} \mathrm{N} \\
69^{\circ} 01.2^{\prime} \mathrm{W}\end{array}$ \\
\hline 10 & WH 495 & April 1 & 1645 & $\begin{array}{l}27^{\circ} 08.8^{\prime} \mathrm{N} \\
70^{\circ} 00.0^{\prime} \mathrm{W}\end{array}$ & June 29 & 0955 & $\begin{array}{l}27^{\circ} 08.5^{\prime} \mathrm{N} \\
70^{\circ} 01.0^{\prime} \mathrm{W}\end{array}$ \\
\hline 11 & WH 485 & March 13 & 2241 & $\begin{array}{l}26^{\circ} 23.8^{\prime} \mathrm{N} \\
69^{\circ} 21.0^{\prime} \mathrm{W}\end{array}$ & July 2 & 2113 & $\begin{array}{l}26^{\circ} 23.8^{\prime} \mathrm{N} \\
69^{\circ} 20.6^{\prime} \mathrm{W}\end{array}$ \\
\hline 12 & WH 486 & March 14 & 1513 & $\begin{array}{l}26^{\circ} 57.5^{\prime} \mathrm{N} \\
71^{\circ} 02.6^{\prime} \mathrm{W}\end{array}$ & July 2 & 0523 & $\begin{array}{l}26^{\circ} 55.5^{\prime} \mathrm{N} \\
71^{\circ} 06.5^{\prime} \mathrm{W}\end{array}$ \\
\hline 13 & WH 488 & March 15 & 1516 & $\begin{array}{l}28^{\circ} 33.1^{\prime} \mathrm{N} \\
71^{\circ} 22.9^{\prime} \mathrm{W}\end{array}$ & July 1 & 1348 & $\begin{array}{l}28^{\circ} 29.3^{\prime} \mathrm{N} \\
71^{\circ} 23.9^{\prime} \mathrm{W}\end{array}$ \\
\hline 14 & WH 489 & March 16 & 0434 & $\begin{array}{l}29^{\circ} 35.0^{\prime} \mathrm{N} \\
69^{\circ} 59.1^{\prime} \mathrm{W}\end{array}$ & June 30 & 2325 & $\begin{array}{l}29^{\circ} 36.4^{\prime} \mathrm{N} \\
69^{\circ} 59.4^{\prime} \mathrm{W}\end{array}$ \\
\hline 15 & WH 483 & March 12 & 1519 & $\begin{array}{l}29^{\circ} 02.3^{\prime} \mathrm{N} \\
68^{\circ} 13.8^{\prime} \mathrm{W}\end{array}$ & July 3 & 2322 & $\begin{array}{l}29^{\circ} 02.6^{\prime} \mathrm{N} \\
68^{\circ} 14.0^{\prime} \mathrm{W}\end{array}$ \\
\hline 16 & WH 484 & March 13 & 0834 & $\begin{array}{l}27^{\circ} 25.1^{\prime} \mathrm{N} \\
67^{\circ} 59.5^{\prime} \mathrm{W}\end{array}$ & July 3 & 1004 & $\begin{array}{l}27^{\circ} 22.7^{\prime} \mathrm{N} \\
67^{\circ} 57.9^{\prime} \mathrm{W}\end{array}$ \\
\hline
\end{tabular}

Data are taken from Chausse and Tarbell [1976].

new instrument, we will devote a little space in Appendix A to a discussion of their performance and use, apart from the central issue of what the ocean appeared to do during Mode I.

The distribution of current meters and $\mathrm{T} / \mathrm{P}$ recorders and the geographical positions of the moorings are given in Table 1. Approximately half of the moorings were over the Hatteras Abyssal Plain (moorings 1-6, 10, 12, and 14), while the remainder were in a field of abyssal hills, generally roughening toward the east [Bush, 1977]. Toward the west the array comes close to the Blake-Bahama Outer Rise.

After considerable debate among the participants the array was designed to draw maps of the velocity and temperature fields. At this early state of exploration of the variability field it was believed that a visualization, or map, of the field would provide confidence in its interpretation. As will be seen, such maps were achieved; however, despite the weighting of the design procedure the array did function, at least partially, as an antenna as well. The resulting information is useful for interpreting the maps.

To test the representativeness of Mode I and to begin collecting proper statistical information about the eddy field, two site moorings were maintained in the area following the end of

TABLE 1b. Instrument Actual Mean Depths and Design Depths

\begin{tabular}{|c|c|c|c|c|c|c|c|c|c|c|c|c|c|c|c|c|}
\hline \multirow{2}{*}{$\begin{array}{c}\text { Design Depth, } \\
m\end{array}$} & \multicolumn{16}{|c|}{ WHOI Mooring Number } \\
\hline & 481 & 482 & 483 & 484 & 485 & 486 & 488 & 489 & 493 & 494 & 495 & 497 & 498 & 499 & 500 & 501 \\
\hline 500 & 391 & 406 & 447 & 441 & 421 & 415 & 419 & 404 & 408 & 391 & 452 & 374 & 413 & 427 & 379 & 421 \\
\hline 600 & 490 & 507 & 550 & 543 & 520 & & 521 & 507 & 512 & 492 & 554 & 478 & 513 & 531 & 485 & 523 \\
\hline 800 & 697 & 706 & 750 & 744 & 723 & 715 & 719 & 708 & 709 & 691 & 753 & 676 & 713 & 728 & 681 & 723 \\
\hline 1000 & 897 & 911 & & & & & & & 908 & 893 & & 880 & 914 & 933 & 882 & \\
\hline 1200 & 1095 & & & & 1133 & & & & & & & 1080 & & & & \\
\hline $\begin{array}{l}1500 \\
2000\end{array}$ & 1392 & 1411 & 1450 & 1443 & $\begin{array}{l}1426 \\
1926\end{array}$ & 1420 & 1429 & 1414 & 1410 & 1395 & 1452 & 1381 & 1414 & 1428 & 1382 & 1425 \\
\hline $\begin{array}{l}2000 \\
2500\end{array}$ & 2396 & & & & 2442 & & & & & & & 2392 & & & & \\
\hline 3000 & 2919 & 2936 & 2960 & 2953 & 2943 & 2940 & 2952 & 2936 & 2933 & 2924 & 2959 & 2913 & 2933 & 2945 & 2914 & 2936 \\
\hline 3500 & 3437 & & & & & & & & & & & 3433 & & & & \\
\hline $\begin{array}{l}4000 \\
4400\end{array}$ & 3963 & 3957 & 3968 & 3973 & $\begin{array}{l}3981 \\
4387\end{array}$ & 3948 & 3972 & 3959 & 3957 & 3954 & 3962 & $\begin{array}{l}3940 \\
4346\end{array}$ & 3948 & 3956 & 3936 & 3951 \\
\hline $\begin{array}{r}4400 \\
B-100\end{array}$ & $\begin{array}{l}4382 \\
5345\end{array}$ & 5128 & 5087 & & $\begin{array}{l}4387 \\
5317\end{array}$ & 5392 & 5226 & 5339 & 5347 & 5346 & 5374 & $\begin{array}{l}4346 \\
5185\end{array}$ & & & & 5297 \\
\hline
\end{tabular}

$\mathrm{B}$ is bottom. 


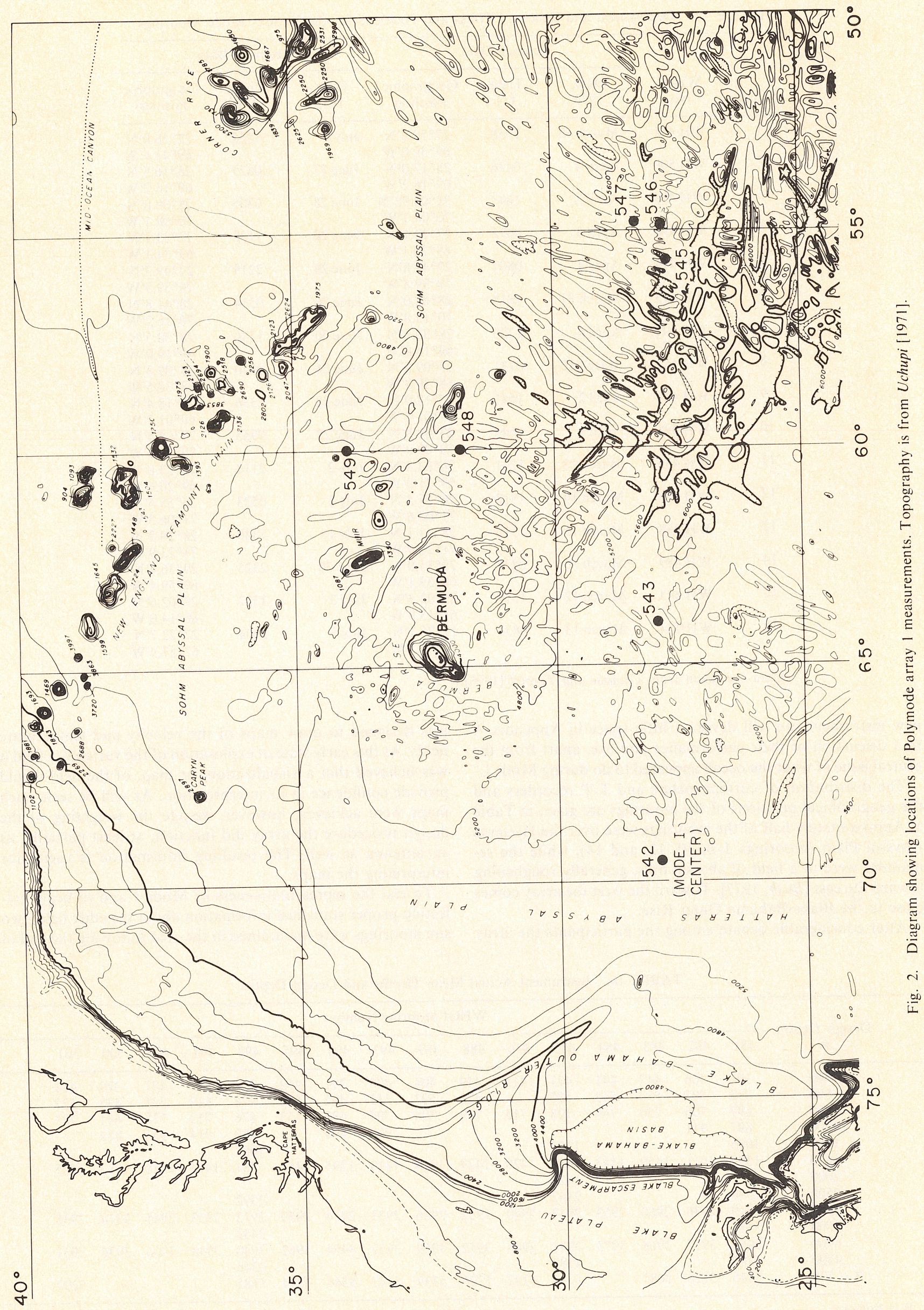




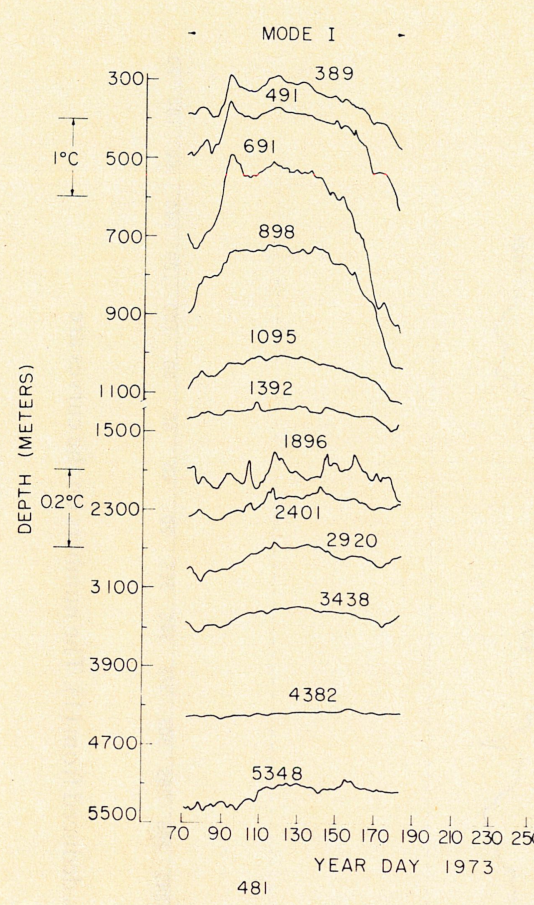

481 Fig. 3a. Temperature as a function of time at Mode center (mooring 1 position). Mode I itself occupied only the time
shown in 1973. Numbers at the bottom are WHOI mooring designations. For plotting purposes, records were placed in the vertical so that they begin at the appropriate depth, and they are thus somewhat arbitrary. Later records were sometimes displaced vertically to make transitions 'smooth' to the eye. The numbers on the curves are the measured mean pressure depths. The temperature scale $0.1^{\circ} \mathrm{C}$ applies to records above $1500-\mathrm{m}$ depth.

Mode I. These moorings were placed by the WHOI Moored Array Project ('Buoy Group') at the positions of Mode I moorings 1 and 8 and were maintained until July 1974. We will refer to the data from these moorings as 'post-Mode' data and to the locations of moorings 1 and 8 as 'Mode center' and 'Mode east,' respectively.

A hiatus in the temperature record occurred immediately following Mode I owing to the use of all instruments capable of measuring temperature in Mode I itself. A special internal wave experiment, called 'Iwex' [see Briscoe, 1975], was conducted $27 \mathrm{~km} \mathrm{SW}$ of Mode center on the abyssal plane during the period November-December 1973. A few of the temperature records from that experiment are included in our discussion as though they were obtained at Mode center. A number of investigators have used the specialized measurements obtained during Iwex to study Mode-related questions.

An experiment to follow Mode I was designed in the meantime, and some early information from part of that experiment, called Polymode array 1, is available. These moorings were placed in the western North Atlantic by the WHOI Buoy Group as is shown in Figure 2, the westernmost mooring being at Mode center. Schmitz [1976a, 1977] has discussed some results of these measurements.

Because of difficulties with the (then new) VACM instruments the current field was poorly sampled during Mode I [see Dexter et al., 1975]. We will tend therefore to concentrate upon the temperature field, which was well sampled by both the $\mathrm{T} / \mathrm{P}$ recorders and the current meters.

\section{Temporal Plots}

\section{General Description of Results}

We begin by describing in an overall sense the results of the moored velocity and (primarily) temperature measurements during Mode I. We will then examine the extended site mooring data set to provide a statistical context, to the extent that it is possible.

The central mooring (designated as either Mode mooring 1 or WHOI mooring 481) was the most heavily instrumented. In Figure $3 a$ we show the temporal evolution of the temperature field at that mooring during the course of the experiment. (A few instruments on the mooring were redundant, being paired very closely with others for test purposes, and have been omitted.) The mean temperature structure in the area is not really known. Thus the traces in Figure $3 a$ have been somewhat arbitrarily placed in the vertical by having them begin at the instrument mean depth. The temperature records have been low-pass-filtered prior to use, energy at periods shorter than 1 day thus being removed.

A number of features are worth comment. One sees in the thermocline a rapid warming that occurred during the first 20 days and a subsequent asymmetric cooling on a time scale about equal to the record length. Such a major warm feature is obvious in all the Mode I thermocline temperature records. This gross trend of the isotherms is apparent nearly all the way to the bottom, evidently in phase from the thermocline to 3500 $\mathrm{m}$ and perhaps below. That Mode I saw at best a single realization of the energetically dominant process is obvious. One also sees superimposed upon the large-scale thermocline feature some smaller oscillations with about 10- to 20-day periods. These appear to be coherent in the vertical only within the thermocline itself. Deeper down, less small-scale variability is obvious to the eye, except at $1392 \mathrm{~m}$ and $1896 \mathrm{~m}$, where the records appear to be dominated by smaller scales. Most variability at these levels is believed to be due to variations in the TS relation resulting from the presence of the complex-structured Mediterranean salt tongue rather than to the actual dis- 


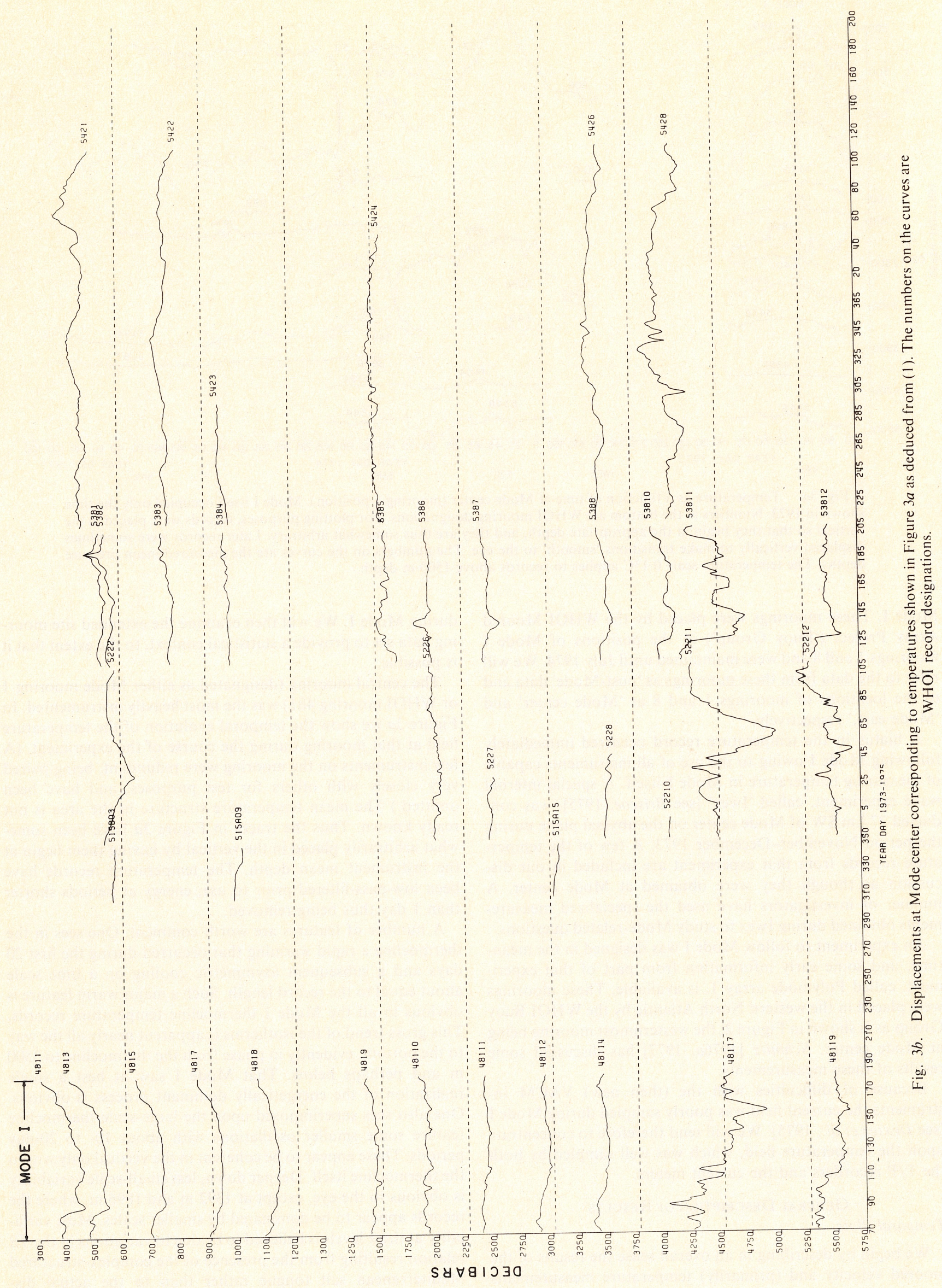




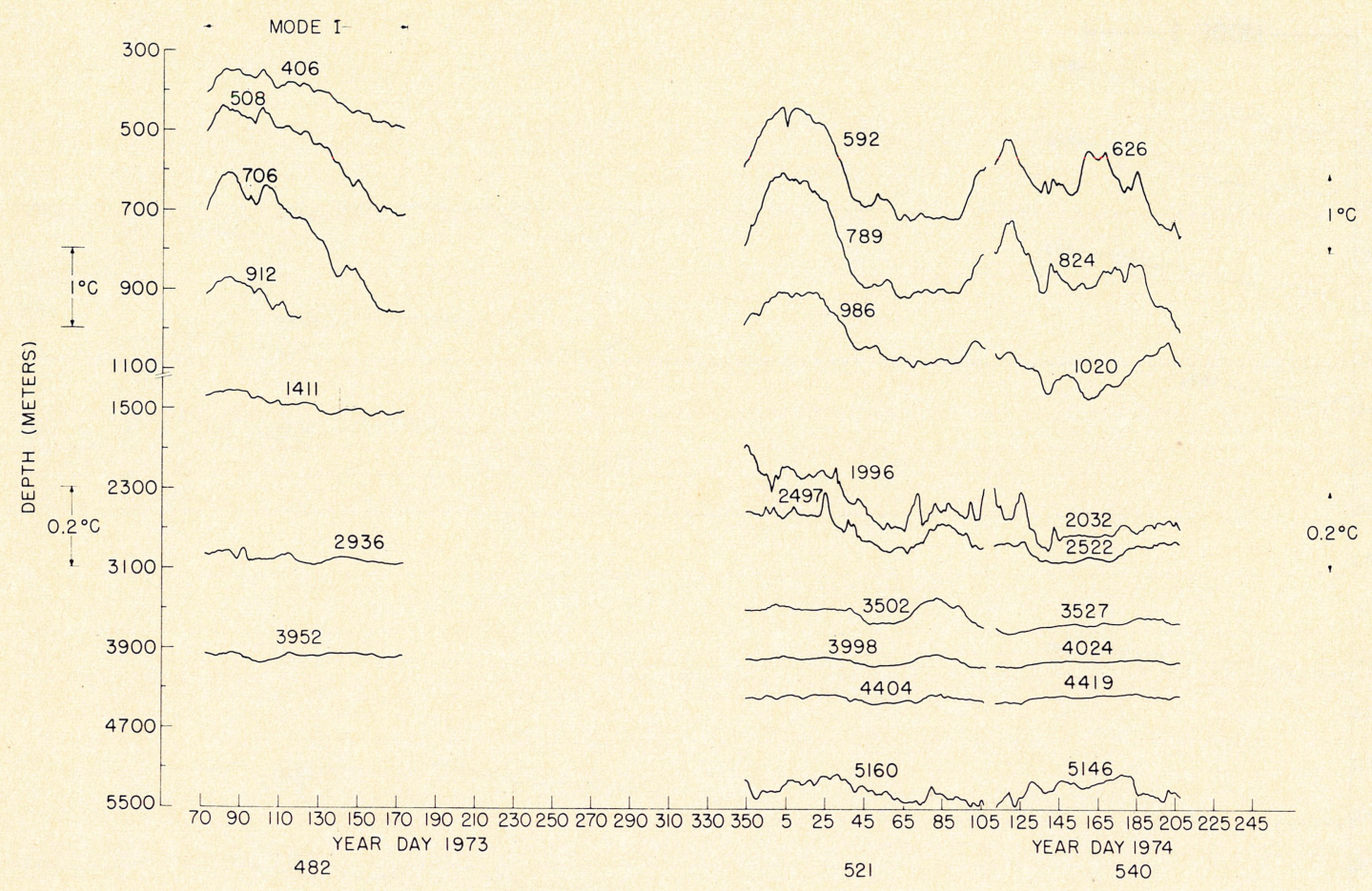

Fig. 4a. Same as Figure $3 a$ except at Mode east, i.e., position of mooring 8 .

placement of the isopycnals. The deepest record, only $100 \mathrm{~m}$ from the bottom, also appears to be slightly different, being dominated by two roughly constant temperature periods separated by a rather abrupt transition. This transition may represent a passage of the boundary between a pool of Antarctic Bottom Water and surrounding North Atlantic Deep Water.

The temperature field plotted in Figure $3 a$ distorts to some extent one's picture of the actual movement of water owing to the large changes in temperature gradient over the water column. A different view of the motion, embodying different distortions, can be obtained by plotting vertical displacement in the form

$$
\zeta(t)=T(t) /\left(d T_{0} / d z\right)+C
$$

The vertical temperature gradient $d T_{0} / d z$ used in (1) was obtained as an average of 11 CTD (conductivity, temperature, and depth) stations within $3.6 \mathrm{~km}$ of the mooring position (see Appendix B for a display of the mean station). The constant $C$ is chosen to give zero displacement at the appropriate mean temperature. The result is shown in Figure $3 b$, which makes it clearer than the temperature record does that large vertical displacements occur in the deep, low-stability water. The application of (1) to the lowest record is dubious if, as is supposed above, the temperature changes there are primarily due to horizontal advection.

Another heavily instrumented mooring was Mode mooring 8 (WHOI 482) to the east-northeast of the center; its temperature records are shown in Figure $4 a$, and the displacement field is shown in Figure $4 b$. Though fewer instruments are available, the records are much the same as those at Mode center. The warm thermocline feature apparently was seen in a later stage of its passage, the abrupt initial onset evidently occurring just prior to the setting of the mooring. The simplest interpretation of the relationship between Figures 3 and 4 is that this feature reached mooring 8 prior to reaching mooring 1. Superimposed smaller scales are also clearly seen.
Maps

Some intuitive feeling for the movement and evolution of atmospheric weather systems can be achieved by studying newspaper weather maps. One can construct analogous maps within the Mode I area at a variety of depths in a variety of ways. The moored array was designed largely in accordance with the requirements of the objective mapping scheme described by Bretherton et al. [1976].

To construct these maps, a number of preliminary steps were required. First, the data were filtered to remove effectively all energy at periods shorter than 12 days. Second, the simplest of possible mooring motion correction schemes was used, in which the mean gradients were taken from a spatial average of the hydrographic temperature gradients as supplied by R. T. Millard and H. L. Bryden (personal communication, 1974). The procedure is equivalent to the regression scheme used elsewhere in this paper (see Appendix A). Third, by using the same mean gradient profile the instruments were reduced to seven nominal mean depths.

Because descriptions of the objective analysis method have now been published in a number of places and because it falls under the general rubric of 'optimal estimation' [e.g., Liebelt, 1967], we will not describe it again. We will only point out that one needs an estimate of the two-dimensional temperature correlation function at each level to be mapped and an estimate of the mean temperature of each level. The algorithm as implemented by Bretherton et al. [1976] makes the vastly simplifying assumption that the correlation function is horizontally isotropic. The estimate of the mean depends upon the correlation function and is the maximum likelihood estimate for Gaussian variates.

In principle, the correlation function is determined from the available data. But as was noted, the Mode I experiment was too short to produce statistically meaningful results on the time and space scales of the energetically dominant signal. Because the maps are to be used qualitatively and because 


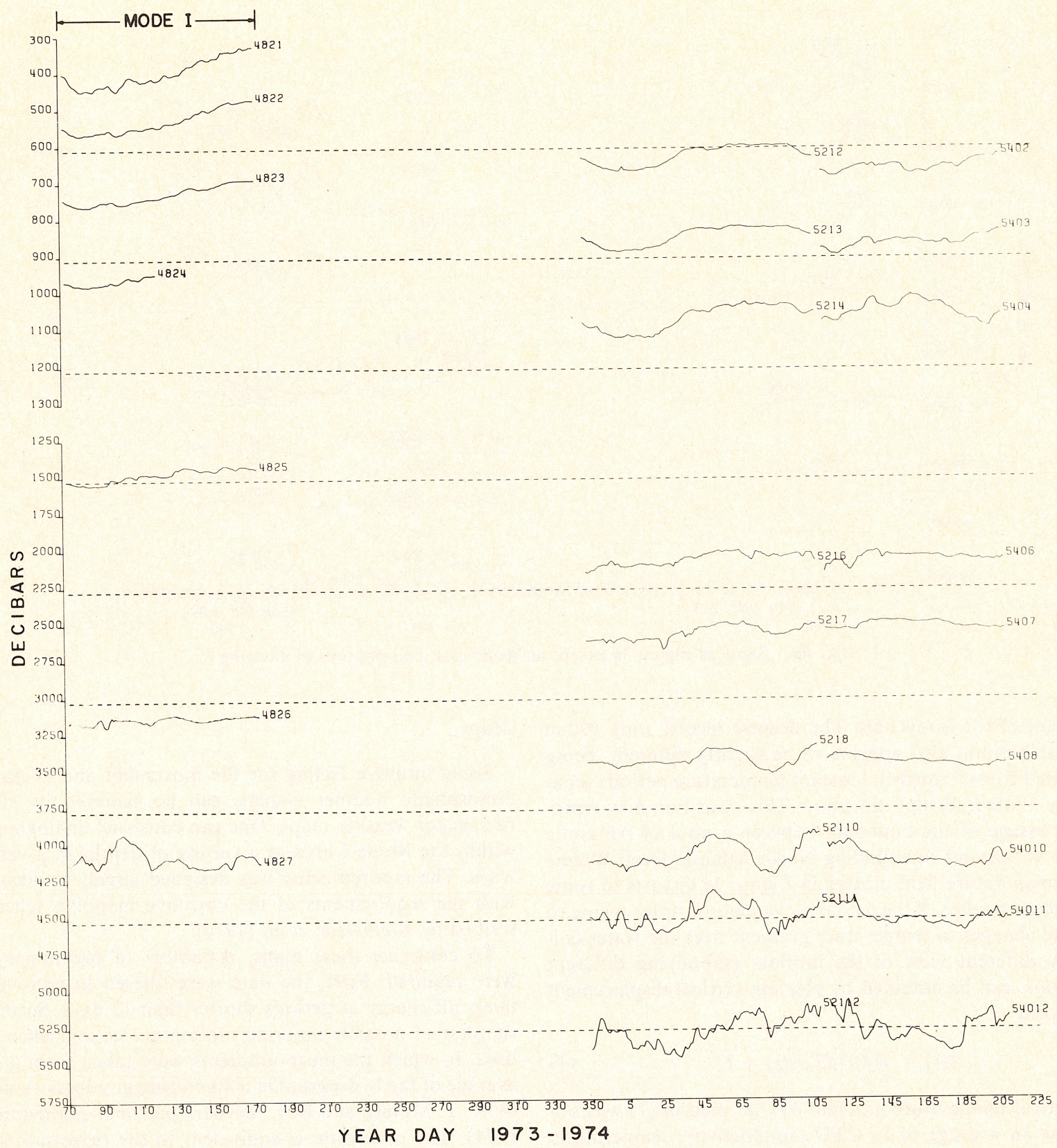

Fig. $4 b$. Same as Figure $3 b$ except at Mode east, i.e., position of mooring 8.

experimentation with different correlation functions did not significantly change the maps, we have chosen to use an analytic form of correlation, $R(\tau)$, where

$$
R(\tau)=\epsilon^{2} \delta(\tau)+\left(1-\epsilon^{2}\right) \exp \left\{-\tau^{2} / \Delta^{2}\right\}
$$

where $\Delta=100 \mathrm{~km}$ for all levels. The delta function represents an assumed noise level for the measurement and could be thought of as internal waves of about $5 \mathrm{~m}$ in the thermocline. The correlation function (2) is a simple two-parameter approximation that roughly reproduces the small separation behavior of the correlation functions estimated from the data. It does differ from the empirical functions in not giving negative lobes beyond $100 \mathrm{~km}$ (see discussion below), but the use of correlations with negative lobes did not give very different results within the accurate mapping region. Estimates of the mapping error are, however, more sensitive to the exact form of the correlation function.

Representative 12-day mean maps from three levels, 420, 1420 , and $3960 \mathrm{~m}$, a subset of the possible mapping levels, are shown in Figure $5 a$. (A fuller map display can be found in the work of Hogg [1977].) The error variance for each level is shown in Figure $5 b$ and differs at each level owing to differing instrument distribution and noise level. By using these error estimates, contours in the maps from regions where the expected error exceeds $50 \%$ have been eliminated, and the regions have been shown as shaded. Superimposed upon the maps are available moored current vectors averaged over the same 12-day period.

Thermocline $(420 \mathrm{~m})$. Initially, a warm patch of water is centered on mooring 1 , the central mooring. Maximum measured temperature is about $17.5^{\circ} \mathrm{C}$, there being an $\mathrm{E}-\mathrm{W}$ elon- 

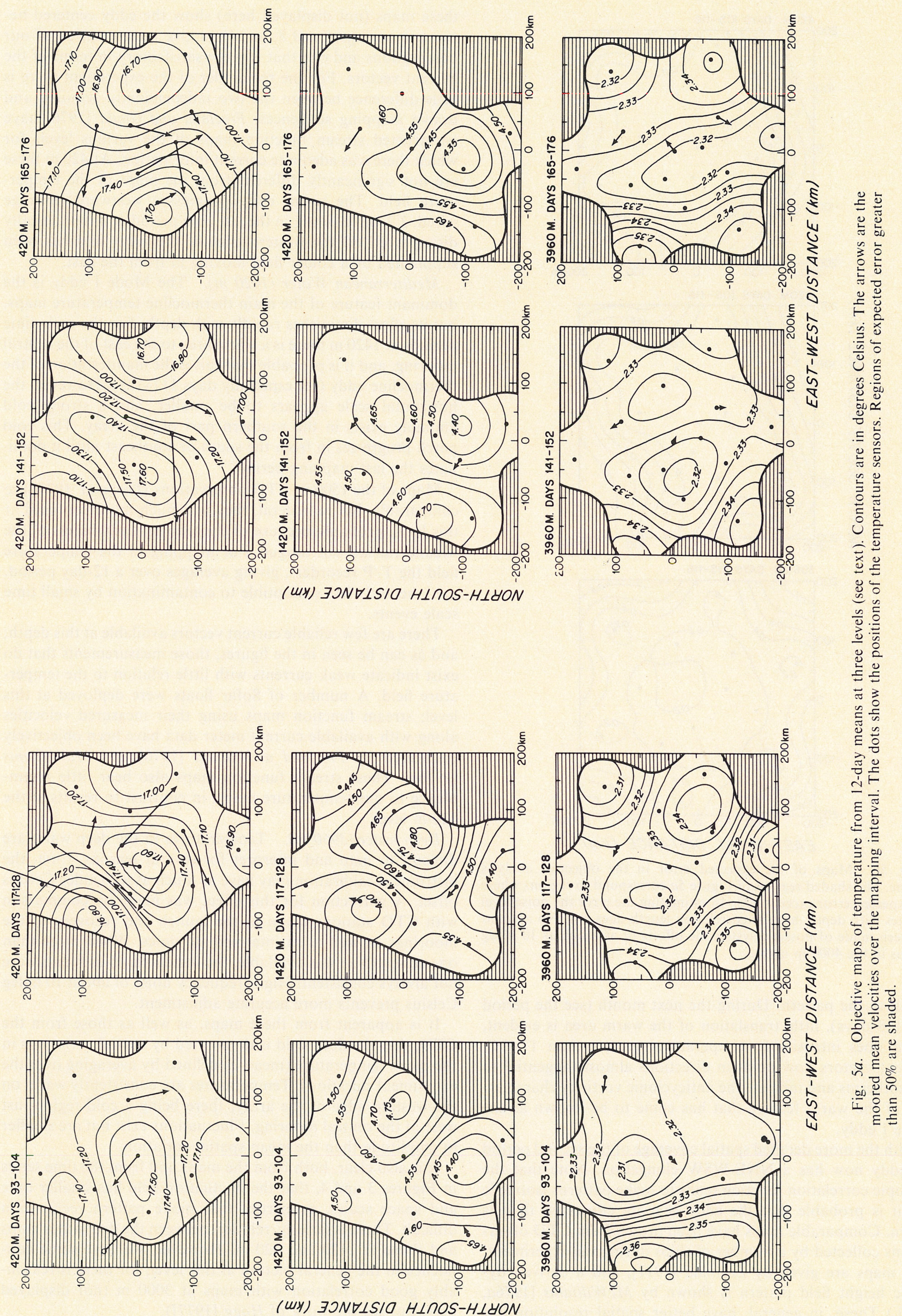

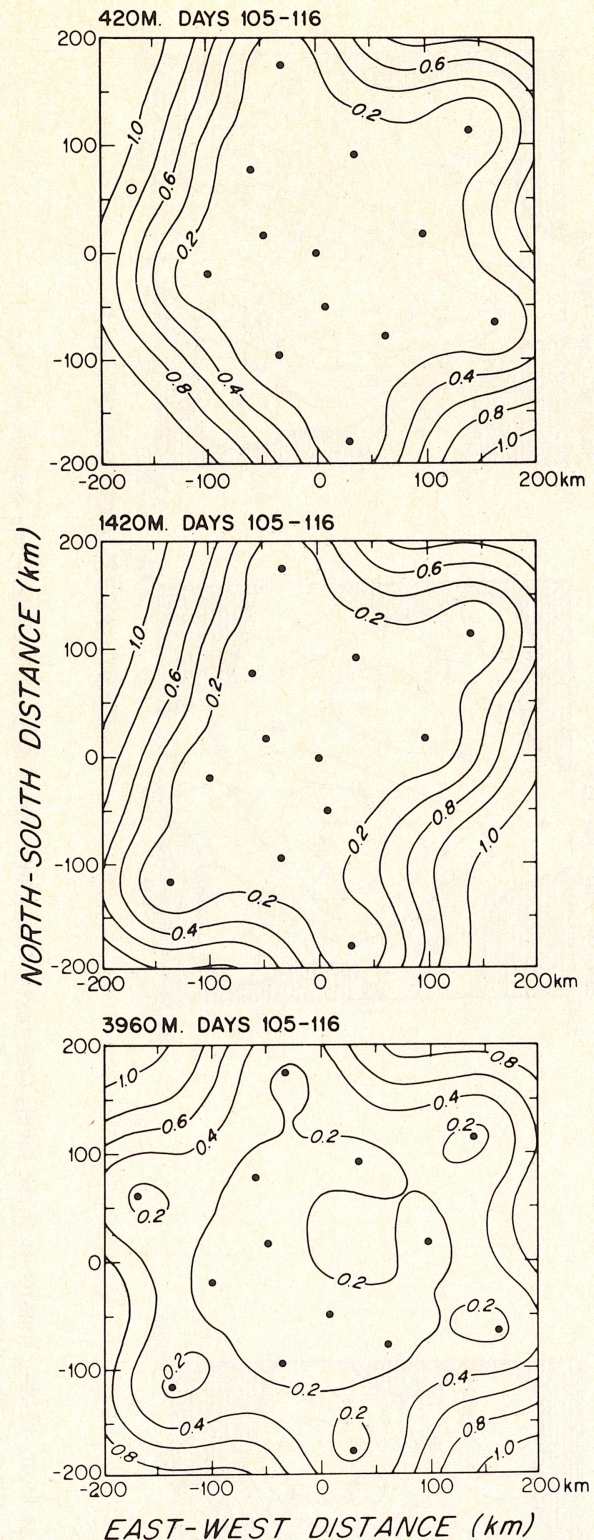

Fig. $5 b$. Maps of the expected error in the objective analysis scheme. The shaded regions of Figure $5 a$ correspond to regions where the expected error exceeds $50 \%$. In estimating the error the noise level changes with depth, but the correlation length does not. No account has been made of possible systematic offsets of as much as $10 \mathrm{mdeg}$ Celsius in the 4000-m maps.

gation to the pattern. During the next month (see the period 117-128 days), little translation of the warm area is evident, but it does intensify to temperatures greater than $17.6^{\circ} \mathrm{C}$. Current vectors now point in directions almost tangential to the isotherms and indicate the anticyclonic vorticity characteristic of the warm feature that has come to be known as the Mode I eddy.

With the more detailed spatial coverage of the second period the eddy now has a NNE-WSW elongation. Note that the isotropic correlation function tends to make patterns isotropic and it is probable that the eddy is more elongated than is shown. Comparable maps have been drawn from CTD observations collected by a number of ships during the experiment. (The maps are given by Leetmaa [1977], and a derived dynamic height field pattern is shown by McWilliams [1976a, 1977].) These, in general, have better spatial resolution but poorer temporal resolution. For the first period, days 93-104, these maps (not displayed here) show the eddy centered between moorings 1 and 8 , an alternative interpretation of our observations and one that is more satisfactory in terms of the current vectors. For the remainder of the experiment there is little difference between the two independently acquired and drawn mapping sequences. Freeland and Gould [1976] have constructed stream function maps of the various levels for which there was adequate current information. At $420 \mathrm{~m}$ these are not significantly different from the maps of the temperature field. The warm eddy progresses westward (average speed, $2.2 \mathrm{~km} / \mathrm{d}$ ) until, in the last time period, it has practically disappeared off the western edge of the array and has been supplanted by a colder field moving in from the east.

Mediterranean Water $(1420 \mathrm{~m})$. The Mode I eddy is the dominant feature of the main thermocline temperature maps, but its effect diminishes rapidly with depth. For the early time periods at $1420 \mathrm{~m}$ there is a warm area to the east of the central mooring, and it is probable that this is the manifestation of the thermocline eddy (see especially days 117-128). However, the horizontal scale appears to be smaller, and a strong cold anomaly exists in the southern part of the array. This cold patch progresses in from the south or southeast until it dominates the last mapping period.

Maps of the 1500-m CTD observations [Leetmaa, 1977] are comparable, but in general, they are much more confused at this level, probably because of the temporal patchiness of the Mediterranean salt tongue. For mapping of the temperature field the $\mathrm{T} / \mathrm{P}$ recorders, giving averages over a 12-day period, are inherently less susceptible to contamination by small time scale events.

There are few reliable current vectors available at this depth, and as can be seen in the figures, those measurements that do exist indicate weak currents with little relation to the temperature field. A number of Sofar floats were deployed at this level; stream function maps using their measured velocities along with available current meter data have been objectively contoured by Freeland and Gould [1976] and McWilliams $[1976 a]$. These stream function maps also bear little resemblance to our temperature maps, in contrast to results at the 420-m level.

Deep water $(3960 \mathrm{~m})$. Temperatures in the deep water are difficult to map and interpret for several reasons. First, the instrument calibration may have as much as a $20 \mathrm{mdeg}$ Celsius offset. A correction for this effect was made by comparison with CTD stations taken at the launch and recovery of the moorings as well as at intermediate times. When more than one comparison was available, the indicated adjustments were not always consistent. High-frequency noise of about $10 \mathrm{mdeg}$ Celsius prevents more accurate adjustment.

It is apparent from these maps, as well as those from the CTD, that the deep field is dominated by spatial variations in the mean temperature (mean as defined by averaging over the experiment duration). Temperatures are consistently warm on the western edge of the array, there being a cold region just west of the central mooring. Fluctuations exist but are smaller in amplitude than the mean spatial variation.

It is also clear, both from the maps and from the time series in Figures 3 and 4, that the fluctuation field has smaller time and space scales, properties that make pattern recognition difficult. There is little correlation between the deepwater maps and those at 1420 and $420 \mathrm{~m}$. However, we have some confidence in the general picture at this level, for there is reasonably good correlation with maps at $3000 \mathrm{~m}$ (not displayed here, but see the work of Hogg [1977]).

There is a tendency for the mean spatial variation of the 

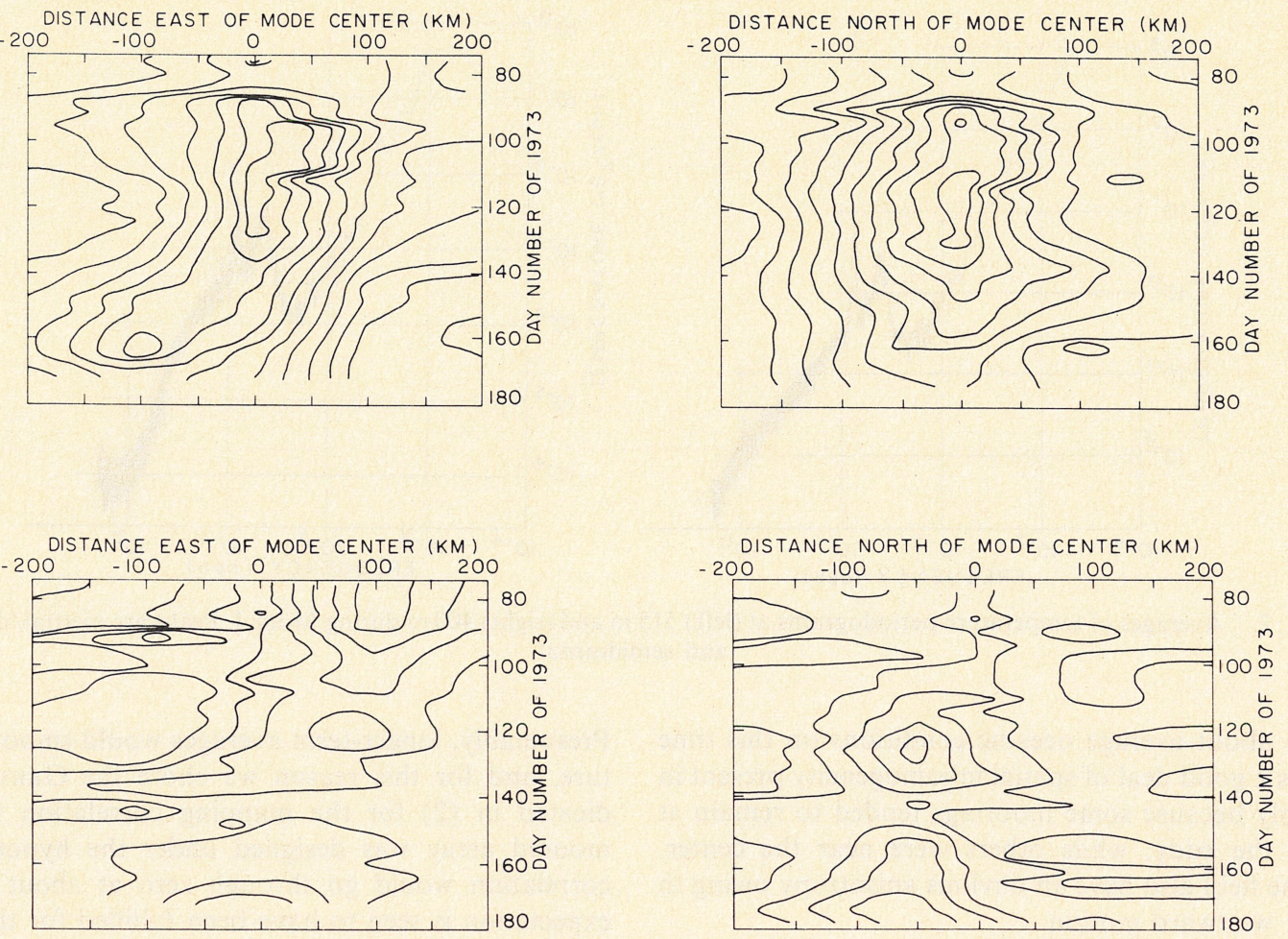

a

Fig. 6. Phase diagrams of the temperature field at depths of $(a) 420 \mathrm{~m}$ and $(b) 1420 \mathrm{~m}$ showing the eastward and northward components of propagation. Note the clear westward movement in the thermocline.

temperature to follow the topography, cold water occurring over the abyssal plain and warmer water over the rough topography. Geostrophically, this would suggest a weak northward flow on the west and a weak southward flow on the east (a $0.02^{\circ} \mathrm{C} / 100 \mathrm{~km}$ temperature gradient translates to about a 0.2 $\mathrm{cm} / \mathrm{s} / \mathrm{km}$ velocity gradient). Historically, we expect the mean flow in the Mode region to be a weak northward bottom flow of Antarctic Bottom Water and a southward flow of North Atlantic Deep Water above and in the western boundary undercurrent along the Blake-Bahama Outer Rise [Hollister and Heezen, 1972]. Over the abyssal plain, all the bottom current meters have a mean northward component. However, over the hills the mean flow pattern is confused but suggests a topographic control to the deep flow, although none of the mean flows observed during Mode I are statistically different from zero. The only significant mean flow occurs in the longerduration records in the deep water at Mode east [Schmitz, $1976 b$ ] and is a southward flow roughly parallel to the local topography [cf. Wunsch, 1977] consistent with our observation of generally colder water on the abyssal plain. McWilliams and Flierl [1976] note from the historical density data in the region that only above $400 \mathrm{~m}$ is any significant geostrophic shear expected. In general, the mean flow in the Mode region is small.

Phase diagrams. A dominant feature of the temperature field maps is the westward motion of the eddy. We can investigate further the pattern motion in the maps by constructing E-W and N-S phase diagrams along $28^{\circ} \mathrm{N}$ and $69^{\circ} 40^{\prime} \mathrm{W}$, respectively (through the center of the array), shown in Figure 6.

The motion of the main thermocline eddy cannot be described by a constant westward velocity. During the early part of Mode I the pattern speed is about $1.2 \mathrm{~km} / \mathrm{d}$ to the west, increasing to $3.3 \mathrm{~km} / \mathrm{d}$ after day 130 and averaging $2.2 \mathrm{~km} / \mathrm{d}$ for the experiment. There is no appreciable north-south motion of the eddy.

Freeland and Gould [1976], assuming that the observed velocity field is horizontally nondivergent and may be represented by the curl of a stream function derived from float and current meter measurements, found a mean westward phase speed of $2.2 \mathrm{~km} / \mathrm{d}$ for the thermocline stream function, consistent with the temperature pattern motion. Maps of temperature and stream function in the thermocline are visually similar.

In the Mediterranean Water, westward motion of the eddy field of $2-3 \mathrm{~km} / \mathrm{d}$ is readily apparent. However, at this depth, Freeland and Gould found a stream function phase speed of $5.1 \mathrm{~km} / \mathrm{d}$, and there is little visual similarity to the temperature maps. In the deep water, no westward motion of the temperature field was evident during Mode I. No phase diagram at this depth is shown because the short space and time scales make a sensible contouring difficult. In contrast to the temperature field, Freeland and Gould obtained a $5-\mathrm{km} / \mathrm{d}$ phase speed for the deepwater stream function. It is possible to relate some of the differences between the temperature maps and the stream function maps to the relative strengths of the barotropic and baroclinic components of the motion at a given level (see the section below on dynamical considerations).

\section{Empirical Spectra and Correlation}

The temperature and velocity maps give one a qualitative feeling for the evolution of the field during Mode I. But to relate these fields to any dynamical notions, one must quantify them in some way. It is fairly obvious from Figures 3 and 4 that Mode I was dominated by a single 'event' in the thermocline and that from these measurements alone one cannot 

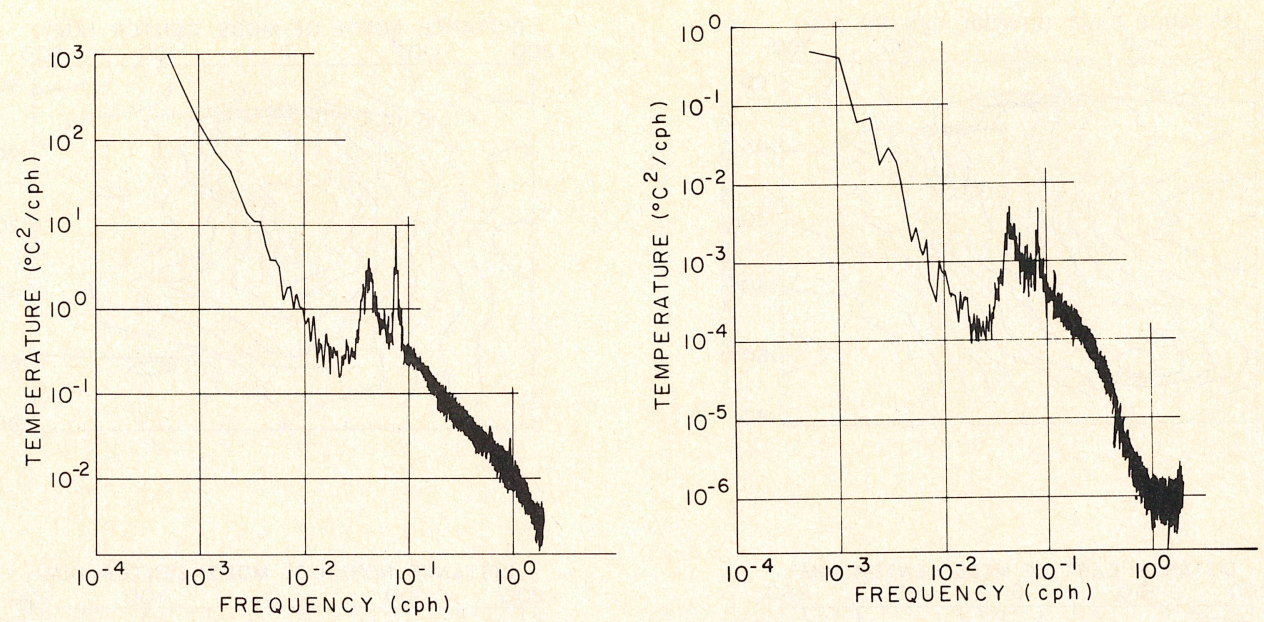

Fig. 7. Averages of temperature periodograms at (left) $515 \mathrm{~m}$ and (right) $400 \mathrm{~m}$ during Mode I. Peaks are inertial/diurnal and semidiurnal.

deduce much about average oceanic conditions on this time scale. There is a good deal of spatial inhomogeneity present in the field simply because some moorings tended to remain at the edges of the eddy, while others were near the center. Changes in the field also have an obvious anisotropy owing to the dominant westward motion.

A formal representation of the time and length scales can be obtained by computing the spectra and/or correlation functions of the data. In Figure 7 we show the temperature spectra computed by averaging the periodograms at two levels, $515 \mathrm{~m}$ and $4000 \mathrm{~m}$, from all the moorings. The 'reddish' nature of the spectra is the most prominent characteristic. There is a hint that the $4000-\mathrm{m}$ spectrum is tending to plateau at the lowest frequencies, consistent with the shorter time scales in the deep water as seen in the maps. It is also obvious from the maps that the temperature variability at the individual moorings is correlated and that the number of degrees of freedom at the lowfrequency end of the spectra in Figure 7 is far less than the number of periodograms used in the average.

For the spatial scales, one possible representation is the coherence between the moorings as a function of horizontal separation (independent of azimuth) shown in Figure 8 for the band of periods of 7-78 days. In the thermocline, there seems to be significant coherence out to separations of at least 300 $\mathrm{km}$. In the deep water the coherence is much weaker but evidently still real out to at least $100 \mathrm{~km}$. In the next higher frequency band (periods of 2-7 days), no significant coherence is found between even the closest moorings $(50 \mathrm{~km})$, an observation suggesting that in this band the periodograms may be regarded as being independent. (Richman [1976] shows that with the data available the distribution of temperature fluctuations in time is indistinguishable from a Gaussian.)

A somewhat different representation of the spatial relationship can be found by computing the (assumed isotropic) correlation function between the moorings. Owing to the red nature of the spectra (see Figure 7), the correlation function will be dominated by the energy in the lowest available frequencies. The correlation function, shown for three depths in Figure 9, can be used to define a simple length scale. Correlations determined at lags greater than $125 \mathrm{~km}$ are generally not significantly different from zero, although there are negative lobes at all depths. The data used to calculate these correlations come from less than one realization of the dominant process and therefore will appear quasi-periodic and yield negative lobes.
Presumably, longer-term averages would smooth out this feature, and for this reason we chose the Gaussian shape indicated in (2) for the mapping correlation function. (The moored array was designed under the hypothesis that the correlation would go through zero at about $100 \mathrm{~km}$. This expectation is seen to have been fulfilled for the temperature field.)

Implicit in the above discussion of the correlation function is the choice of a time scale to determine the number of degrees of freedom of the estimates. It is useful in studies of turbulence [e.g., Taylor, 1921] to define an integral time scale

$$
t_{i}=\frac{1}{R(0)} \int_{0}^{\infty} R(\tau) d \tau
$$

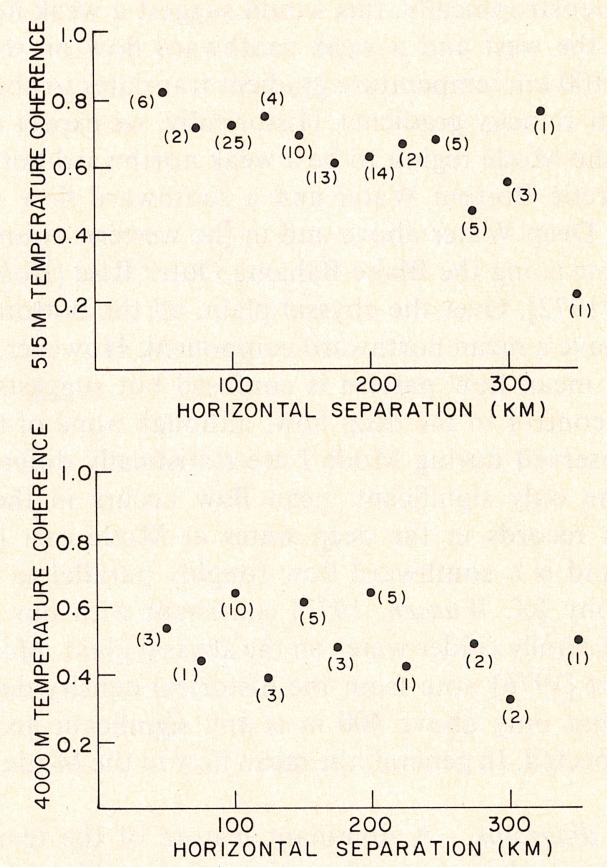

Fig. 8. Temperature coherence between moorings as a function of horizontal separation. The numbers in parentheses are the numbers of pairs of moorings in the estimates. The field is assumed to be homogeneous for this purpose. The periods involved are 7-78 days, but because of the red nature of the spectrum the result is dominated by the longer periods. By using our estimates of correlation time, each pair represents 2 degrees of freedom in the main thermocline and 3 in the deep water. 

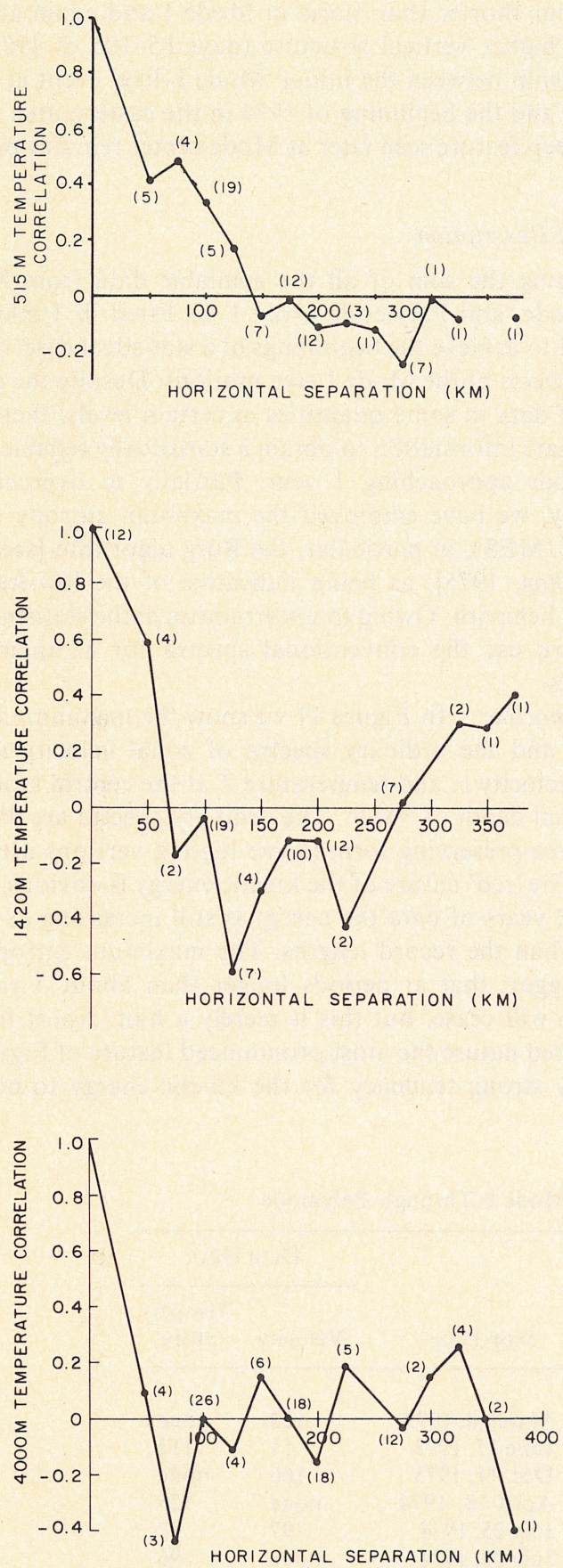

Fig. 9. Empirical horizontal correlation function of the temperature field. Notice the tendency toward negative lobes at large lags in contrast to the analytic form (2) used to draw the maps. As a guide, an estimate based on 10 degrees of freedom must exceed 0.5 to be significantly correlated at $95 \%$.

which is a measure of the correlation time of a process. This measure was used for the Mode 1 float data by Freeland et al. [1975], who suggested that the time scale was about 10 days for floats at $1500 \mathrm{~m}$. This time scale is a reasonable measure for essentially positive correlation functions, such as are often found, for example, in longitudinal velocities of isotropic turbulence [Batchelor, 1953]. However, if the correlation functions oscillate (there is a tendency for this to occur, for example, in the temperature autocorrelations shown in Figure 10 ), then the measure is a poor one tending to yield correlation times that are too short. An extreme example would come from a purely periodic process, for then the correlation time would oscillate between $1 / 2 \pi$ times the periodicity interval and zero, depending on the limits of integration. One would prefer a measure which in that case would yield an infinite correlation time.

If we redefine the correlation time as

$$
t_{i}=\frac{1}{R^{2}(0)} \int_{0}^{\infty} R^{2}(\tau) d \tau
$$

then we have a more well behaved measure, which can be related to the discussion by Kendall and Stuart [1976] of the expected variance of the correlation function itself. Table 2 shows the correlation times given by (4) for the velocity and temperature at several depths. We note here what will be obvious in our later discussion of the kinetic energy spectra, i.e., that the time scale of the zonal thermocline velocity is much longer than any of the other time scales. Also, the time scale of the thermocline temperature is greater than the time scale of the deep water, an observation consistent with the spectra in Figure 7. In general, all these time scales are considerably larger than those estimated by Freeland et al. [1975] from (3).

\section{Site Mooring Data}

Two moorings were maintained in the area following Mode 1. At the center a mooring was maintained through the beginning of the Polymode measurements, yielding nearly 2 years of data, but at the eastern mooring (Mode east) the measurement program ceased after about 1 year of data had been obtained.
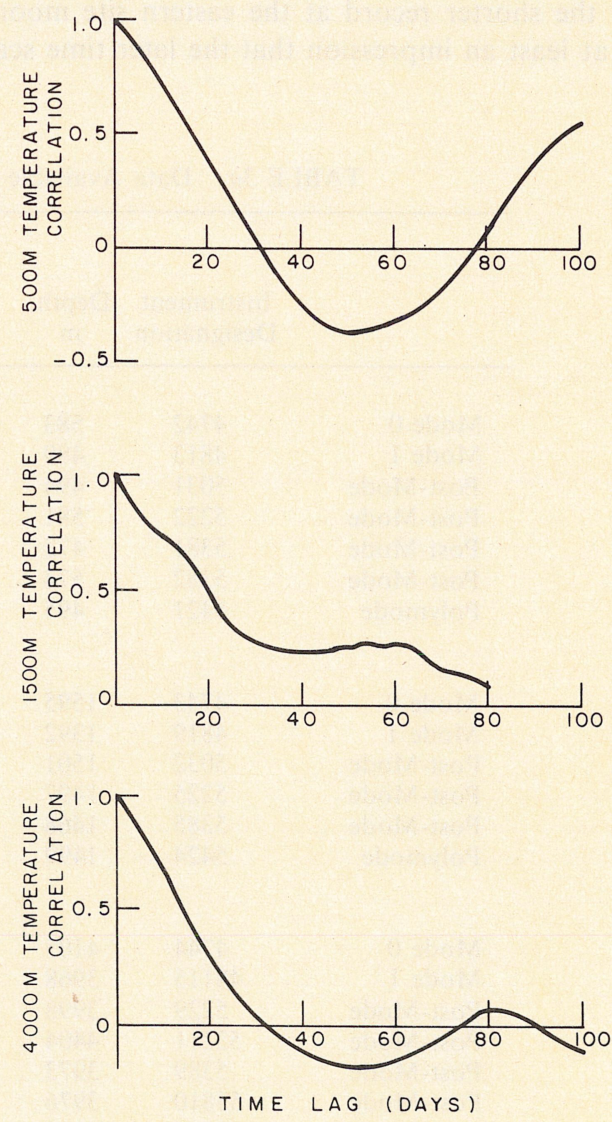

Fig. 10. Temporal autocorrelations at the central mooring during Mode I. These are, of necessity, consistent with the spectra displayed in Figure 7. 
TABLE 2. Square Integrable Time Scale at Mode Center During Mode I

\begin{tabular}{cccc}
\hline & \multicolumn{3}{c}{ Time Scale, days } \\
\cline { 2 - 4 } Depth, $m$ & Temperature & $\begin{array}{c}\text { Zonal } \\
\text { Velocity }\end{array}$ & $\begin{array}{c}\text { Meridional } \\
\text { Velocity }\end{array}$ \\
\hline \multirow{2}{*}{500} & 36.4 & 70.0 & 23.3 \\
1500 & 32.4 & 20.4 & 27.8 \\
4000 & 22.8 & 21.2 & 25.8 \\
\hline
\end{tabular}

Values are calculated from (4).

A summary of available data is seen in Table 3 and includes a small amount of data from the Mode 0 experiment [Gould et al., 1974]. The temperatures measured at these positions are shown in Figures 3 and 4 in both raw and displacement form, as was described for the Mode I measurements. A segment of the Iwex data is included in Figure 3. The Mode center mooring was not as heavily instrumented in the later periods as it was during Mode I, and so a detailed comparison of the measurements is difficult. Visually, the overall character of the later results is roughly similar to that of the Mode I results. One does obtain a clear impression that the Mode I results were typical of the gross time scale of the energy-containing phenomenon (in temperature) but were perhaps untypical in showing rather gentle temperature changes (compare days 45, 140 , and 360 of 1974 with the earlier period). In particular, the central mooring does show that in the later periods there is an occasional incidence of energetic events (e.g., day 190 of 1974) with vertical structure not extending all through the water column.

From the shorter record at the eastern site mooring, one obtains at least an impression that the later time scales were somewhat shorter than those in Mode I and again at least a hint of higher vertical structure (days 85-105 of 1974). The relationship between the initial 'Mode I-like' event at the end of 1973 and the beginning of 1974 in the eastern area and the large steep feature seen later at Mode center remains problematical.

\section{Spectral Description}

By using the sum of all the available data from Mode I, post-Mode, and Polymode array 1 , as listed in Table 3, it is possible to achieve the beginnings of a statistical description of some aspects of the Mode I area motions. Despite the nearly 2 years of data in some quantities at certain levels, there is still inadequate information to obtain a statistically reliable picture at periods approaching 1 year. Partially to overcome this difficulty, we have employed the maximum entropy spectral method (MES), in particular, the Burg algorithm [see Ulrych and Bishop, 1975], as being indicative of the low-frequency spectral behavior. Owing to uncertainties in the statistics of the MES, we use the conventional spectra for all quantitative purposes.

Thermocline. In Figure 11 we show the maximum entropy spectra and the ordinary spectra of zonal velocity $u$, meridional velocity $v$, and temperature $T$ at the central mooring at a nominal depth of $500 \mathrm{~m}$. The ordinary spectra are displayed in an area-preserving form (some log-log versions are shown later). The 'red' nature of the kinetic energy is obvious: despite nearly 2 years of data the energy is still increasing at periods longer than the record lengths. The maximum entropy form does suggest that at periods longer than about 3 years the increase will cease, but this is merely a hint. Apart from the overall red nature the most pronounced feature of Figure 11 is the very strong tendency for the kinetic energy to be domi-

TABLE 3a. Data Available at Mode Center for Mode 0 Through Polymode

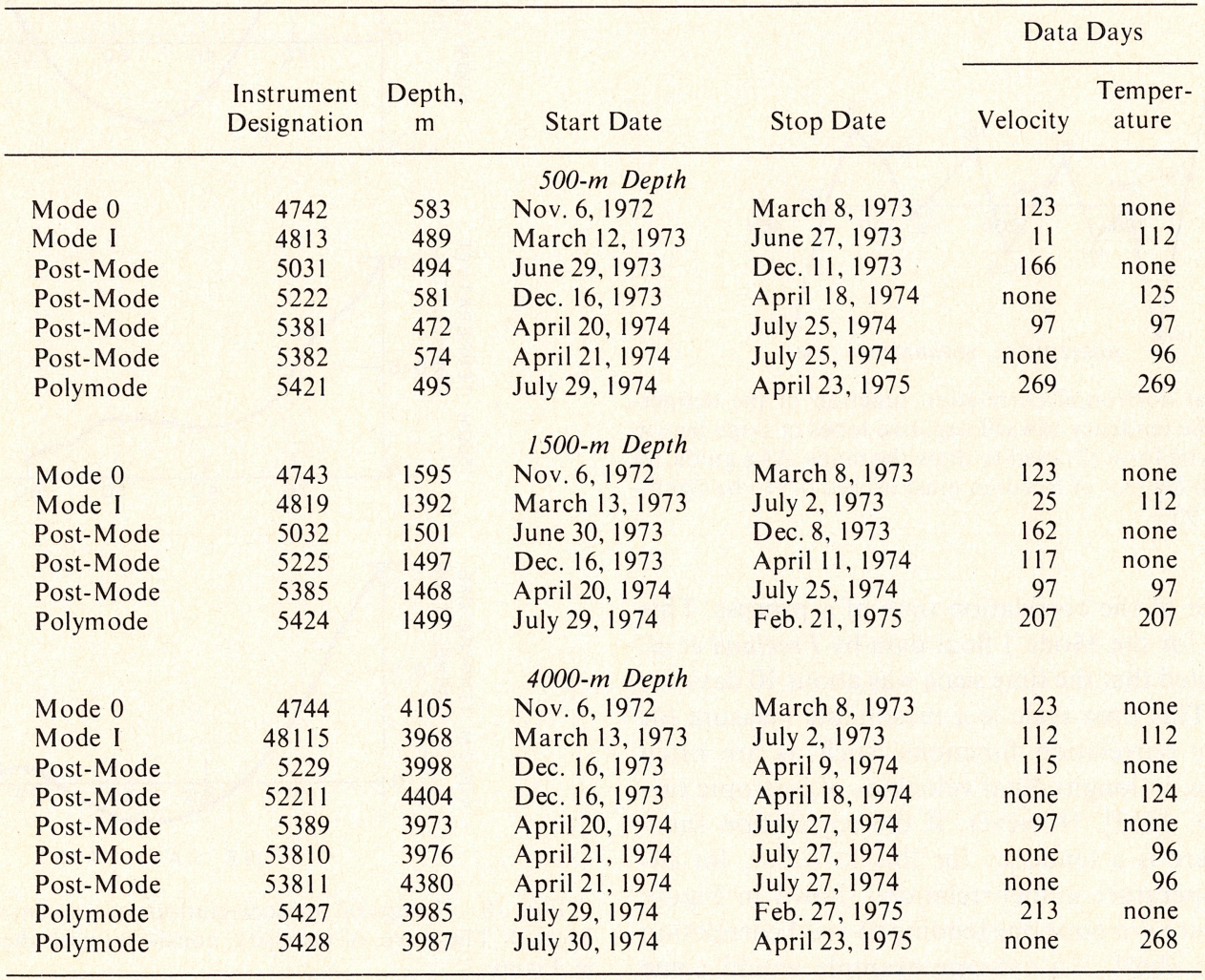


TABLE $3 b$. Data Available at Mode East for Mode 0 Through Polymode

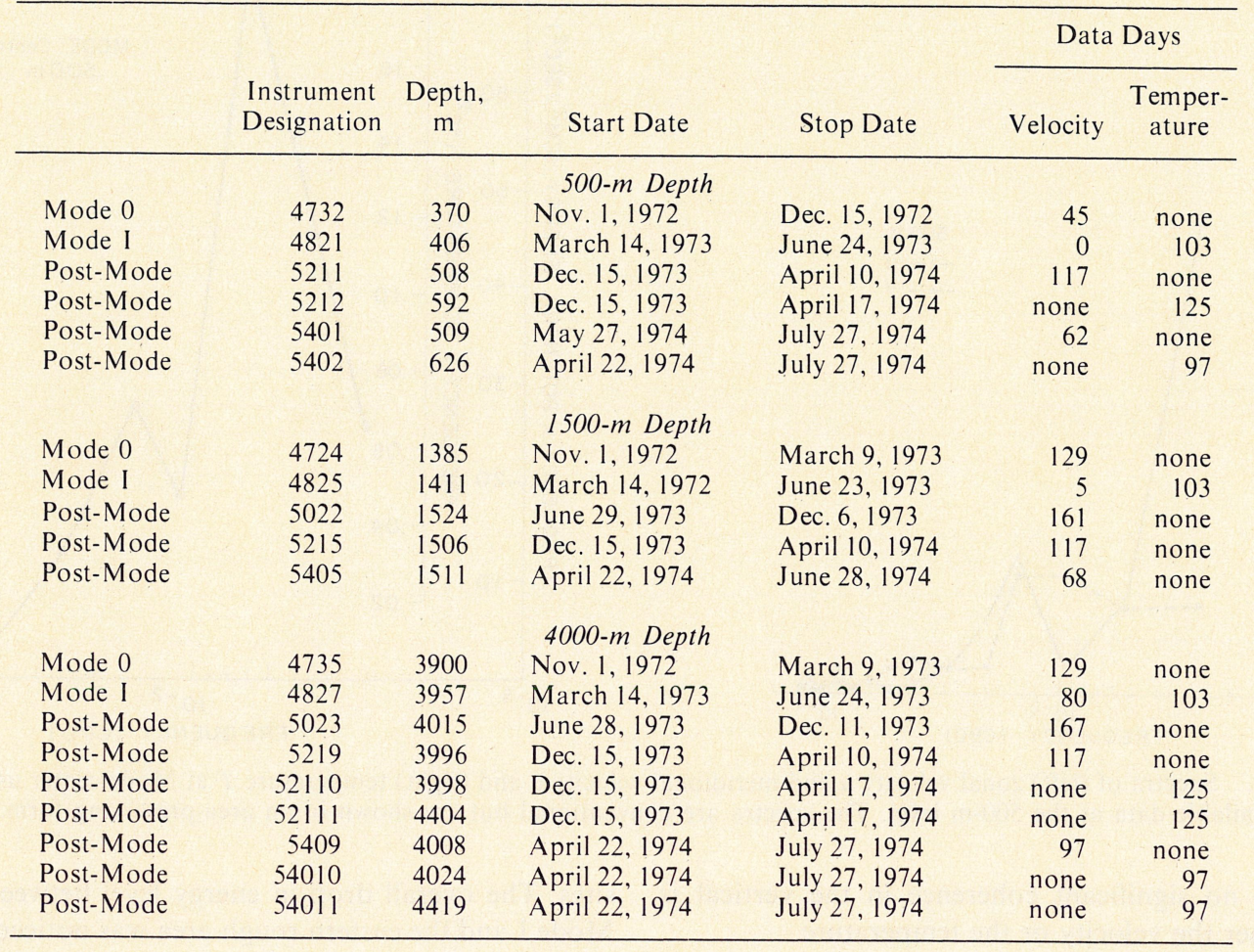

nated by the zonal component. At periods longer than about 200 days the zonal kinetic energy is nearly an order of magnitude greater than the meridional. For periods of about $50-100$ days there is an energy maximum in $u, v$, and $T$. It is this range that contains the Mode I eddy, and it does appear as a distinct spectral region, showing approximate equipartition of the zonal and meridional energies, consistent with the roughly circular shape of the Mode I eddy. The observed ratio of zonal to meridional kinetic energy is 0.7 , which is not significantly different from equipartition at $90 \%$ confidence. Strong dominance of the 100-day period in the temperature spectrum is consistent with that observed from 13 years of records by Wunsch [1972]. At periods shorter than 50 days the spectra in the log-log form drop off as a power law, approximately $\omega^{-2.5}$, with equipartition of zonal and meridional energies. (For high frequencies this slope of -2.5 has been estimated by eye. By using $90 \%$ confidence limits, estimates range from -1.8 to $-3.5,-2.5$ being the central estimate.) The high-frequency temperature spectrum is similar.

For convenience we can then nominally divide the spectrum into three regions: (1) a 'low-frequency,' zonally dominated region having periods greater than 200 days; (2) an isotropic 'eddy-containing' region (though the entire frequency range presumably is 'eddies') having periods of 50-120 days; and (3) a 'high-frequency' region having periods of 5-30 days. We will discuss below the question of whether this distinction of bands is likely to represent a change in physics as well.

Mediterranean Water. These spectra are shown in Figure 12 , where the marked red nature of the velocity spectra is not quite as apparent but the eddy-containing region is somewhat more obvious. Evidently, this level differs from the thermocline in that the eddy-containing region is dominated by the meridional velocity, but the tendency toward zonal domination still occurs at the longer periods. The spectra are otherwise similar to those in the thermocline except for a general reduction in energy level. At this level the Sofar floats seem to show a significant anisotropy which Freeland et al. [1975] suggest is topographically determined.

Deep water. The deep water (Figure 13) generally resembles the intermediate (Mediterranean Water) level, having a tendency toward meridional dominance of energy in the eddy band and only a weak zonal dominance at lower frequencies. The meridional velocity spectrum also seems to exhibit an additional energy peak at about 40-50 days.

\section{Vertical Comparison of Spectra}

For reasons discussed below, it is sensible to try scaling the kinetic and potential energies according to the WKBJ normalization such that the depth dependence of the energy under that assumption is proportional to the buoyancy frequency. With this scaling it is found that the high-frequency bands at all the depth levels nearly overlay each other but there tends to be an increasing discrepancy between the levels upon reaching the eddy-containing band and lower frequencies. In particular, the deep water appears to have an excess of kinetic energy in the eddy-containing band, and the thermocline has an excess at very long periods, dominantly in the zonal component.

We can ask the degree to which different levels are linearly related, i.e., to what extent the motions are vertically coherent. The vertical coherence as a function of frequency is given for velocity and temperature at four depth levels in Table 4 . It is not possible with the data available to determine the vertical coherence in the very low frequency band. For the eddycontaining band the pattern of velocity coherences is somewhat confused but, in general, shows high coherence in the vertical of the meridional velocity and no significant coherence in the vertical of the zonal flow. The temperature in this band is coherent within the thermocline and within the deep water and is not significantly coherent anywhere else. For the high- 

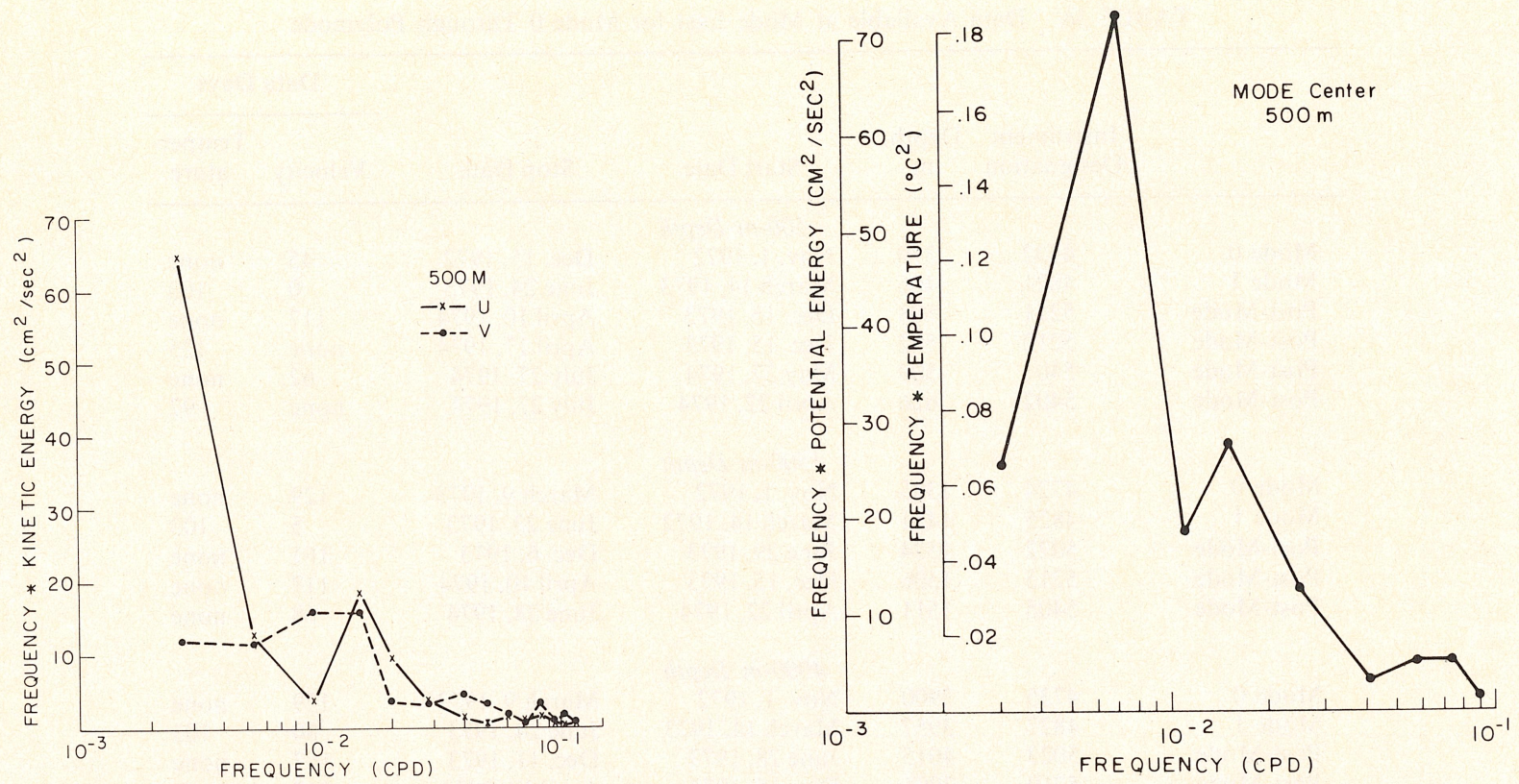

Fig. 11a. Spectra of (left) zonal velocity $u$ and meridional velocity $v$ and (right) temperature $T$ at Mode center using all available data at the $500-\mathrm{m}$ level. The spectra are conventional but are shown in an area-preserving form.

frequency band, no significant coherence in the vertical is observed for either the velocity or the temperature.

\section{East-West or Rough-Smooth Differences}

The two site moorings permit a start on studying the possible differences between measurements made at the edge of an abyssal plain and those made in a region of abyssal hills. However, the comparative brevity of the eastern site mooring record makes some of the conclusions tentative.

In Figures 14 and 15 we have superposed the log-log form spectra of the eastern site mooring on those of the central site mooring. The low-frequency range is clearly inaccessible at the eastern site except with the maximum entropy method. In the main thermocline, as far as the spectra (not shown) go, there is no significant difference between the two sites. But at $1500 \mathrm{~m}$, and only at $1500 \mathrm{~m}$, there is a major difference. In the eddycontaining band at this level the strong meridional dominance at Mode center is not present in the eastern area, and indeed, the entire kinetic energy level is reduced. Notice, however, that both the kinetic energy and the potential energy of the highfrequency portion of the spectrum have the same level at both sites. The overall drop in energy level between the center of Mode I and the eastern rough area was noticed by Freeland et al. [1975] from the float data and by W. J. Schmitz (private communication, 1975) from the moored kinetic energy data. But this change seems to be confined to this depth level and particular frequency band. Its possible significance is discussed below.

At $4000 \mathrm{~m}$ (Figure 15) there is a hint of a loss of energy to the east in the eddy-containing band, the energy decreasing by a factor of 2, but the change is not statistically significant. The high-frequency energy levels are the same at both sites as far as can be determined.

\section{Partitioning of Potential} and Kinetic Energies

An estimate of the partition of kinetic and potential energies can be obtained visually from the spectra in Figures 11-14. At very low frequencies the zonal kinetic energy exceeds the meridional kinetic energy approximately by a factor of 4 in the thermocline and Mediterranean Water and by a factor of 2 in the deep water. In the same band the kinetic energy is nearly 10

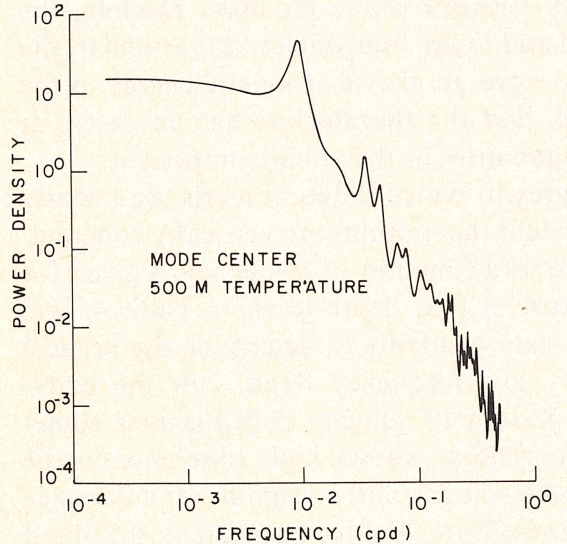

Fig. 11b. Maximum entropy spectra in log-log
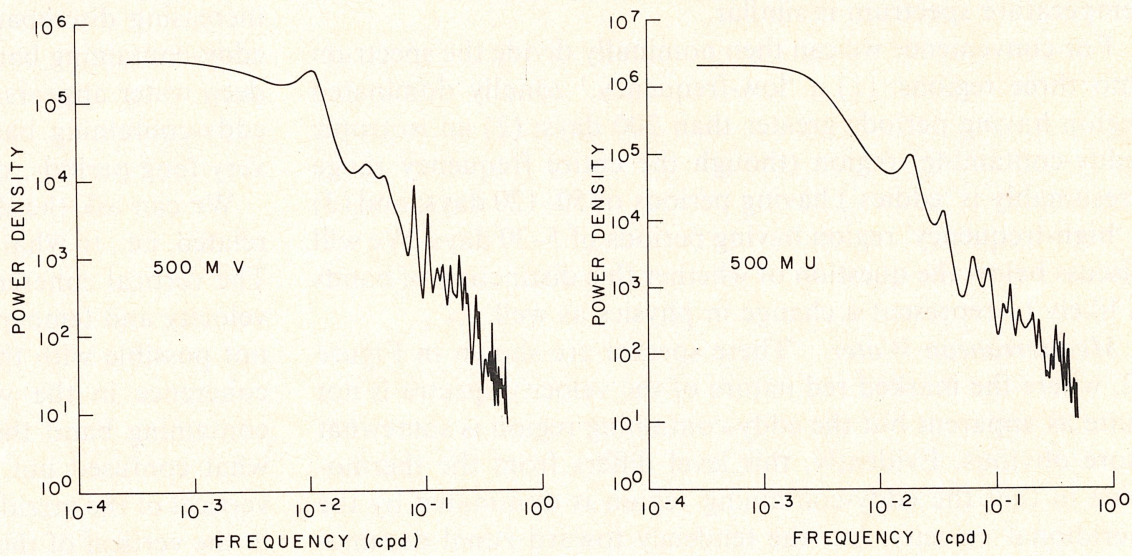

different vertical axes. 

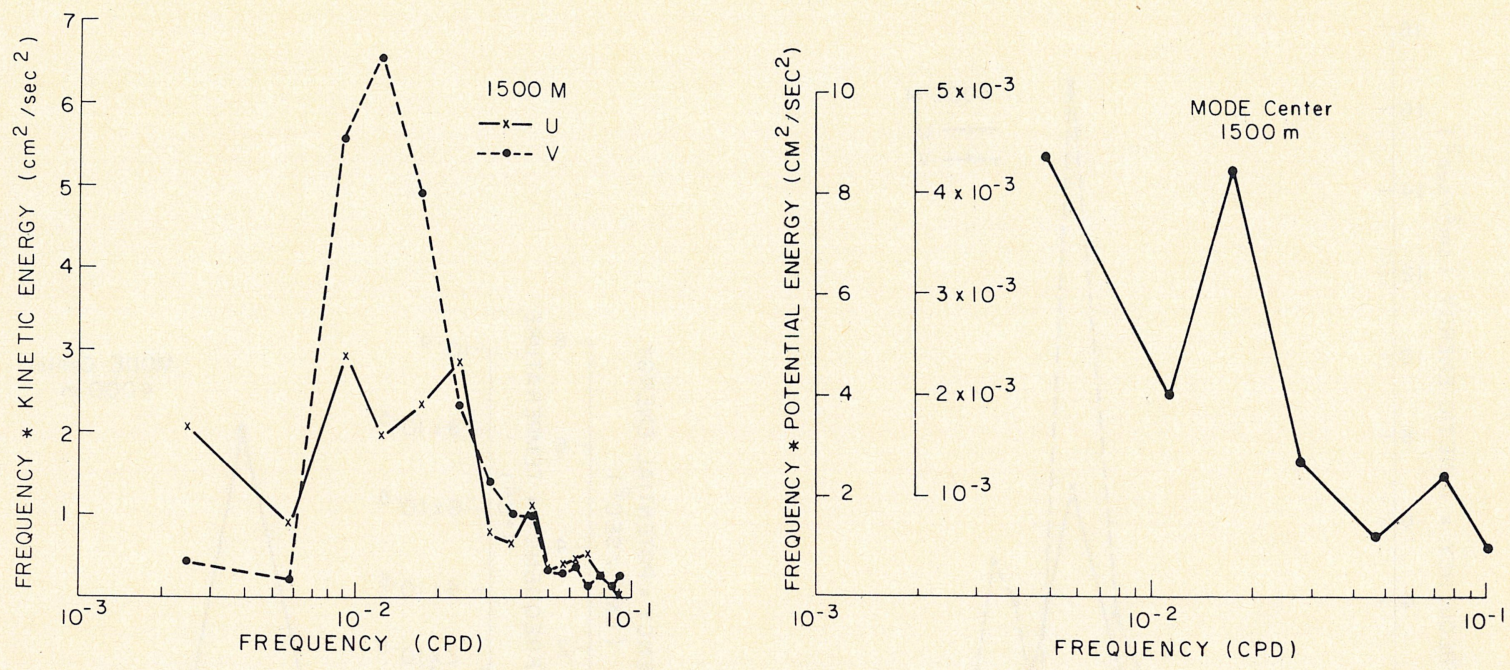

Fig. 12a. Same as figure $11 a$ except at a nominal 1500-m level.

times greater than the potential energy in the thermocline but is only half as large below the thermocline. At all depths in the eddy-containing band the zonal kinetic energy is half the meridional, and the total kinetic energy is twice the potential energy. In the high-frequency band at all depths the energy is partitioned with one third in the zonal kinetic energy, one third in the meridional kinetic energy, and one third in the potential energy.

\section{Discussion of Mode I in}

Site Mooring Context

The less than 4 months of Mode I can now be fit into an overall temporal context. The prominent feature identified as the Mode I eddy appears generally to be representative of those features having periods in the range of about 100 days. The smaller-scale superimposed features, visible, for example, in Figure 3, represent real motions dominantly found in the high-frequency spectral range at periods shorter than about 40 days. Because a single feature occupied the bulk of the Mode I array in both time and space during the experiment, no significance should be attached to the average differences between Mode I moorings. If real (i.e., geographical) average differences exist, they are obscured by the spatial inhomogeneity imposed by the eddy itself.

We have seen from the longer-duration data that some real spatial differences exist, confined, as far as we can tell, primar- ily to the Mediterranean Water level, between the eastern and central parts of the Mode I array.

Overall, it can now be seen that the Mode I eddy motion is superimposed upon a background continuum possessing both longer and shorter time scales and, presumably, longer and shorter space scales as well, though we can be less certain of these. The Mode I period represented a time when the eddycontaining spectral range was particularly well developed in relation to the background and which in its apparently simple structure may have been a somewhat misleading time. Frequency spectra strongly suggest that the overall eddy field in this area is a space-time continuum, and one should not seek more than an occasional appearance of a pronounced feature with the Mode I scales.

\section{Reynolds Stresses and Heat Flux}

The zonal and meridional eddy kinetic energies, discussed earlier, are the diagonal terms of the Reynolds stress tensor. In the Mediterranean Water and deep water the off-diagonal Reynolds stress $\left\langle u^{\prime} v^{\prime}\right\rangle$ is significantly different from zero at both site moorings (Table 5) and is greater at Mode center than at Mode east, although the difference is not significant at $90 \%$ confidence. With two moorings the full suite of terms in the Reynolds stress tensor have not been measured. Schmitz [1977] observes an order of magnitude variation over gyre scales and has suggested that stresses exerted by the eddy
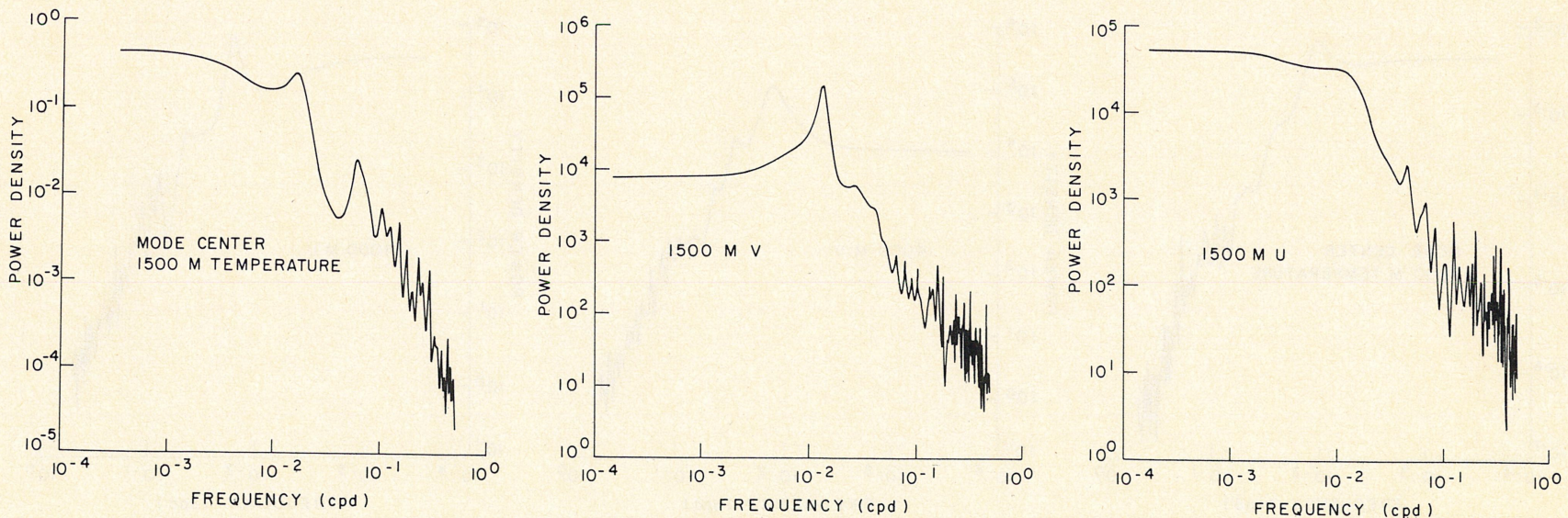

Fig. 12b. Same as Figure $11 b$ except at a nominal 1500-m level. 

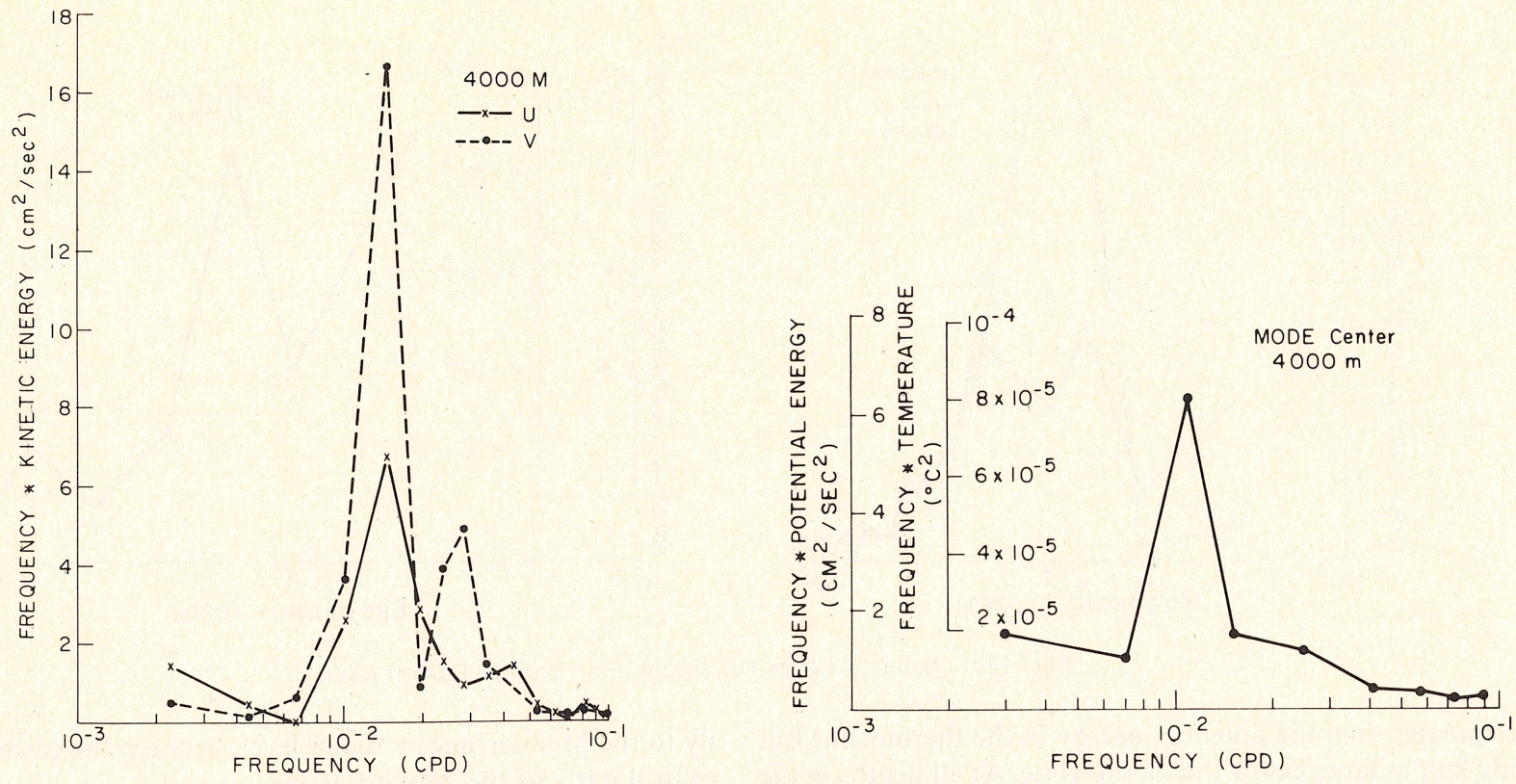

Fig. 13a. Same as Figure 11 a except at a nominal 4000-m level.

motion may be driving the deep circulation. Results from the site moorings and Sofar floats [Freeland et al., 1975] indicate insignificant changes on the eddy scale within the Mode area except, perhaps, in the kinetic energy levels at $1500 \mathrm{~m}$.

The eddies may transport heat as well as momentum. In the deep water at Mode center a significantly nonzero zonal heat flux is observed (Table 5). This is the only velocity-temperature covariance which is distinguishable from zero at $95 \%$ confidence. To assess the importance of the eddy heat transport in the thermal balance of the ocean, we can compare the observed heat flux with the estimated poleward heat flux carried by the ocean annually. Von der Haar and Oort [1973] estimate the poleward heat transport of the northern hemisphere oceans to be approximately $3 \times 10^{15} \mathrm{~W}$. If we assumed an average oceanic depth of $4 \mathrm{~km}$, the average heat flux would be approximately $6 \times 10^{4} \mathrm{~W} / \mathrm{m}^{2}$. Our observed deep eddy zonal heat flux is 2 orders of magnitude less than the average annual poleward heat flux. In the thermocline, where the observed values are an upper bound, they are, at a maximum, of the same order of magnitude as the poleward heat flux. While the eddy heat transport is potentially important to the oceanic thermal balance, the observed heat flux in the Mode region is small.

\section{Some Dynamical Considerations}

In any discussion of mesoscale variability a large number of possible dynamical processes are potentially active. At one extreme, one could imagine the motions to represent linearized wave processes, the interpretation applied by Phillips [1966] to the 1959 float measurements of Crease [1962] and Swallow [1971] and by McWilliams and Flierl [1976] to the measurements under discussion here: At the other extreme it might be imagined that the motions are completely nonlinear and turbulent and that a quite different dynamics applies. With the data base at hand we can begin to make some positive statements.

First, it has been shown [Bryden, 1974; C. W. Horton and W. Sturges, unpublished manuscript, 1977] that the data cannot be distinguished from nondivergent geostrophic motion within the errors of the measurements. McWilliams [1976b] has gone a step beyond and shown that within the (large) error bars the Mode I motions are indistinguishable from motions
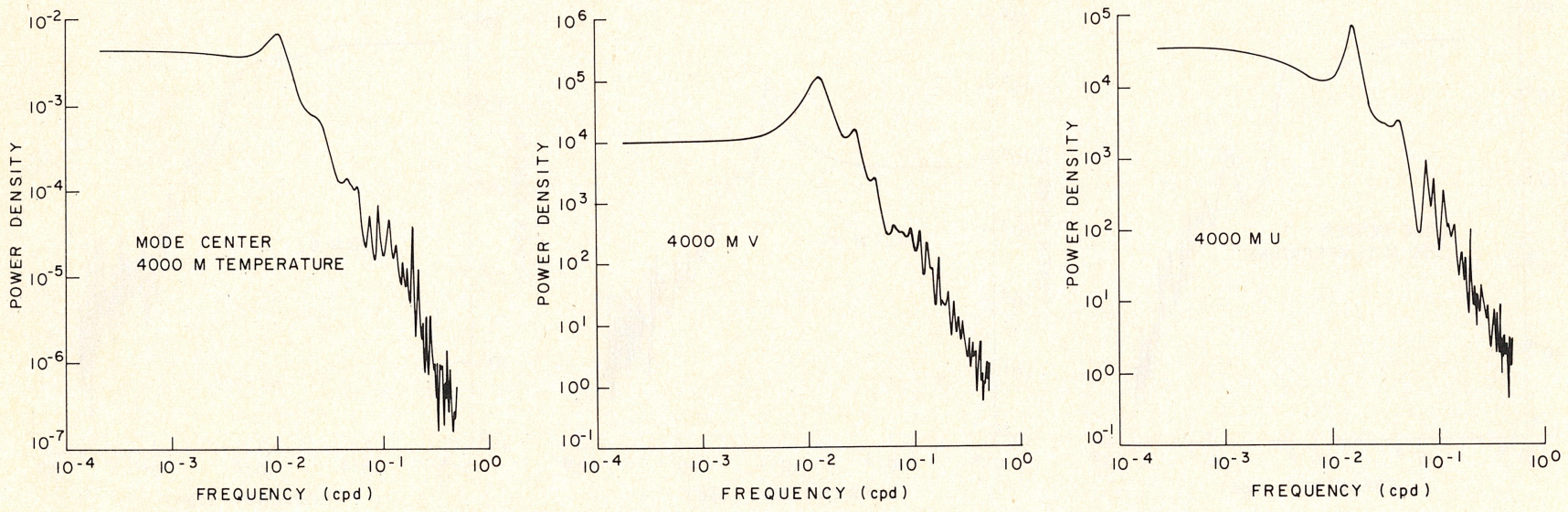

Fig. 13b. Same as Figure $11 b$ except at a nominal 4000-m level. 
TABLE 4a. Vertical Coherence Amplitude and Phase of Temperature at Mode Center

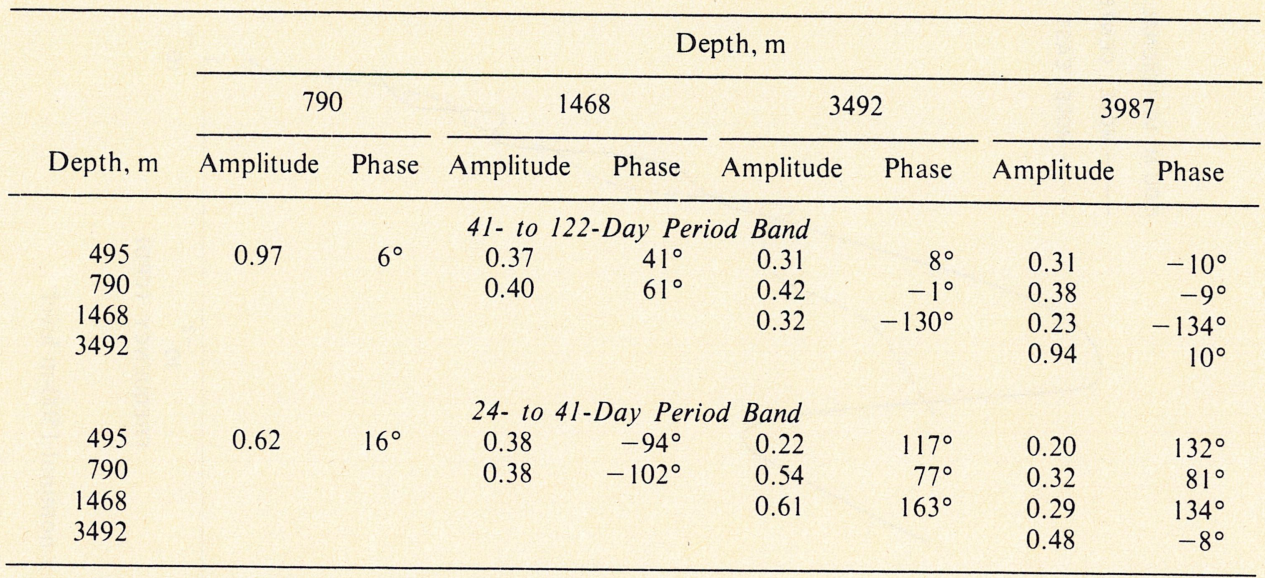

The $90 \%$ confidence limit for zero coherence is 0.48 .

which conserve potential vorticity. These results suggest that any dynamical model which is quasi-geostrophic is unlikely to be distinguishable from another such model, at least by direct means, i.e., by a balance of forces in the momentum or vorticity equations (there is a little hope for the latter equation [see McWilliams, 1976b]). Bryden [1976] has shown, from a partial balance of forces in the density conservation equation, that nonlinear dynamics are important in the Mode I area [cf. Richman, 1976].

It is useful and interesting to try first to establish the extent to which linear dynamics may apply to the motions, even if, as will turn out, the motion cannot be regarded as being strictly linear.

\section{Linear Motion}

Discussions of free linear Rossby wave dynamics are commonplace. Suffice it to say that in the absence of topography, if one defines the frequency $\omega$ and the horizontal wave number $k$ $=(k, l)$, the motion obeys a dispersion relation

$$
\omega=\frac{-\beta k}{k^{2}+l^{2}+f^{2} / g h_{n}}
$$

where the vertical eigenvalue $h_{n}$ is determined from the equation

$$
W^{\prime \prime}+\left(f^{2} / g h_{n}\right) N^{2} W=0
$$

such that the horizontal velocity is proportional to $W^{\prime}(z)$ and the vertical velocity or displacement is proportional to $W(z) ; n$ represents the mode number, and $n$ ranges from 0 , the barotropic mode, through the higher baroclinic modes. In practice, (6) is solved subject to the boundary conditions $W=0$ on $z=$ $0,-H$ (top and bottom of the ocean).

The modal structure for the Mode I area is displayed in Figure 16 for the first few baroclinic modes. Even if the dynamics assumed here are inappropriate, these modes are a complete set and may be used to represent the data. A discussion of the problems of actually calculating modal fits is given by Richman [1976]. During Mode I itself, only the tem-

\begin{tabular}{|c|c|c|c|c|c|c|c|c|c|c|}
\hline \multirow[b]{3}{*}{$\begin{array}{l}\text { Depth, } \\
\text { m }\end{array}$} & \multirow{2}{*}{\multicolumn{2}{|c|}{$\begin{array}{c}500-\mathrm{m} \text { Depth } \\
v\end{array}$}} & \multicolumn{4}{|c|}{ 1500-m Depth } & \multicolumn{4}{|c|}{ 4000-m Depth } \\
\hline & & & \multicolumn{2}{|c|}{$u$} & \multicolumn{2}{|c|}{$v$} & \multicolumn{2}{|c|}{$u$} & \multicolumn{2}{|c|}{$v$} \\
\hline & $\begin{array}{l}\text { Ampli- } \\
\text { tude }\end{array}$ & Phase & $\begin{array}{l}\text { Ampli- } \\
\text { tude }\end{array}$ & Phase & $\begin{array}{l}\text { Ampli- } \\
\text { tude }\end{array}$ & Phase & $\begin{array}{l}\text { Ampli- } \\
\text { tude }\end{array}$ & Phase & $\begin{array}{l}\text { Ampli- } \\
\text { tude }\end{array}$ & Phase \\
\hline 500 & \multicolumn{10}{|c|}{ 67- to 200-Day Period Band } \\
\hline $\begin{array}{c}u \\
v \\
1500\end{array}$ & 0.25 & $25^{\circ}$ & $\begin{array}{l}0.52 \\
0.81\end{array}$ & $\begin{array}{l}76^{\circ} \\
36^{\circ}\end{array}$ & $\begin{array}{l}0.54 \\
0.27\end{array}$ & $\begin{array}{r}-120^{\circ} \\
128^{\circ}\end{array}$ & $\begin{array}{l}0.50 \\
0.96\end{array}$ & $\begin{array}{r}133^{\circ} \\
17^{\circ}\end{array}$ & $\begin{array}{l}0.42 \\
0.79\end{array}$ & $\begin{array}{l}-59^{\circ} \\
-24^{\circ}\end{array}$ \\
\hline $\begin{array}{c}u \\
v \\
4000\end{array}$ & & & & & 0.85 & $-51^{\circ}$ & $\begin{array}{l}0.37 \\
0.72\end{array}$ & $\begin{array}{r}49^{\circ} \\
-11^{\circ}\end{array}$ & $\begin{array}{l}0.32 \\
0.81\end{array}$ & $\begin{array}{r}134^{\circ} \\
-14^{\circ}\end{array}$ \\
\hline$u$ & & & & & & & & & 0.46 & $-95^{\circ}$ \\
\hline \multicolumn{11}{|c|}{ 40- to 67-Day Period Band } \\
\hline $\begin{array}{c}u \\
v \\
1500\end{array}$ & 0.36 & $127^{\circ}$ & $\begin{array}{l}0.72 \\
0.64\end{array}$ & $\begin{array}{r}-29^{\circ} \\
89^{\circ}\end{array}$ & $\begin{array}{l}0.77 \\
0.69\end{array}$ & $\begin{array}{r}156^{\circ} \\
59^{\circ}\end{array}$ & $\begin{array}{l}0.96 \\
0.72\end{array}$ & $\begin{array}{r}-36^{\circ} \\
-102^{\circ}\end{array}$ & $\begin{array}{l}0.43 \\
0.77\end{array}$ & $\begin{array}{r}-177^{\circ} \\
103^{\circ}\end{array}$ \\
\hline $\begin{array}{c}u \\
v \\
4000\end{array}$ & & & & & 0.94 & $80^{\circ}$ & $\begin{array}{l}0.89 \\
0.70\end{array}$ & $\begin{array}{l}-12^{\circ} \\
-72^{\circ}\end{array}$ & $\begin{array}{l}0.80 \\
0.56\end{array}$ & $\begin{array}{r}51^{\circ} \\
5^{\circ}\end{array}$ \\
\hline$u$ & & & & & & & & & 0.66 & $-76^{\circ}$ \\
\hline
\end{tabular}

TABLE 4b. Vertical Coherence Amplitude and Phase of Velocity at Mode Center

The $90 \%$ confidence limit for zero coherence is 0.83 . 


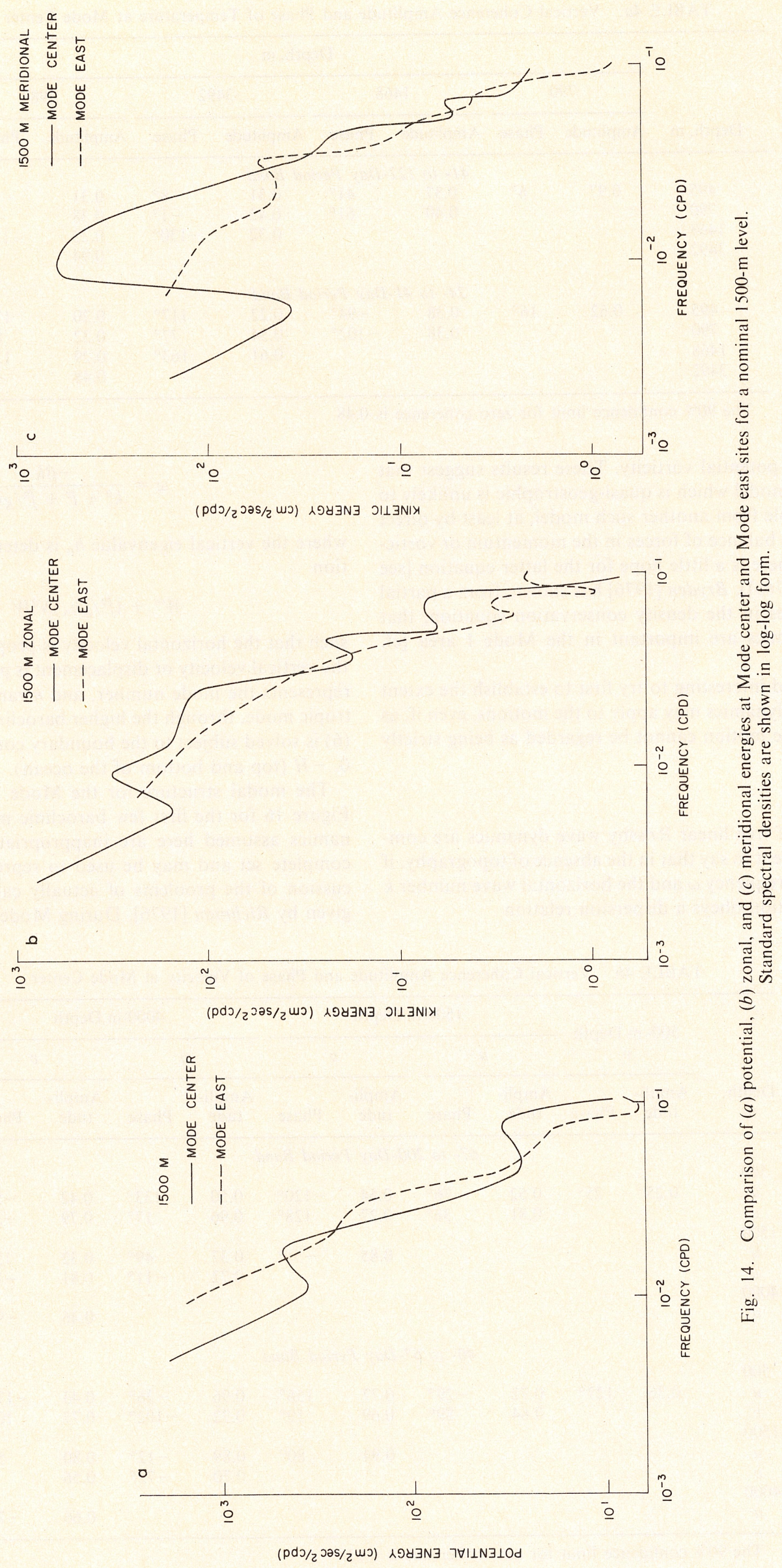



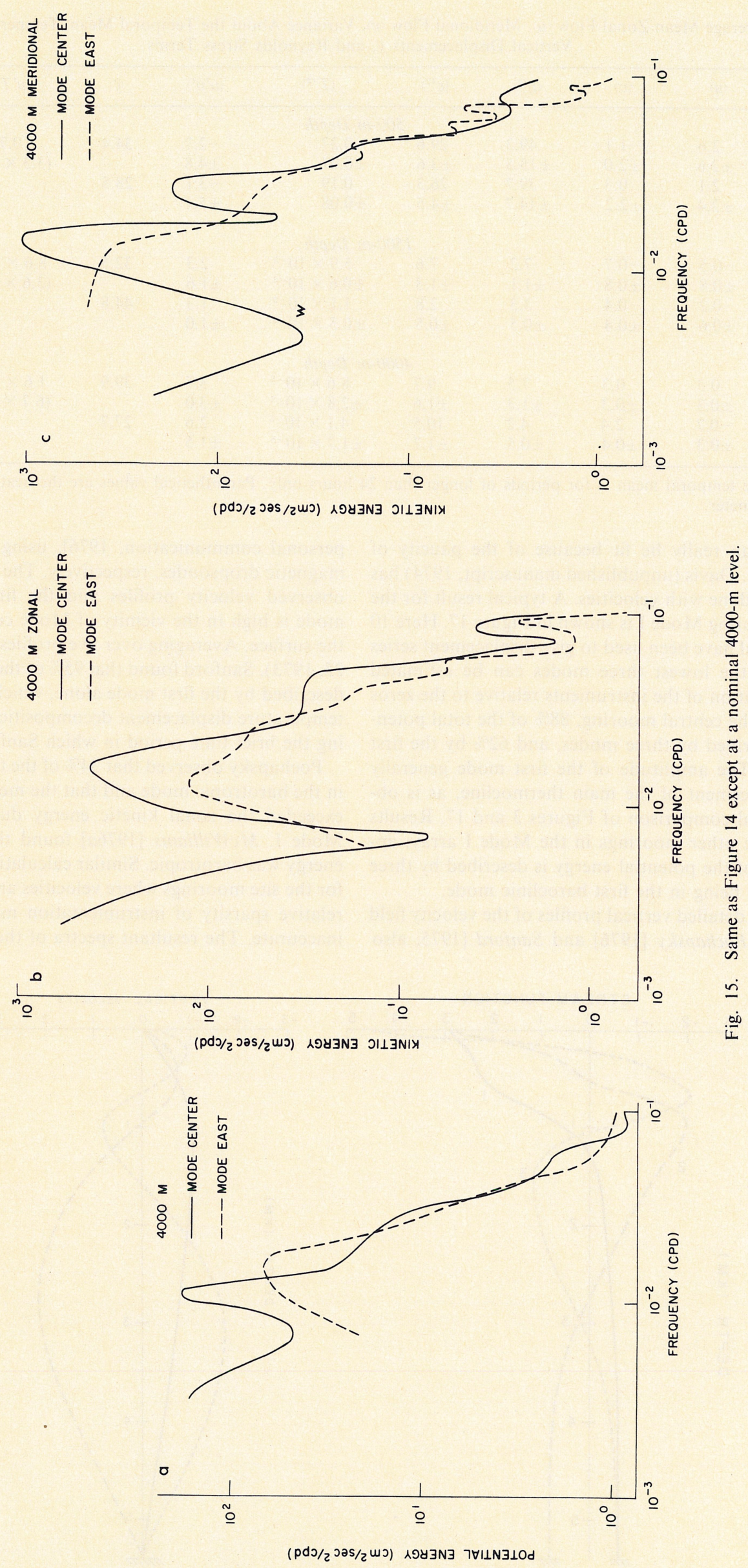
TABLE 5. Time Average Mean Zonal Flow $\langle u\rangle$, Meridional Flow $\langle v\rangle$, Variance About the Temporal Mean, Temperature Variance $\left\langle T^{\prime 2}\right\rangle$, rms Vertical Displacements $\zeta$, and Reynolds Stress Terms

\begin{tabular}{|c|c|c|c|c|c|c|c|c|c|}
\hline Location & $\langle u\rangle$ & $\langle v\rangle$ & $\left\langle u^{\prime 2}\right\rangle$ & $\left\langle v^{\prime 2}\right\rangle$ & $\left\langle T^{\prime 2}\right\rangle$ & $\left\langle u^{\prime} v^{\prime}\right\rangle$ & $\zeta$ & $\left\langle u^{\prime} T^{\prime}\right\rangle$ & $\left\langle v^{\prime} T^{\prime}\right\rangle$ \\
\hline $\begin{array}{l}\text { Mode center } \\
\text { Mode east }\end{array}$ & $\begin{array}{r}2.6 \\
\pm 2.6 \\
2.1 \\
\pm 2.4\end{array}$ & $\begin{array}{r}-1.1 \\
\pm 2.0 \\
0.3 \\
\pm 2.2\end{array}$ & $\begin{array}{r}49.3 \\
\pm 15.5 \\
39.7 \\
\pm 14.7\end{array}$ & $\begin{array}{r}29.6 \\
\pm 3.6 \\
26.3 \\
\pm 4.5\end{array}$ & $\begin{array}{c}m \text { Depth } \\
0.27 \\
\pm 0.07 \\
0.19 \\
\pm 0.08\end{array}$ & $\begin{array}{l}-2.7 \\
\pm 4.8 \\
-3.1 \\
\pm 5.1\end{array}$ & $\begin{array}{l}34.4 \\
28.5\end{array}$ & $\begin{array}{c}0.79 \\
\left(3.3 \times 10^{4}\right)\end{array}$ & $\begin{array}{c}8.9 \times 10^{-2} \\
\left(3.7 \times 10^{3}\right)\end{array}$ \\
\hline $\begin{array}{l}\text { Mode center } \\
\text { Mode east }\end{array}$ & $\begin{array}{l}-0.5 \\
\pm 0.8 \\
-0.2 \\
\pm 0.6\end{array}$ & $\begin{array}{l}-0.7 \\
\pm 0.8 \\
-0.4 \\
\pm 0.4\end{array}$ & $\begin{array}{r}7.2 \\
\pm 1.1 \\
3.3 \\
\pm 0.5\end{array}$ & $\begin{array}{r}7.6 \\
\pm 1.3 \\
2.8 \\
\pm 0.5\end{array}$ & $\begin{array}{l}m \text { Depth } \\
5.9 \times 10^{-3} \\
\pm 0.6 \times 10^{-3} \\
1.1 \times 10^{-2} \\
\pm 0.5 \times 10^{-2}\end{array}$ & $\begin{array}{r}2.3 \\
\pm 1.6 \\
1.3 \\
\pm 1.0\end{array}$ & $\begin{array}{l}32.5 \\
44.8\end{array}$ & $\begin{array}{c}8.6 \times 10^{-2} \\
\left(3.6 \times 10^{3}\right)\end{array}$ & $\begin{array}{c}8.4 \times 10^{-2} \\
\left(3.5 \times 10^{3}\right)\end{array}$ \\
\hline $\begin{array}{l}\text { Mode center } \\
\text { Mode east }\end{array}$ & $\begin{array}{r}0.3 \\
\pm 0.3 \\
-0.7 \\
\pm 0.3\end{array}$ & $\begin{array}{r}0.3 \\
\pm 0.3 \\
2.4 \\
\pm 0.4\end{array}$ & $\begin{array}{r}7.5 \\
\pm 1.3 \\
4.2 \\
\pm 0.5\end{array}$ & $\begin{array}{r}9.7 \\
\pm 1.6 \\
10.5 \\
\pm 1.7\end{array}$ & $\begin{aligned} m \text { Depth } \\
\quad 8.6 \times 10^{-5} \\
\pm 2.8 \times 10^{-5} \\
4.1 \times 10^{-5} \\
\pm 1.7 \times 10^{-5}\end{aligned}$ & $\begin{array}{r}3.7 \\
\pm 3.0 \\
2.6 \\
\pm 1.5\end{array}$ & $\begin{array}{l}39.9 \\
27.7\end{array}$ & $\begin{array}{r}1.6 \times 10^{-2} \\
\left(6.7 \times 10^{2}\right)\end{array}$ & $\begin{array}{c}-5.0 \times 10^{-4} \\
(-2.4)\end{array}$ \\
\hline
\end{tabular}

Variance about the temporal mean is for periods of longer than 24 hours only. Parenthetical values are the heat flux equivalents of $\left\langle v^{\prime} T\right\rangle$ in watts per square meter.

perature modes can really be fit because of the paucity of velocity data; R. E. Davis (unpublished manuscript, 1974) has done what can be done with velocities. A typical result for the central mooring during Mode I is shown in Figure 17. Here 10 levels in the vertical have been used to give displacement series from which only the lowest three modes can be estimated because of the location of the instruments relative to the zeros of the modes. At the central mooring, $88 \%$ of the total potential energy is described by three modes, and $62 \%$ by the first baroclinic mode. The amplitude of the first mode generally follows the displacement of the main thermocline, as is obvious from a visual comparison of Figures 3 and 17. Results are similar for the other moorings in the Mode I array; approximately $90 \%$ of the potential energy is described by three modes, about $65 \%$ being in the first baroclinic mode.

During Mode I, detailed vertical profiles of the velocity field were obtained by Pochapsky [1976] and Sanford [1975, also personal communication, 1976], using acoustic and electromagnetic dropsondes, respectively. The visual similarity of the observed velocity profiles and the first baroclinic velocity mode is high in the vicinity of Mode center, except very near the surface. Averaging over five profiles around day 146 (May $25,1973)$, Sanford found that $95 \%$ of the baroclinic energy was described by the first mode alone, which is consistent with the temperature displacement decomposition at mooring 481 during the brief time period in which Sanford was working.

Pochapsky observed that $34 \%$ of the total kinetic energy was in the barotropic mode and that the meridional kinetic energy exceeded the zonal kinetic energy during the later part of Mode I. McWilliams [1976a] found that $37 \%$ of the kinetic energy was barotropic. Similar calculations may be carried out for the site moorings where velocities are available, though the relative sparsity of instrumentation makes the modal fitting inaccurate. The resultant spectra of the barotropic and baro-
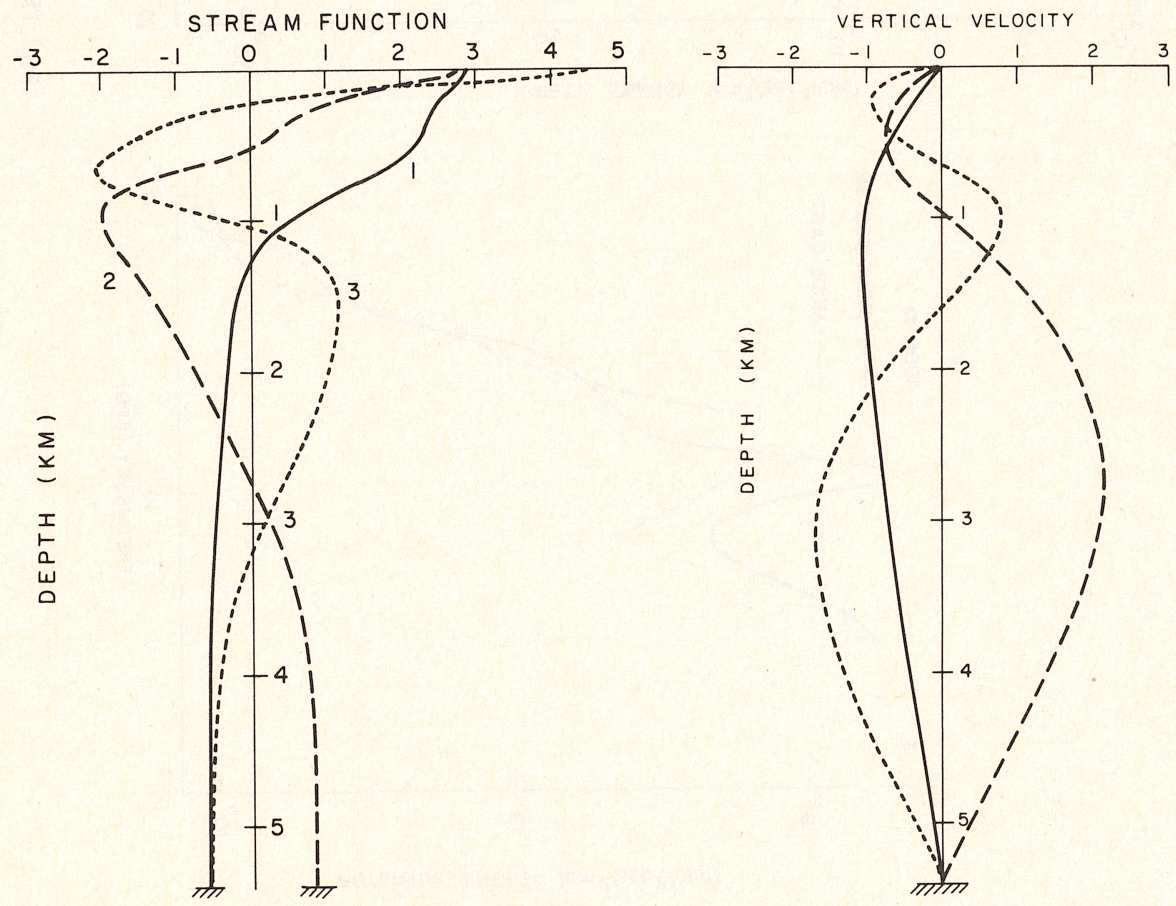

Fig. 16. Linear normal modes for (left) velocity and (right) vertical velocity/displacement for Mode center. 


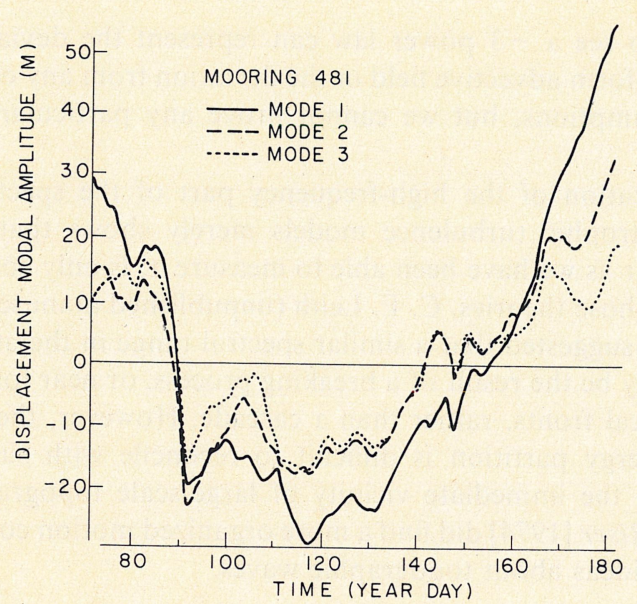

Fig. 17. Amplitudes of the first three vertical displacement modes as a function of time at Mode center during Mode I estimated from 10 instrument depths.

clinic energy spectra at Mode center are shown in Figure 18. Over the duration of the site moorings the barotropic kinetic energy was $54 \%$ of the total kinetic energy, differing somewhat from Pochapsky's [1976] and McWilliams's [1976a] results. The difference may be significant, indicating that the average velocity field is more barotropic than it was during the field experiment; however, the information comes from just three levels and does not allow us to be too certain. No significant east-west differences in the displacement of the first baroclinic mode exist, as is seen in Figure 19. This result is consistent with the temperature spectra shown in Figure 15, although, as was already noted, there is indeed a decrease in barotropic energy.

The comparatively good fit of the low modes to the data suggests that perhaps linear dynamics may have some validity. But there are some serious problems. First, the low-mode fit is confined to the eddy-containing range and possibly lower. In the high-frequency range the loss of vertical coherence (Table 5) implies that the low-mode fits fail, and all one can say is that many modes would be required to reproduce the small coherence.

Second, the tendency for the modal amplitudes to rise and fall together (Figure 17) suggests that either there is something wrong with our estimation procedure or the modes are phase locked. For example, precise knowledge of the mean temperature field could contribute energy to the higher modes in a

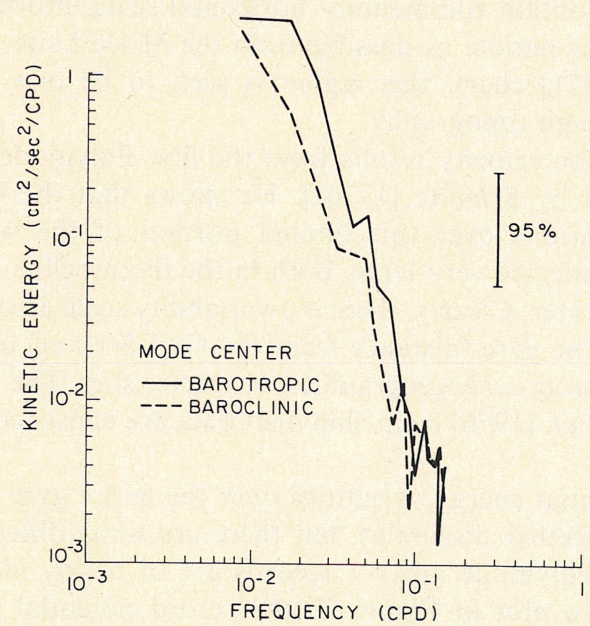

Fig. 18. Spectra of barotropic and first baroclinic normal modes at Mode center from post-Mode and Polymode velocity measurements.

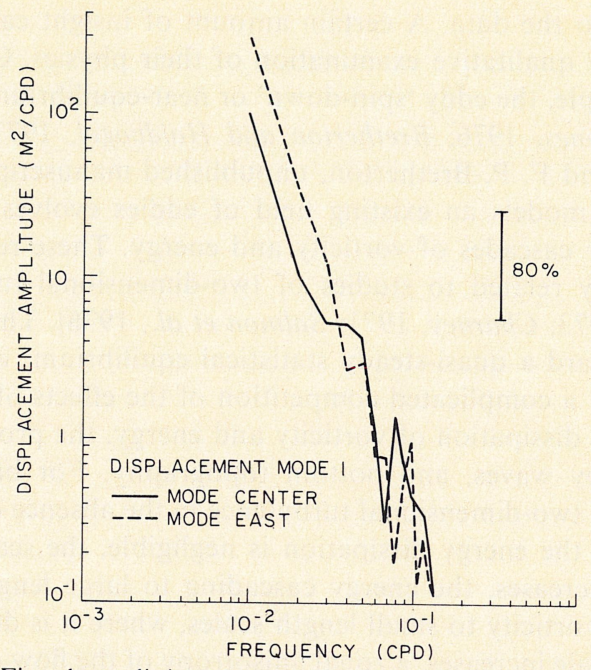

Fig. 19. First baroclinic mode spectra at Mode center and Mode east over entire data set. Differences do not appear to be significant.

field that was strictly first mode through errors in the buoyancy frequency and the means that must be removed from the temperature time series. However, our reasonable agreement with the decompositions of Pochapsky and Sanford suggests that this phase locking is real. Inspection of the time series (Figure $3 b$ ) shows that it arises from a displacement field that reaches a maximum in the main thermocline rather than at the $1300-m$ depth predicted by the linear theory. From the dispersion relation (5) it is clear that different modes travel with very different phase speeds. The maximum phase speeds are $4.4 \mathrm{~cm} / \mathrm{s}$ for the first mode, $0.8 \mathrm{~cm} / \mathrm{s}$ for the second mode, and less for higher modes. For modes to remain in phase at a point requires dynamical coupling and violation of the hypothesis of linearity.

There are other difficulties. Substitution of numerical values into the dispersion relation shows that the shortest period is about 155 days for a fundamental baroclinic mode and 363 days for the second mode, increasing with mode number. In the site mooring spectra the Mode eddy-containing band lies near 100 days, too short a period for even the lowest mode to be available for free propagation. The mean velocities discussed in the section on the general description of the results are too small to provide an advective effect sufficient to compensate.

McWilliams and Flierl [1976] did attempt to fit the Mode I data with a set of linear modes and claimed success. Their best fit was two barotropic waves with 129- and 161-day periods and $291-$ and $171-\mathrm{km}$ wavelengths, respectively, and two fundamental mode baroclinic waves with 187- and 332-day periods and $301-$ and $290-\mathrm{km}$ wavelengths, respectively. But the spectra displayed here show no sign that waves of such periods are in any way prominent. Even if such waves were present during the brief interval of Mode I, they were not persistent, and their significance is doubtful. Furthermore, in their fit, McWilliams and Flierl completely ignored the deepwater thermal variations, and their best fit picked up only $40 \%$ of the thermocline energy (their claim of approximately $60 \%$ fit is obtained by dealing with amplitudes rather than energies). A partial expansion in any complete set must pick up some of the energy. The fit is therefore of dubious merit. (McWilliams [1976a] essentially withdraws the model.)

\section{Nonlinear Models}

A number of nonlinear models of mesoscale motions exist, though none of them is sufficiently realistic to be directly 
applied to the data. A certain amount of insight can be obtained by qualitative examination of their physics. Consider, for example, the eddy 'spin-down' or near-equilibrium models [e.g., Rhines, 1976; Bretherton and Haidvogel, 1977; W. B. Owens and F. P. Bretherton, unpublished manuscript, 1977]. In these models an existing field of eddies evolves through nonlinear cascades of vorticity and energy. These results are intimately related to studies of two-dimensional turbulence [Lilly, 1973; Charney, 1971; Salmon et al., 1976]. The models tend toward a quasi-steady statistical equilibrium, which depends on a complicated competition of the effects of the cascade and dissipation of vorticity and energy, the propagation of Rossby waves, and bottom topography. For barotropic eddies or two-dimensional turbulence in the absence of topography, if the energy dissipation is negligible, the scale of the eddies increases, the energy cascading to large length scales and the vorticity to small length scales, where it is dissipated. As the scale increases, a zonal anisotropy of the flow develops, zonal kinetic energy being greater than meridional kinetic energy (no boundaries are present). The cascade eventually is cut off by the propagation of nonlinear Rossby waves. For baroclinic eddies the energy cascades from both larger and smaller scales toward the internal radius of deformation scale, where the vorticity cascade to small scales is cut off by the propagation of baroclinic Rossby waves. At the deformation radius, vertical interactions lead to occlusion of the eddies, and a barotropic cascade toward larger scales may occur. However, if the energy dissipation is significant, then the energy cascade toward large scale is inhibited. Similarly, topography can prevent the occlusion of the eddies and the development of large-scale barotropic flow.

In the face of these results it is difficult to make many useful comments in relation to the data. For the most part we lack appropriate statistical averages, cannot measure transfers of energy in wave number or frequency space, and cannot tell if the energy distribution that we see is locally generated or propagated in. With point measurements, all we can say is that those mechanisms which are isolated in the numerical models presumably act, but we cannot tell whether any are dominant or even of particular significance.

In the high-frequency range we can be a little more specific, however. This region of the temporal spectra obtained from the data appears to be distinct from the lower frequencies, the energies scaling in the vertical following the WKBJ normalization, while the energy partition is such that one third of the energy is in each of the two horizontal velocities and the remaining one third is in the potential energy. The vertical scale of these motions is presumed to be small by virtue of the absence of any coherence between sensors separated by more than $300 \mathrm{~m}$ in the vertical. In this band the energy levels appeared to be independent of proximity to topography. Finally, the spectrum obeys a power law at these periods, dropping as $\omega^{-2.5}$.

All of these features of the high-frequency spectra are consistent with Charney's [1971] model of geostrophic turbulence. This model implies the development of an equilibrium spectrum through the cascade of vorticity to small scales, the constraints being no energy cascade and conservation of pseudopotential vorticity. Strictly speaking, the model describes a wave number spectrum of $k^{-3}$ rather than a frequency spectrum. By invoking the Taylor hypothesis, one might obtain an equivalent wave number spectrum. Given the inaccuracy in the estimate of the frequency power law, as discussed previously, our results are not inconsistent. The failure actually to see a -3 power law can represent the deviation from a uniform advective field or the deviation from any of the other assumptions, but we cannot prove any particular hypothesis.

Identification of the high-frequency part of the spectrum with geostrophic turbulence models merely shows that the field, as far as we have been able to measure it, is only consistent with those theories. C. E. Leith (unpublished manuscript, 1972) has suggested that a similar spectral range in the atmosphere may be the result of a breaking process, or near formation of local fronts, rather than a cascade. However, the observed energy partition is difficult to reconcile with such a model. In the immediate vicinity of large-scale topographic features, Riser [1974] did find a more organized motion consistent with ideas about topographic waves.

\section{Mode I as a Representative Region}

Mode I was forced to occur in the area shown in Figure 1 largely through logistic considerations of various sorts. Nevertheless, it was envisioned as a truly 'midocean' experiment, preferably one that might be considered 'typical' (in some suitably defined way) of the open sea. The definition of what is meant by typical is not a trivial one. One might find that in different regions of the ocean, eddies look quite different on, say, maps but that they have similar dynamics.

It was known prior to Mode I (W. Schmitz, private communication, 1972) that the kinetic energy density of the ocean variability declined along $70^{\circ} \mathrm{W}$ as one went south away from the Gulf Stream system. The result has been documented and extended by Schmitz [1976a]. Freeland et al. [1975] suggested that the energy measured by the floats increased rapidly to the south. Thus on the gyre spatial scale at least, one aspect of the eddy field changes rapidly, the eddy kinetic energy. One of the major questions remaining was whether Mode I was sufficiently far from the Gulf Stream system for it to be considered midocean and, in addition, whether it was free of the immediate influence of the western boundary.

The subsequent Polymode experiment thus has, among its other goals, to answer the question of whether the Mode I results were in any sense representative of the rest of the ocean and explicitly to make clear what 'representative' might mean. As part of this experiment, moorings were set by the WHOI Buoy Group as is shown in Figure 2. The widely spaced moorings were capable of measuring local energy levels and local vertical structure. A small triangular array (consisting of moorings 545,546 , and 547 ) on a roughly $50-\mathrm{km}$ scale was intended to obtain rudimentary horizontal scale information in a region as remote as possible from the Mode I site. From Uchupi's [1971] chart, this region is seen to be one of exceedingly rough topography.

Some of the velocity results from the first Polymode array are reported by Schmitz [1976a]. He shows that the kinetic energy variations over this limited portion of the western North Atlantic are very large, both in the thermocline and in the deeper water. Clearly, there is a variability scale associated either with the gyre (distance from the Gulf Stream) or with some other large-scale geographical characteristics. The results of Wyrtki et al. [1976] from ship drift data are consistent with this scale.

The potential energy variations over the entire gyre region are not altogether dissimilar, but there are some differences. All of the Polymode array 1 records are of nearly identical duration. We plot in Figure 20 the record potential energy between 9 months and 4 days. At the 500-m level, one sees a 


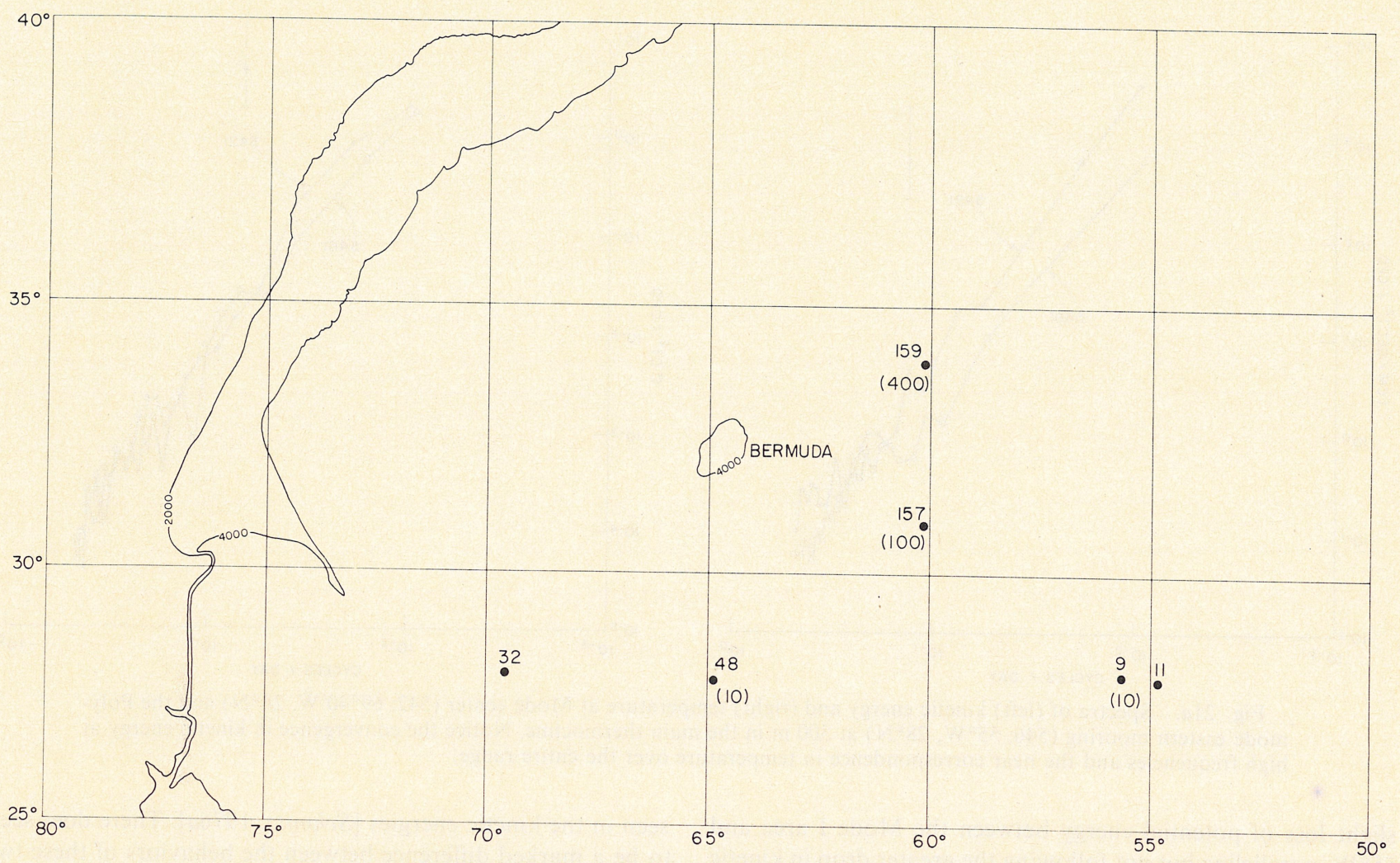

Fig. 20a. Potential energies at $500 \mathrm{~m}$ from homogeneous 9-month Polymode array 1 records. Parenthetical values are the corresponding kinetic energies obtained by Schmitz [1976a].

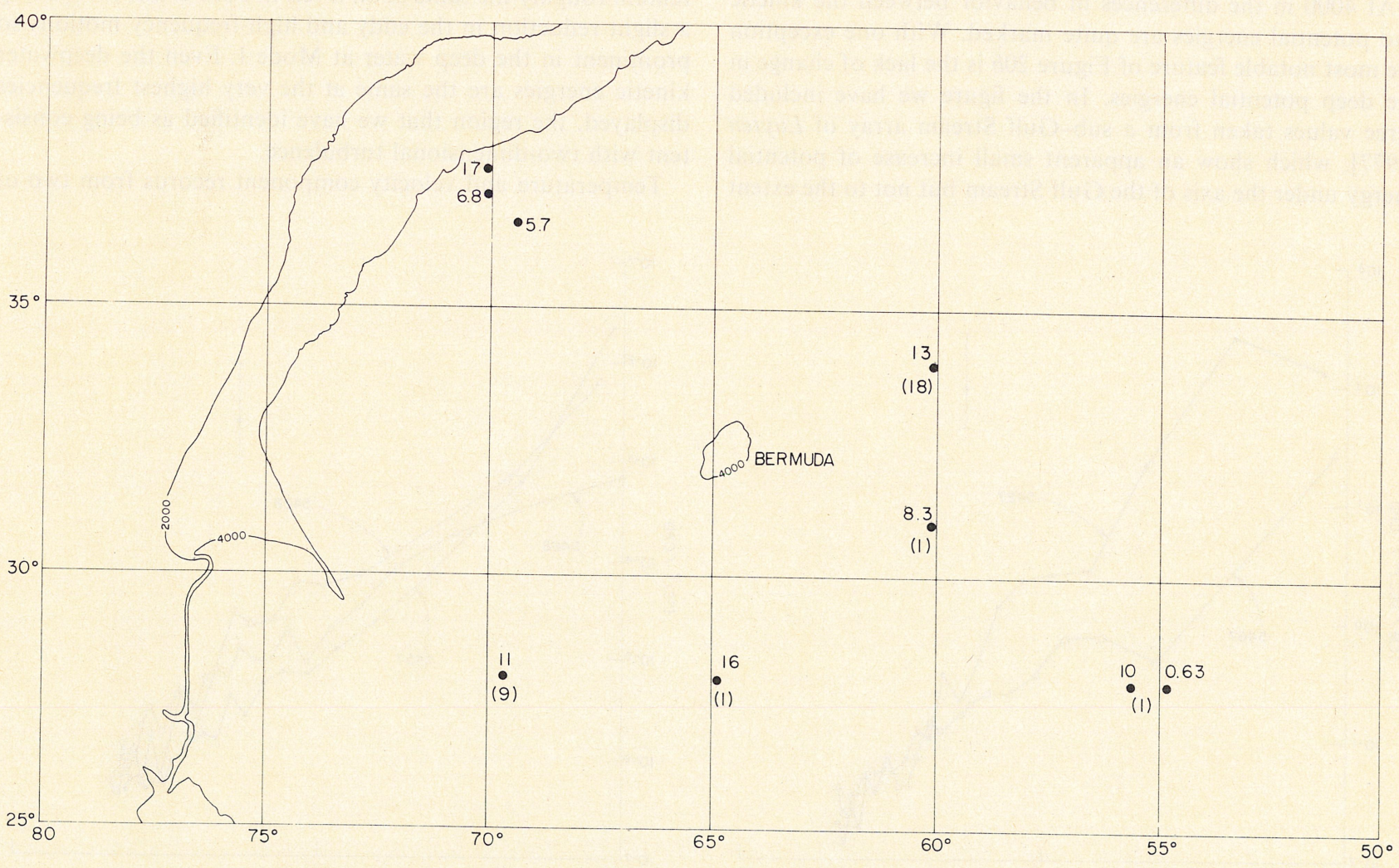

Fig. 20b. Potential energies at $4000 \mathrm{~m}$ from homogeneous 9-month Polymode array 1 records. In addition, some values under the Gulf Stream obtained by Luyten [1977] are also shown. Parenthetical values are the corresponding kinetic
energies obtained by Schmitz [1976a]. 

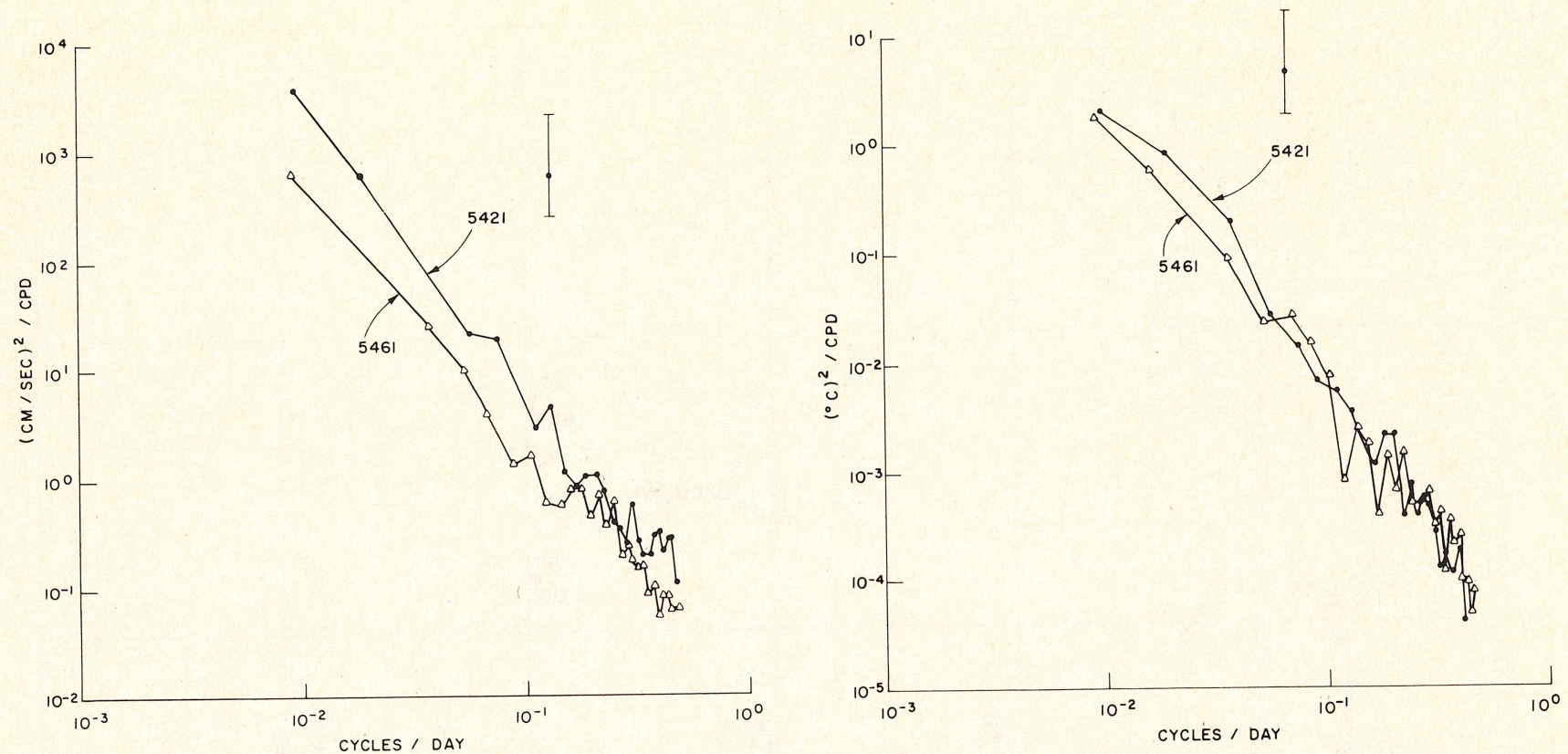

Fig. 21a. Spectra of (left) kinetic energy and (right) temperature at Mode center $\left(542 ; 69^{\circ} 40^{\prime} \mathrm{W}, 28^{\circ} \mathrm{N}\right)$ and the Polymode eastern mooring $\left(546 ; 55^{\circ} \mathrm{W}, 28^{\circ} \mathrm{N}\right)$ at $500 \mathrm{~m}$ in the main thermocline. Notice the convergence in kinetic energy at high frequencies and the near correspondence in temperature over the entire range.

slight loss of potential energy between the Mode I area and $55^{\circ} \mathrm{W}$, paralleling but not following the greater drop in kinetic energy density. On proceeding northward along $60^{\circ} \mathrm{W}$ the rise in potential energy again is not as marked as that in the kinetic energy densities (cf. the near-surface results deduced from XBT's (expendable bathythermographs) by Dantzler [1976, 1977]).

At $4000 \mathrm{~m}$ the differences in behavior between the kinetic and potential energies are quite marked. With one exception the most notable feature of Figure $20 b$ is the lack of change in the deep potential energies. In the figure we have included three values taken from a sub-Gulf Stream array of Luyten [1977], which show an apparent small increase of potential energy under the axis of the Gulf Stream but not to the extent seen in the kinetic energies [Schmitz, 1976a]. There does seem to be a marked difference between the behaviors of these two energies.

Comparative spectra of temperature and velocity between the Mode center Polymode records and those of the eastern region are displayed in Figure 21. The only striking differences are in the deepwater kinetic energies. Potential energy levels remain roughly the same at all levels in both areas, there being a slight reduction in the eddy and high-frequency motions so prominent in the deep water at Mode I. Even the deepwater kinetic energies are the same at the very highest frequencies displayed, the region that we have identified as being consistent with two-dimensional turbulence.

Temperature and velocity component records from two of

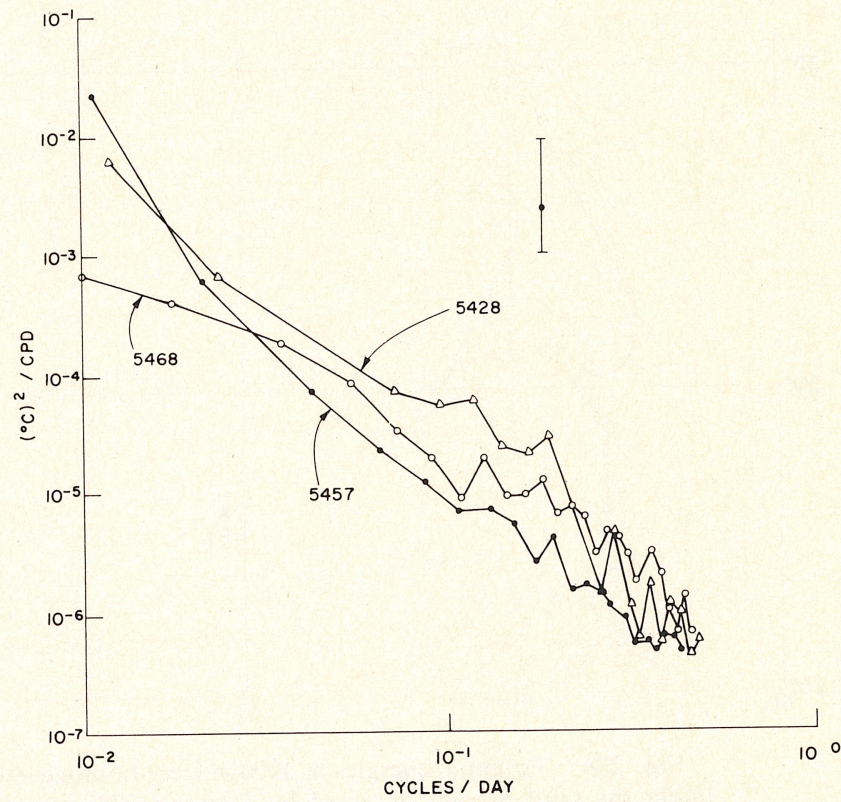

Fig. $21 b$. Same as Figure $21 a$ except at $4000 \mathrm{~m}$. 
the three moorings in the eastern cluster are plotted in Figure 22. By eye, one can see that the low-mode dominance of the Mode I region is clearly present here too. A considerable lowfrequency coherence between the moorings is also evident. The most striking difference from the Mode I region is the much longer time scale in both the thermocline and the deep water. There is a general lack of the short time scale evident in the Mode I deepwater region. By presumption, this change is related to the rugged bottom relief, but it is difficult to be sure.

There has been an unfortunate tendency to refer to this region as an 'eddy desert.' Clearly, eddies are present here; their potential energy is nearly as great as that in the Mode I area. Potential energy in the thermocline is comparable, and kinetic energy is only slightly reduced in comparison to that in the Mode I region. But time-dependent eddylike motion is still present. The periods seem longer, sufficiently long that little more than one realization was obtained.

The spectra displayed in Figure 21 are at least consistent with the idea that the baroclinic levels of motion are roughly constant over the gyre, even though their spectral distribution does change. The reduction of energy in the eastern region that is so prominent in the deep kinetic energies might be due to the removal of a barotropic mode of motion from the presence of very rough topography or to a horizontal scale change in that mode.

With these longer periods and weaker amplitudes, it may be that in this region of the ocean the linear wave models have some validity. The dominant period observed is now comparable to the period of the lowest linear baroclinic mode.

Records further north along $60^{\circ} \mathrm{W}$ (not shown) have an apparently shorter time scale again, shorter perhaps even than that in the Mode I area. The kinetic energy [Schmitz, 1976a] increases very abruptly, much more so than the potential energy. Evidently, one is entering a region dominated by Gulf Stream rings and the direct influence of that current. This region is being studied by a special Polymode array (array 2) still in progress, and it is not discussed further here [see Schmitz, 1977].

To summarize the question of typicality on the basis of what we have seen thus far, it is fairly clear that one major feature of the ocean mesoscale variability is an inhomogeneity over the gyre. We see rapidly changing ratios of potential to kinetic energy and marked changes in time scale and, by inference, in horizontal spatial scale as well. On the other hand, a tendency on the low-frequency end of the motions for the vertical scale to be comparable to the water depth (low-mode dominance) does seem universal (thus far). But the vertical distribution of energy seems to change rapidly. With the data in hand, one can suppose that these changes are the result of changing proximity to the Gulf Stream system, to the western boundary, or to the varying bottom relief. Dynamically, there may be some reason to believe that the somewhat weaker motions to the east may be more nearly linear, but this is unproven.

\section{SOURCES AND Sinks}

We have described via spectra, correlation functions, etc., the eddy field in the Mode I region as though it were in a steady state, and some of the models do likewise. Nothing has been said concerning the origin or sink of the motions so described. A number of sources of eddylike motion in the sea have been suggested: Schmitz' [1976a] demonstration of the enormous increase in deep kinetic energy toward the Gulf Stream and Dantzler's [1976, 1977] demonstration of nearsurface potential energy increase there suggest it as a possible source; local or more distant baroclinic instability [Giil et al., 1974; Robinson and McWilliams, 1974], topographic features [Huppert and Bryan, 1976; W. B. Owens and F. P. Bretherton, unpublished manuscript, 1976], wind forcing (S. G. H. Philander, unpublished manuscript, 1977), and Gulf Stream ring radiation [Flierl, 1977] are others.

The problem of the sinks of motion seems somewhat less well developed: most of the sources listed can act as sinks in the sense that the large-scale eddy motion may generate other smaller eddies through, for example, baroclinic instability [Kim, 1975; Hogg, 1976]; bottom topography may scatter eddy energy into smaller and thus more easily dissipated scales; critical layers [e.g., Mofjeld and Rattray, 1975; Dickinson, 1970] may absorb the eddy momentum by generating mean flows. Internal waves can act as an effective eddy viscosity, extracting energy from the lower frequencies, as was discussed by Müller [1976], although recent work of Ruddick [1977] has found no evidence for the magnitude of the energy exchange predicted by Müller. Finally, the geostrophic turbulence models of Charney [1971], Lilly [1973], and others and the numerical simulations of Rhines [1976] imply a loss of eddy energy to larger scales through turbulent cascades, presupposing a source capable of maintaining a steady state.

On the basis of the data at hand we can make some statements about some of these source processes. Baroclinic instability, if locally present, represents a release of mean potential energy to eddy kinetic and potential energies. One necessary indication of that process is that there exists a significant eddy heat flux $\left\langle v^{\prime} T^{\prime}\right\rangle$. As we have seen, there is only a weak zonal heat flux, and that is in the deep water. The theoretical papers cited above suggest that baroclinic instability, if it occurs at all, should be most clearly manifest in the thermocline, where the mean shear is greatest. Of course, in the Mode area the mean shear, even in the thermocline, is very weak. Another signature of baroclinic instability is a phase tilt in the vertical of the local modal structure. As we have seen (Table 4), on the average we do not obtain vertical coherences of any of the dependent variables with a phase significantly different from zero. This is another manifestation of the statement that low modes dominate the records. Even though instantaneous pictures of the thermocline may show tilts, to assert that such motions occur on the average in a random field is quite another matter. Thus there is no specific evidence that local large-scale baroclinic instability is of any importance in the Mode I region.

The question of topographic generation is a little more difficult. We have seen some evidence above for differences between the rough and smooth regions of Mode I. What evidence there is suggests a lack of energy in the barotropic mode in the rough area (suggested by Freeland et al. [1975] to explain the float data) consistent with the changes seen in the gyre scale. The theories of topographic generation [e.g., Huppert and Bryan, 1976; Hogg, 1976] suppose that some preexisting mean flow interacts with bottom features to generate primarily baroclinic effects, manifested as Taylor columns, lee waves, or closed eddies. The Mode I eddy showed no obvious evidence of bottom trapping or intensification, and hence it seems unlikely that it was directly the result of an interaction with bottom topography in the immediate vicinity. The eddy could interact with the rough area to the east, and it is possible that the additional energy seen at small horizontal space and time scales in the deep water is a remnant of that interaction [see Hogg, 1976]. However, the bulk of the high-frequency continuum seems independent of the position of the measure- 

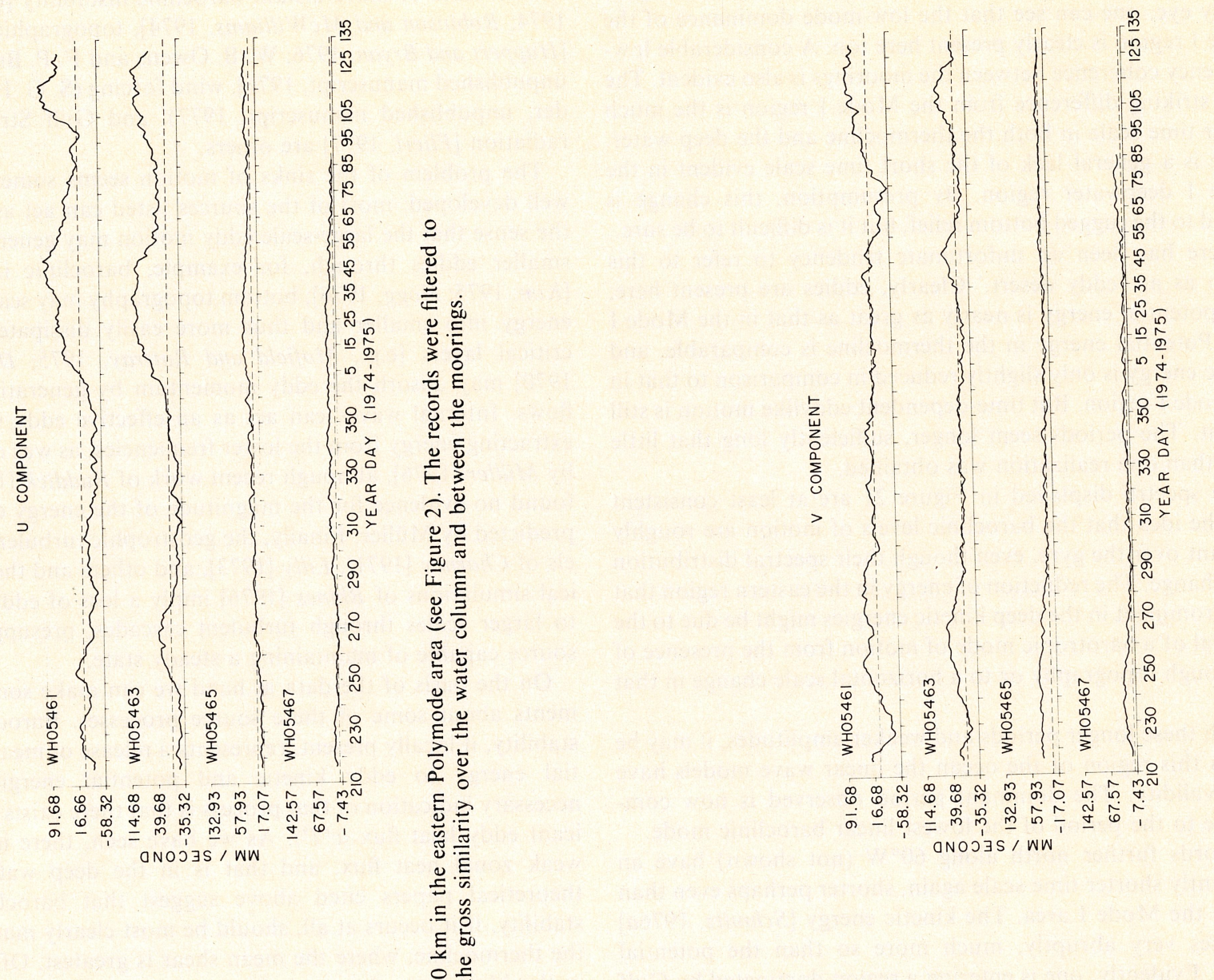

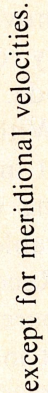
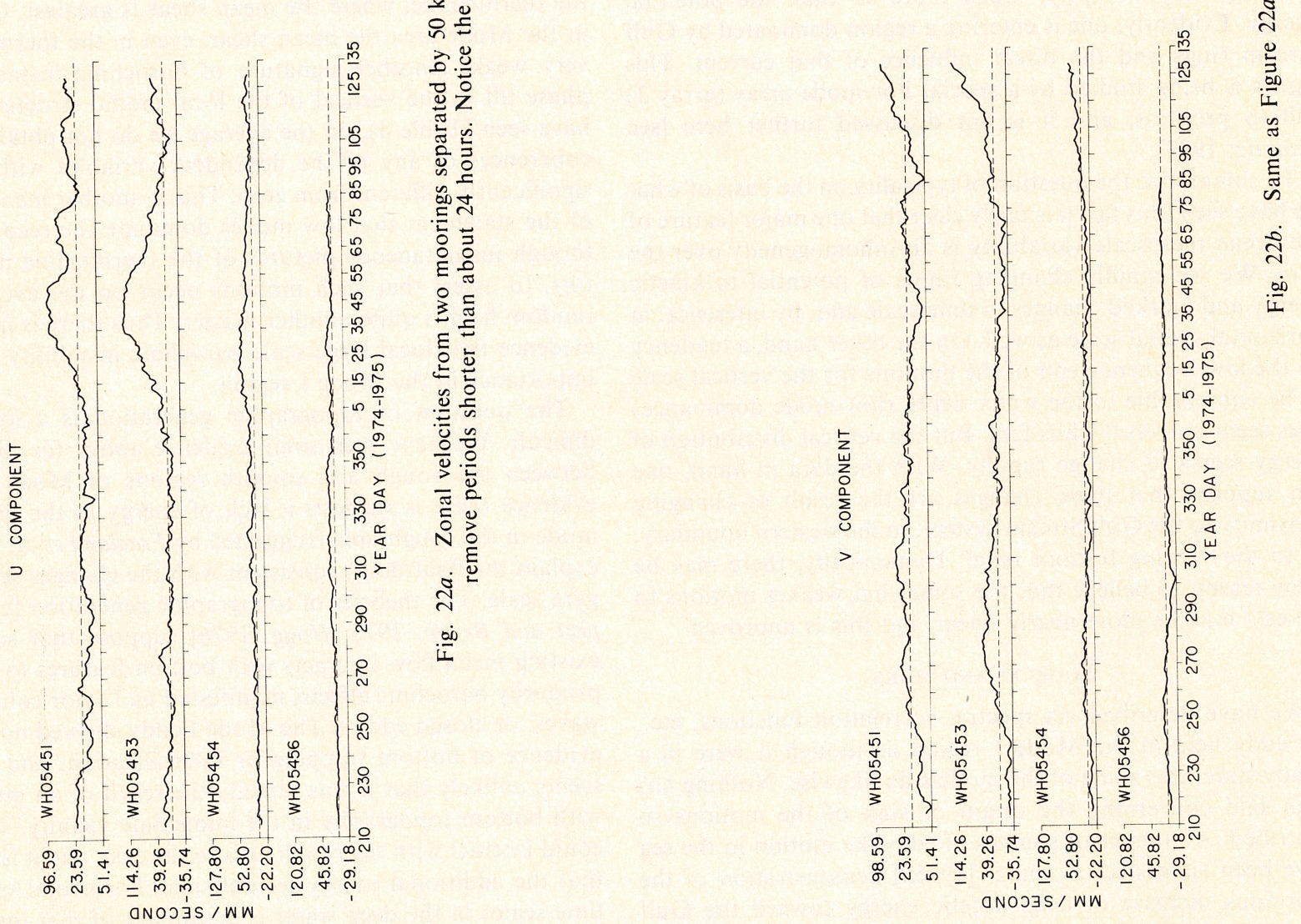


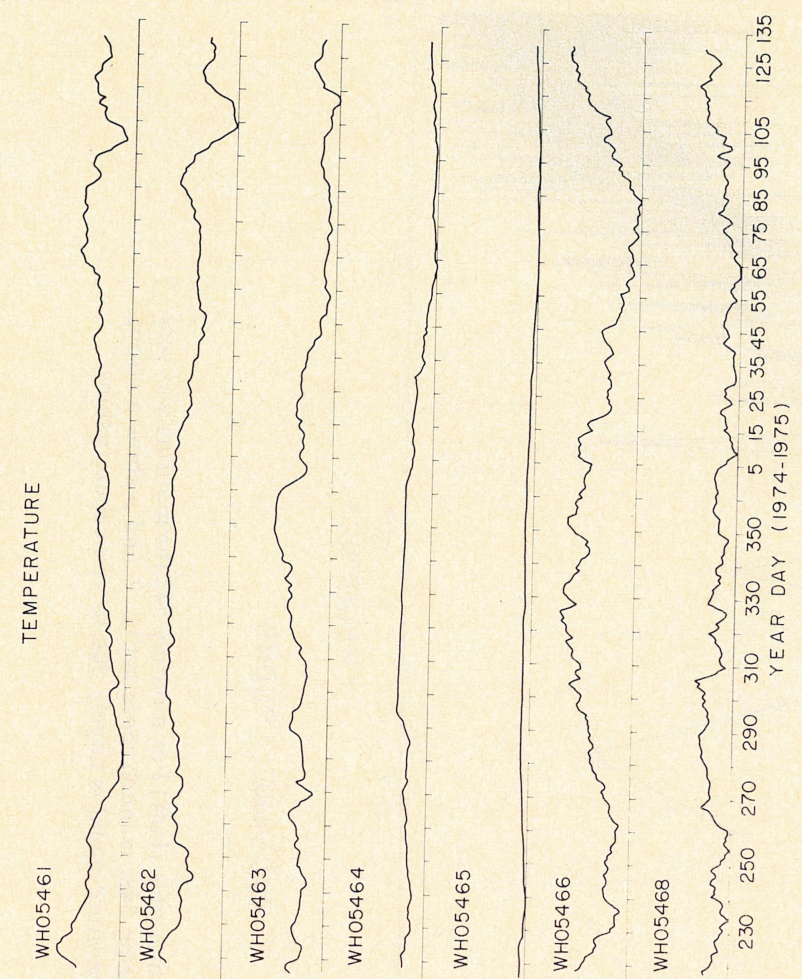

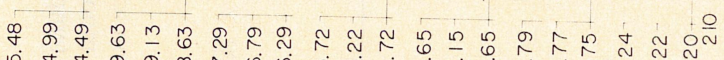

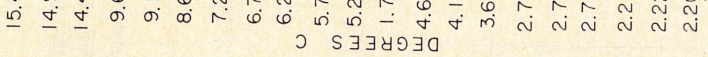

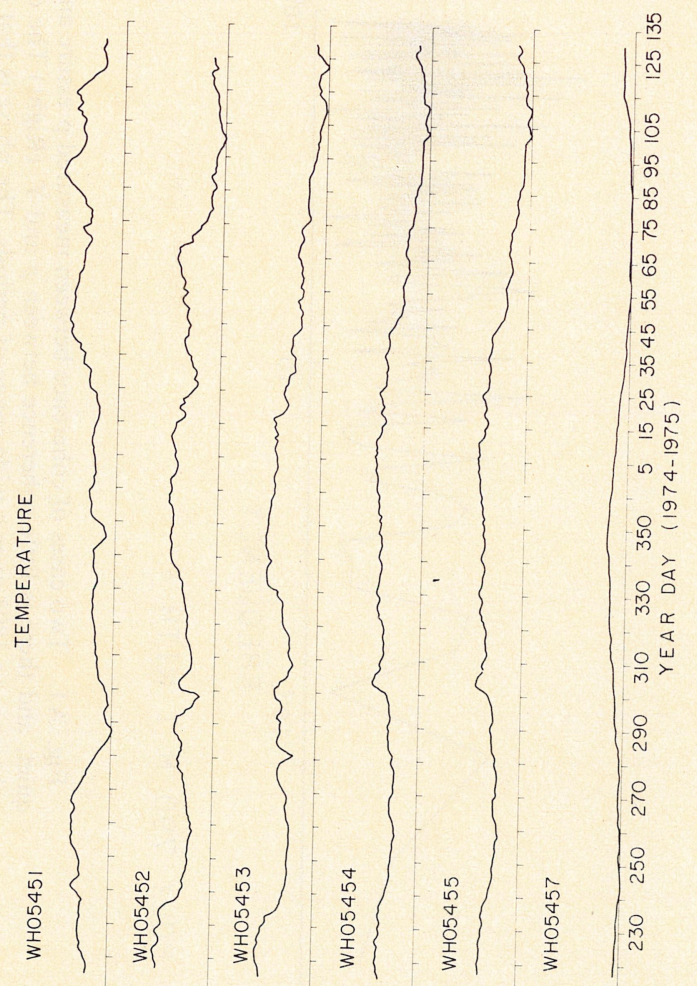

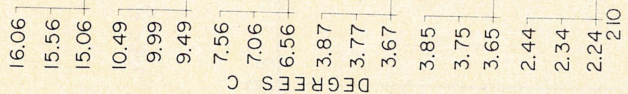

ment relative to the topography, and it seems likely that most of this high-frequency energy comes from some different process, perhaps the quasi-geostrophic turbulence cascade discussed above.

S. G. H. Philander (unpublished manuscript, 1977) has suggested that forced Rossby-type modes could account for at least part of the low-frequency continuum in the ocean. These motions would be surface trapped (having negative equivalent depths) and would tend to reflect the spectral content of the local wind field. Mode I and all subsequent measurements have had poor near-surface sampling. Even so, there is no real evidence of any significant vertical trapping [see Sanford, 1975]. Furthermore, the eddy field does seem to manifest itself in a structured spectrum, a spectrum that seems somewhat at odds with most extant wind spectra (which are very few). Of course, we cannot rule out some motions driven by the wind. However, much more intense near-surface sampling would be needed to seek it directly. Some of the bottom pressure fluctuations reported by Brown et al. [1975] may represent a barotropic response to wind forcing.

The notion of a radiating Gulf Stream as a source [e.g., Schmitz, 1976a; Holland and Lin, 1975] remains a viable one. It is a strong contender simply because there is a lot of energy to be found in its vicinity. But because we have not actually been able to measure directly a flux of energy from the Gulf Stream region to and through the Mode I area, it must be regarded as an undemonstrated hypothesis. One could explain the general intensification toward the Gulf Stream simply as a form of westward intensification, i.e., primarily a form of trapping and dissipation rather than of generation.

It is also difficult to come to grips with the dissipation problem. There are no direct measurements showing a loss of energy from the system. McWilliams's [1976b] study of potential vorticity conservation balances the inviscid equation within the estimated error bars of measurement. Frankignoul [1976] claims to have shown that the relationships between the mean shear and the internal wave field predicted by Müller [1976] for the extraction of energy from the mean are satisfied, yielding a large eddy coefficient of momentum equal to $10^{3}$ $\mathrm{cm}^{2} / \mathrm{s}$. But the calculation is made only over a fraction of the Mode I time interval, which is only a small fraction of the dominant eddy time scale, and Ruddick [1977] has not found momentum fluxes of the required magnitude for long-term averages. Kim [1975] has found that baroclinic Rossby waves are unstable in both the barotropic and the baroclinic senses, suggesting that eddies, perhaps a product of instability, are themeselves unstable. Hogg [1976] has discovered a class of spatially growing baroclinic waves and has suggested that they can be forced by rough topography. Although he finds some evidence for their existence in velocity profiles, we have found no significant differences here on the average between rough and smooth topographies (except at $1500 \mathrm{~m}$, as has been noted). Several processes, for example, the bottom boundary layer, by inference must represent dissipation of eddy energy. Quantitative estimates of their significance are still missing.

\section{Summary and Discussion}

Considerable progress has been made in understanding the qualitative nature of the oceanic mesoscale eddy field in the time since the Mode I experiment. Though it is possible to conclude [e.g., Wyrtki et al., 1976] that oceanographers have long known about eddies, in fact, little more was known than that the noise in hydrographic data was consistent with the presence of a hypothesized scale smaller than the gyre. 

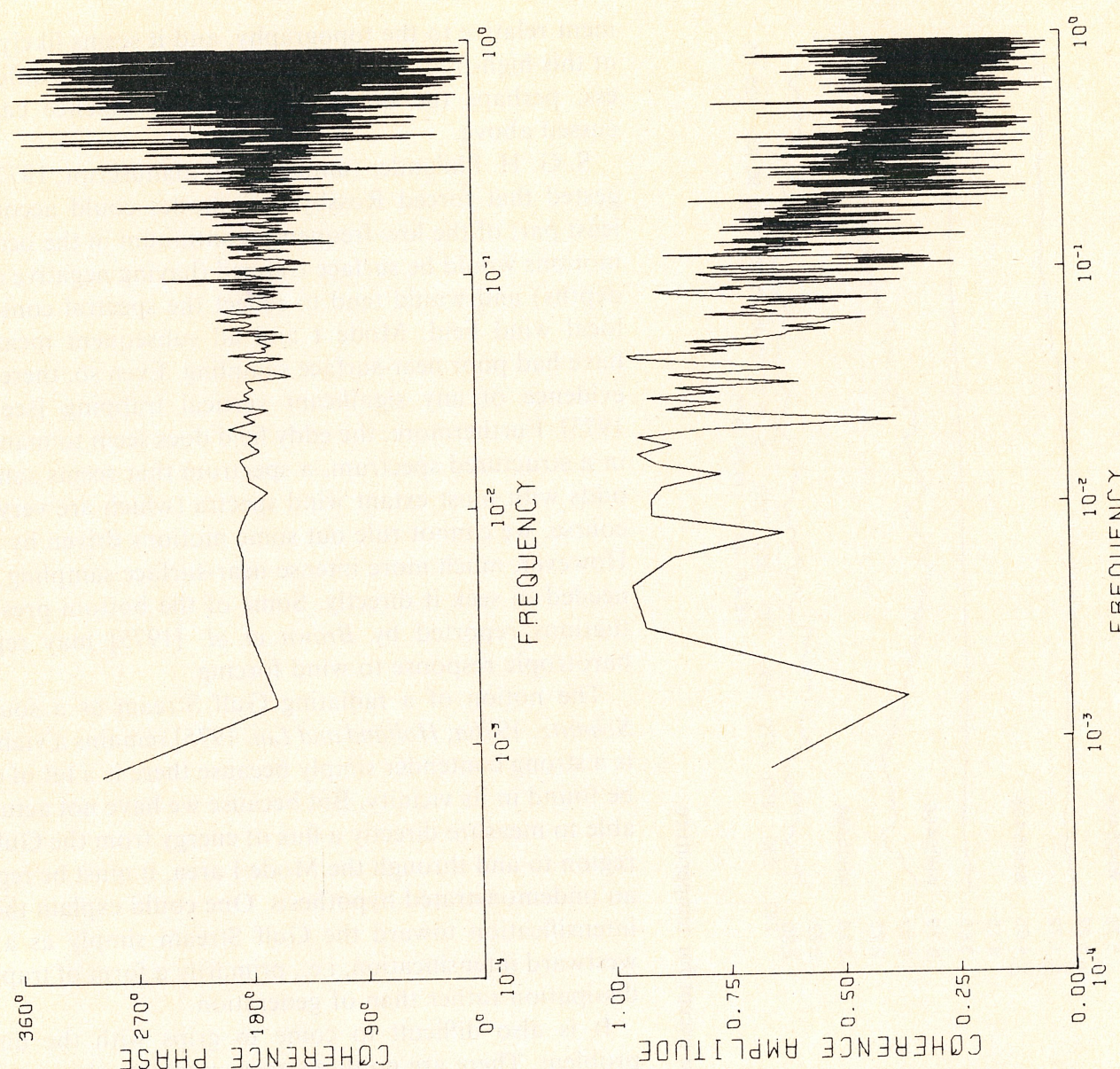

권

$\succ$
2
$w$
$\exists$
0
$w$
cr.
L
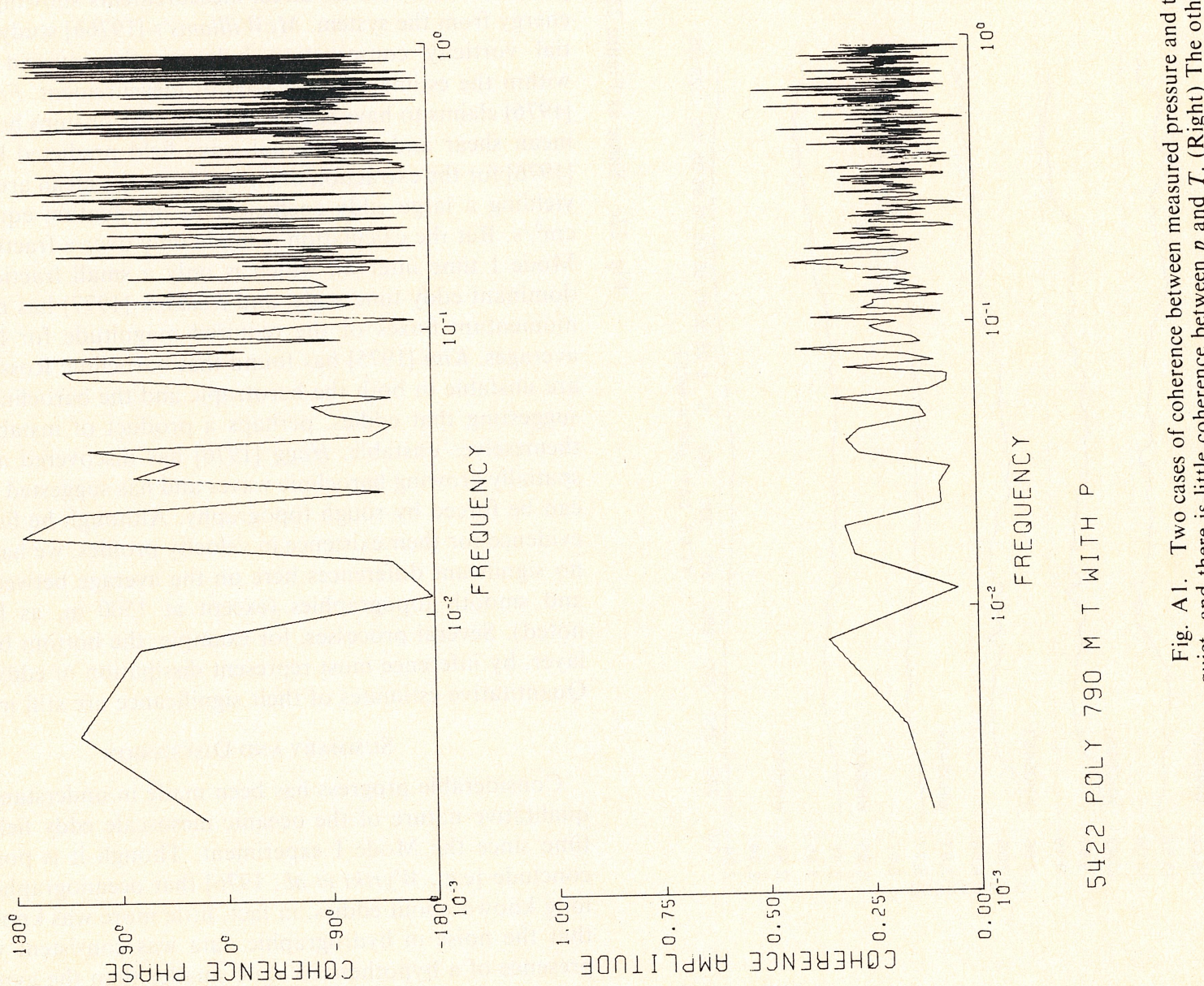

움

$\frac{1}{0}$

ป 
What has emerged here and in studies of other oceans [e.g., Hunkins, 1974; Bernstein and White, 1974] is that superimposed upon the gyre or general circulation scale is an energetic space-time continuum that shows a remarkably intricate spatial inhomogeneity. Some features, for example, kinetic energy at some periods at $1500 \mathrm{~m}$, appear in the Mode l area to change over distances comparable to the eddy scale itself; other, order of magnitude changes in energy level occur vertically from thermocline to deep water; and others occur over the subtropical gyre scale.

While a lot of detail can be extracted from the Mode and post-Mode data sets, we can summarize what, at this time, appears to be the qualitatively important features.

1. There does appear, in the Mode 1 area, to be an identifiable region of the frequency spectrum, centered on about a 100-day period, of a horizontally isotropic velocity field dominated by a vertical scale comparable to the water depth (low modes).

2. At periods longer than about 100 days the motion tends to be dominantly zonal in character and confined largely to the thermocline.

3. At periods shorter than 100 days the eddy field is not inconsistent with the hypothesis that it is the result of a geostrophic turbulence cascade.

4. Evidence exists for a reduction in the barotropic flow energy as one encounters rougher topography.

5. East of the Mode I area the motions may occur at longer periods.

6. Kinetic energy levels grow markedly as the Gulf Stream is approached from the south.

7. Linear dynamics appear to fail in the Mode I region but may be applicable in the regions to the east.

8. Specific conclusions concerning sources or sinks of the variability are purely speculative.

\section{APPENDIX A}

\section{Temperature and Pressure Measurement}

Some of the earliest results of this type of measurement were described by Wunsch and Dahlen [1974] and Gould et al.
[1974]. In the trials for Mode I (called Mode 0) it had been concluded on the basis of energy level discrepancies and the large excursions of the $T / P$ recorder on a surface mooring that only the WHOl-type subsurface moorings were suitable for use in the experiment. A detailed mooring motion experiment (which occurred in rather low meari velocities) has been described by Chhabra et al. [1974] and Chhabra [1977] and seemed to demonstrate the stability of subsurface mooring platforms and the general accuracy of the dynamical models used to describe mooring motion.

Generally speaking, the results of Mode I confirmed the validity of this choice of mooring technique. But some problems did emerge. It was found that the average depths of all instruments as deduced from the pressure measurements were less than was intended, in a few cases by over $100 \mathrm{~m}$. This discrepancy decreased with total instrument depth. Because the shallow displacement was about the same for all moorings, the overall effect on the experiment, which was designed to have certain fixed instrument levels, was not serious. But as a general principle, one wants to be able to preselect instrument depths.

The tendency for instruments to be shallower than is required has been traced to two causes: The first is the tendency for the synthetic line that makes up the moorings below 2000 $m$ to creep under load. A number of the pressure records show a definite creep toward lower pressures in the first days after the moorings were set. The second cause [Heinmiller, 1976] is attributable to small systematic errors in computing the distance from the bottom in the mooring design, both in the difficulty in measuring long lengths of cable and line and in the tendency to ignore small shackles and other mooring hardware, which individually cause errors which are small but which accumulate over $5000 \mathrm{~m}$ of mooring. In the post-Mode and Polymode periods these problems were overcome by using all-wire moorings and by including in the length calculations even the smallest bits of hardware inserted into the mooring [Heinmiller, 1976].

During Mode I the subsurface moorings did provide, for the most part, adequately stable measurement platforms, but they
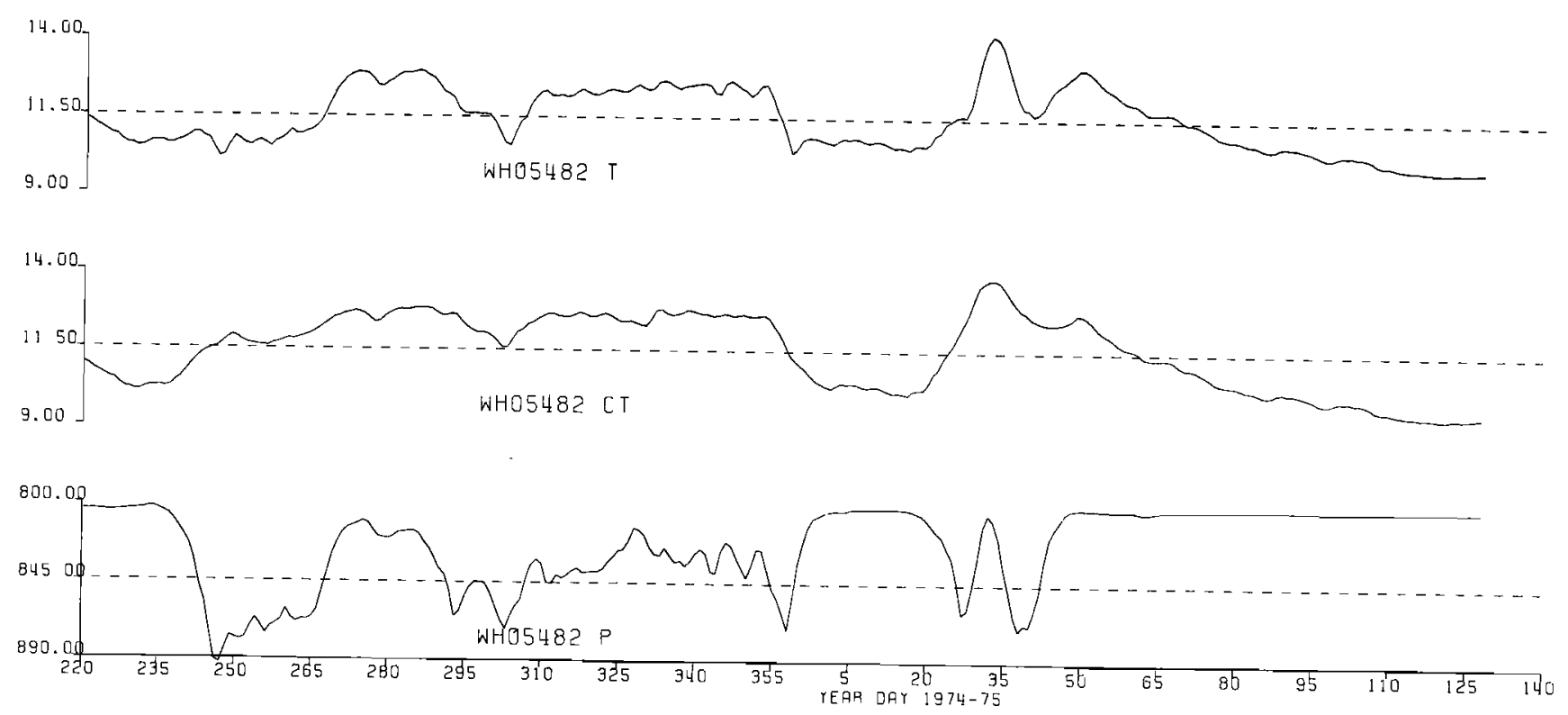

Fig. A2. Filtered temperature and pressure of record 548 whose coherence is shown in Figure Al and the temperature that results $(\mathrm{CT})$ when the procedure described in the text is used. 

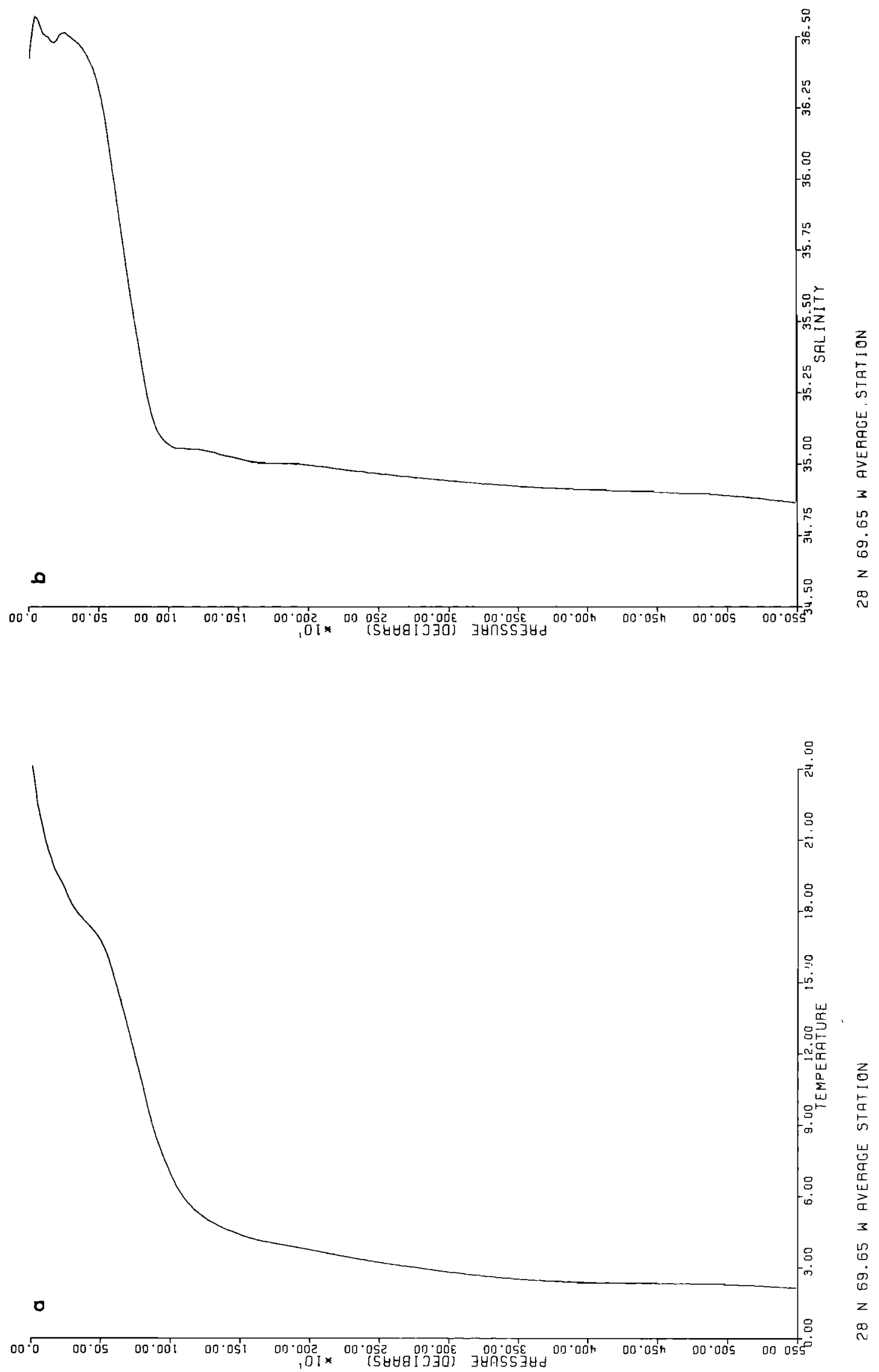


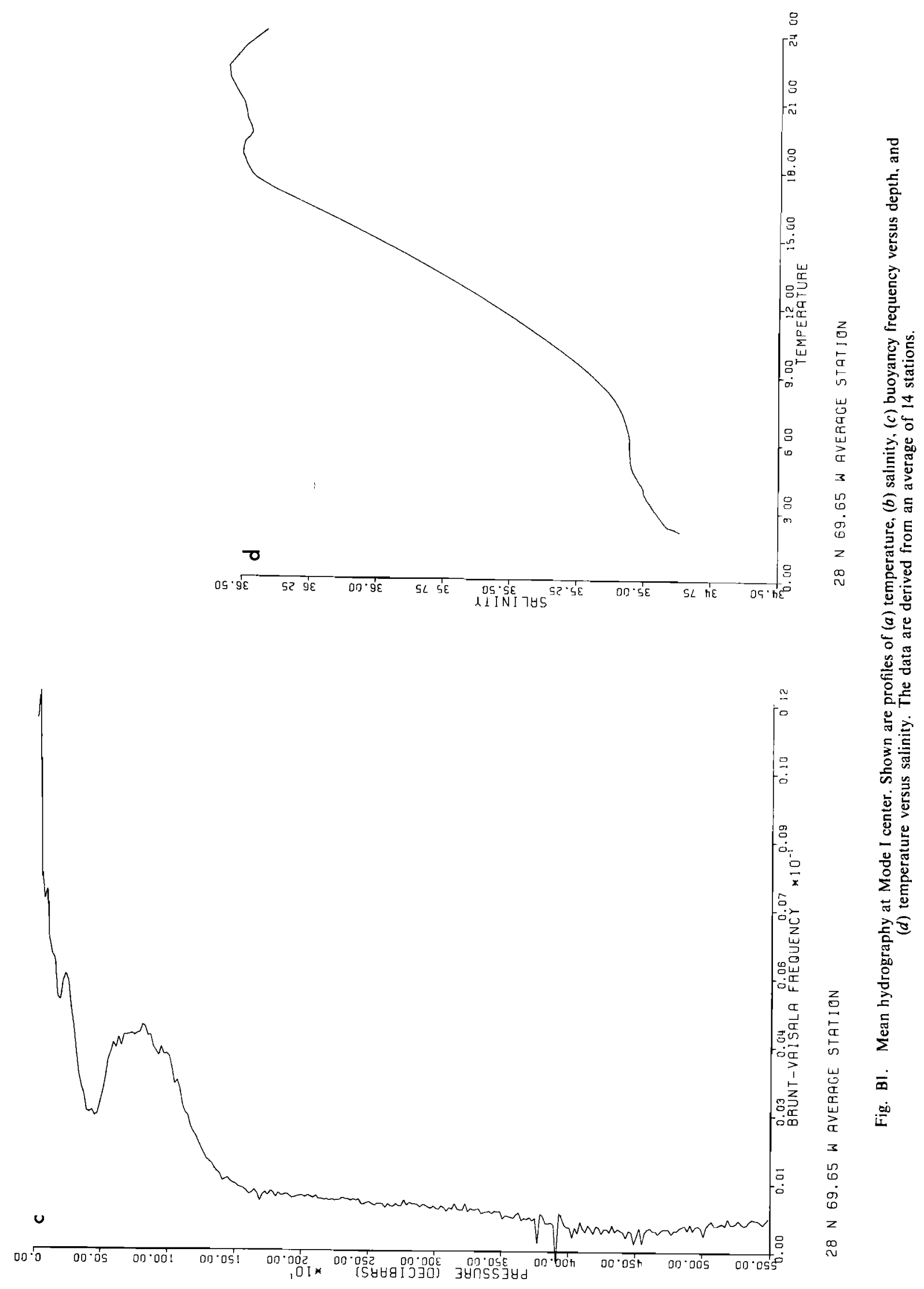


were not quite as stable as was expected. In retrospect, the expectation was based upon the rather low velocities seen during the pre-Mode I period. Over the roughly 4-month period the uppermost portions (approximately the upper 500 $\mathrm{m}$ on moorings extending to $400 \mathrm{~m}$ ) of the 16 moorings had a range of excursions of from $12 \mathrm{dbar}$ (mooring 8) to the large extreme of $127 \mathrm{dbar}$ in the case of mooring 13. The rms excursions about the mean in these two cases were 1.5 and 19 dbar, respectively. As might be expected, vertical excursion is a function of depth on a mooring, necessarily decreasing to zero at the anchor. On the extreme mooring, mooring 13, the excursion is reduced to $33 \mathrm{dbar}$, and the rms to $6.6 \mathrm{dbar}$ at 4033 dbar. Vertical mooring motion, under certain assumptions, is proportional to the fourth power of the ambient velocity [Chhabra et al., 1974; Chhabra, 1977]. It is desirable to reduce expected mooring motion in the thermocline to less than about $10 \mathrm{dbar}$ of maximum excursion. In view of the result of Mode I, subsequent moorings were 'stiffened' by adding and redistributing buoyancy to the system. In the later measurements in the Mode I area, maximum mooring excursion was reduced to $13 \mathrm{dbar}$ (at $800 \mathrm{dbar}$ ). But in Polymode array 1 , mooring 548 , located at $30^{\circ} \mathrm{N}, 60^{\circ} \mathrm{W}$, underwent an excursion of 109 dbar (at 814 dbar mean) with an rms variation of $26 \mathrm{dbar}$. Velocities at the time of maximum excursion were about $60 \mathrm{~cm} / \mathrm{s}$. It does not seem possible (N. P. Fofonoff, personal communication, 1975) to reduce the mooring motion further with the existing technology; this renders computations of quantities like $\left\langle v^{\prime} T^{\prime}\right\rangle$ uncertain.

\section{Correcting Temperatures}

If mooring motion becomes sufficiently great, changes in temperature due to instrument excursion can become a significant fraction of the temperature change due to water motion past the instrument, the latter being the quantity of interest. Whether this mooring motion contribution is significant depends upon the particular record, especially upon instrument depth. In the bulk of the Mode I records, mooring motion corrections, though made, do not contribute in any qualitative way to the resulting measured temperature. But in the extreme cases, cited above, the changes can be drastic and do qualitatively change the results.

We needed some procedure for making corrections in the observed temperature for the known vertical excursions of the instrument. Let $T_{m}$ be temperature as measured by the instrument, $d p / d t$ the vertical velocity (in decibars per unit of time) of the instrument, $w$ the vertical velocity of the water past the instrument, and $T_{0}(p, t)$ the vertical temperature field. Then at any given instant of time we can write

$$
\frac{d T_{m}}{d t}[p(t), t]=\frac{\partial T_{0}}{\partial p} \frac{d p}{d t}+\frac{\partial T_{0}}{\partial t} \equiv \frac{\partial T_{1}}{\partial t}+\frac{\partial T_{0}}{\partial t}
$$

One seeks $T_{0}(\langle p\rangle, t)$, where $\langle p\rangle$ is a nominal measurement depth. To obtain a systematic approximation, we expand (A1) in Taylor series about $\langle p\rangle$ and retain only the leading terms:

$$
\frac{d T_{m}}{d t}(\langle p\rangle, t) \simeq \frac{\partial T_{0}}{\partial p}(\langle p\rangle, 0) \frac{d p}{d t}+\frac{\partial T_{0}}{\partial t}(\langle p\rangle, t)
$$

To this approximation the mean temperature gradient is constant with depth. Then

$$
\frac{\partial T_{0}}{\partial t}(\langle p\rangle, t)=\frac{d T_{m}}{d t}-\gamma \frac{d p}{d t} \quad \gamma=\frac{d T_{0}}{d p}(\langle p\rangle, 0)
$$

In principle, (A3) can be used if $\gamma$ can be determined. But usually, we do not know $\gamma$; if we are fortunate, we will have a few hydrographic stations taken throughout the record. Oftentimes, only a single hydrographic station will be available for use in a 9-month record (as is true in Polymode array 1). One might use temperature recorders in pairs or triads to compute a temperature gradient in time, but one does not often have a sufficient abundance of instruments to concentrate them in the water column as is required. We therefore sought a correction scheme that would be usable if only limited or no hydrographic data were available and that could be implemented as part of the routine processing.

We chose to use a form of regression scheme to deduce an 'optimal' value of $\gamma$ in (A3). But both pressure and temperature have a complex spectrum of motion, and the question of exactly how to carry out the regression is an important one.

Two examples of the coherence between $p$ and $T$ are shown in Figure A1. Both variables are energetic in the low-frequency (below inertial) band and tend to be at least partially coherent there. In the high-frequency (internal wave) band, pressure energy is reduced in relation to that of temperature, and the coherence is low. Now the fundamental difficulty in using a regression between $p$ and $T$ to deduce $\gamma$ is that they may be correlated (coherent) for reasons not fundamentally related to mooring motion. There is the danger of 'overcorrecting' the $T$ record. There are a number of ways in which $T$ and $p$ may be related. For example, at low frequencies it appears that water moving vertically past the instrument locally displaces it in the direction of water motion, the displacement yielding a very high coherence between $T$ and $p$ at near-zero phase lag. At higher frequencies the mooring seems to respond rather more to water velocities remote from the particular sensor, and the local coherence is much reduced.

If one tries to regress $T$ against $p$ (essentially integrating (A3) to give $\left.T_{m}=\gamma(p-\langle p\rangle)+T_{0}\right)$ to determine $\gamma$, the high energies at the low-frequency end of the spectrum dominate the regression, yielding large positive and quite incorrect values of $\gamma$.

On the other hand, if one regresses the raw temperature and pressure time differences against each other, one has effectively applied a strong high-pass filter to the data; there is little correlation between the two time series, and one obtains values of $\gamma$ that are much too small.

After experimenting with these extremes and other schemes we finally chose the following method: 80 -hour averages $\left\langle T_{m}\right\rangle$ and $\langle p\rangle$ are formed. We then regress the 80 -hour time differences of $T$ and $p$ against each other to deduce $\gamma$. This scheme has the effect of giving greatest weight in the spectrum to motions with time scales of about 80 hours. We find empirically that when mooring motion is large, the value of $\gamma$ is in very close agreement with the available hydrographic data. An example is Polymode record 5482 (one of the extreme cases referred to above). We derive a value of $\gamma=-0.020$. The available hydrographic station gives a value of $\gamma=-0.021$ for a $100-\mathrm{m}$ gradient and of $\gamma=-0.024$ for a $20-\mathrm{m}$ gradient. So the regression-deduced value is at least 'reasonable,' and it is impossible to say which value is best. Records with very weak mooring motion often do not give very realistic values of $\gamma$, and it sometimes even has the wrong sign. But in these cases the motion correction is insignificant, and the failure is of no consequence (if $\gamma$ is positive, no correction is made). Below $2000 \mathrm{~m}$ we have not found a case in which the mooring motion correction was significant. (This statement breaks down in the Gulf Stream region.)

There is a rationale for the scheme. Between the inertial frequency and the mesoscale motions that are the primary 
topic of this paper is an apparent dynamical minimum, a form of spectral gap. It appears that at periods near 80 hours, much of the observed temperature signal is induced by mooring motion and the regression tends to be dominated by mooring motion effects.

Experiments with higher-order regression schemes to account for mean gradient curvature were unstable and gave unreliable results.

An example of a corrected record is shown in Figure A2.

\section{Correcting Velocities}

Current meter records are coherent with pressures on moorings having large vertical excursions (not displayed here). 'Contamination' of these velocities occurs in several ways. The instrument is sometimes measuring velocity far from its nominal position in the water column. Particularly in the thermocline, where the mean velocity profile is inferred to have considerable curvature (see Figure 16), a considerable bias may be introduced into the record. Furthermore, if one assumes the presence of a velocity fine structure, then the high-frequency part of the spectrum will show spurious energy related to the vertical motion through it. We do not have any scheme for correcting velocity records comparable to that used for temperature records. Fortunately, in Mode I, post-Mode, and Polymode array 1 the mooring motion tended to be weak, and it is not believed to make any qualitative difference in any use made here of the velocity records. In the later Polymode arrays (not discussed in this paper), very near the Gulf Stream, this is no longer true. In particular, estimates of quantities like $\left\langle v^{\prime} T^{\prime}\right\rangle$ seem to depend qualitatively upon whether and how corrections are made.

\section{APPENDIX B}

In order to compute vertical water displacements and potential energy from temperature records an estimate of the mean values of temperature and buoyancy frequency is needed. At the Mode I center we have used 14 stations, and at the eastern site mooring (Mode mooring 8), 10 stations. The resulting hydrography for the center is shown in Figure B1. No significant difference between the mean stations was apparent. TS properties of the Mode I hydrography are discussed by R. I. Scarlet (unpublished manuscript, 1974). Richman [1976] discusses the significance of TS variations in the Mediterranean Water and the conversion to density. He shows that dynamic height evaluated from temperature alone on a heavily instrumented mooring is within a few percent of the values deduced from CTD casts.

Acknowledgments. All of the mooring data discussed here were obtained by the Woods Hole Oceanographic Institution Moored Array Group through contracts N00014-66-C0241, NR 083-004, and N00014-74-C0262, NR 083-004 from the Office of Naval Research and grants GX-29054 and OCE75-03692 from the National Science Foundation. We are especially indebted to William Schmitz for a sustained free exchange of data and ideas throughout Mode I and its successors. The Charles Stark Draper Laboratory group under the direction of John Dahlen made possible the temperature/pressure recorder data. Special thanks go to R. Araujo for overseeing all those instruments. Most of the computing was carried out by Barbara Grant and Charmaine King. Francis Bretherton made his objective analysis program available to us. Mode I and Polymode are large cooperative experiments involving a great many people and ideas. We are indebted to all of our colleagues who over the last several years have joined with us in the experiments: scientists, engineers, technicians, and ships' crews. The work was supported by the National Science Foundation, Office of the International Decade of Ocean Exploration, under grants GX29034 and IDO82534. Thanks are due to Curt Collins of NSF for his continuing help. J.G.R. was supported by a fellowship of the
Fannie and John Hertz Foundation during this work, and N.G.H. received partial support from the Office of Naval Research through contracts N00014-66-C0241, NR 083-004, and N00014-76-C0197, NR 083-004. Contribution 89 from the Mid-Ocean Dynamics Experiment and contribution 3986 from WHOI.

\section{REFERENCES}

Batchelor, G. K., The Theory of Homogeneous Turbulence, Cambridge University Press, New York, 1953.

Bernstein, R. L., and W. B. White, Time and length scales of baroclinic eddies in the central North Pacific Ocean, J. Phys. Oceanogr., 4, 613-624, 1974.

Bretherton, F. P., and D. Haidvogel, Two-dimensional turbulence above topography, J. Fluid Mech., 78, 129-154, 1977.

Bretherton, F. P., R. E. Davis, and C. Fandry, A technique for objective analysis and design of oceanographic experiments applied to Mode-73, Deep Sea Res., 23, 559-582, 1976.

Briscoe, M. G., Preliminary results from the trimoored internal wave experiment (Iwex), J. Geophys. Res., 80, 3872-3884, 1975.

Brown, W., W. Munk, F. Snodgrass, H. Mofjeld, and B. Zetler, Mode bottom experiment, J. Phys. Oceanogr., 5, 75-85, 1975.

Bryden, H. L., Geostrophic comparisons using moored measurements of current and temperature, Nature, 251, 409-410, 1974.

Bryden, H. L., Horizontal advection of temperature for low-frequency motion, Deep Sea Res., 23, 1165-1174, 1976.

Bush, P., Bathymetry of the Mode-I region, Deep Sea Res., 23, 1105-1114, 1976.

Charney, J. G., Geostrophic turbulence, J. Atmos. Sci., 28, 1087-1095, 1971

Chausse, D., and S. Tarbell, A compilation of moored current data and associated oceanographic observations, XII (1973 Mid-Ocean Dynamics Experiment (Mode 1)), Tech. Rep. 76-101, Woods Hole Oceanogr. Inst., Woods Hole, Mass., 1976.

Chhabra, N. K., Correction of vector-averaging current meter records from the Mode-I central mooring for the effects of low-frequency mooring line motion, Deep Sea Res., 24, 279-288, 1977.

Chhabra, N. L., J. M. Dahlen, and N. R. Froidevaux, Mooring dynamics experiment: Determination of a verified dynamical model of the WHOI intermediate mooring, Tech. Rep. R-283, C. S. Draper Lab., Cambridge, Mass., 1974.

Crease, J., Velocity measurements in the deep water of the western North Atlantic, J. Geophys. Res., 67, 3173-3176, 1962.

Dantzler, H. L., Geographic variations in intensity of the North Atlantic and North Pacific oceanic eddy fields, Deep Sea Res., 23, 783-794, 1976.

Dantzler, H. L., Jr., Potential energy maxima in the tropical and subtropical Atlantic, J. Phys. Oceanogr., 7, 512-519, 1977.

Dexter, S., J. Milliman, and W. J. Schmitz, Jr., Mineral deposition on current meter bearings, Deep Sea Res., 22, 703-706, 1975.

Dickinson, R. E., Development of a Rossby wave critical level, $J$. Atmos. Sci., 27, 627-633, 1970.

Flierl, G. R., The application of linear quasigeostrophic dynamics to Gulf Stream rings, J. Phys. Oceanogr., 7, 365-379, 1977.

Fofonoff, N. P., and T. F. Webster, Current measurements in the western Atlantic, Phil. Trans. Roy. Soc. London, Ser. A, 270, 423-436, 1971.

Frankignoul, C., Observed interaction between oceanic internal waves and mesoscale eddies, Deep Sea Res., 23, 805-820, 1976.

Freeland, H. J., and W. J. Gould, Objective analysis of mesoscale ocean circulation features, Deep Sea Res., 23, 915-923, 1976.

Freeland, H. J., P. B. Rhines, and T. Rossby, Statistical observations of the trajectories of neutrally buoyant floats in the North Atlantic, J. Mar. Res., 33, 383-404, 1975.

Gill, A. E., J. S. A. Green, and A. J. Simmons, Energy partition in the large-scale ocean circulation and the production of mid-ocean eddies, Deep Sea Res., 21, 499-528, 1974.

Gould, W. J., W. J. Schmitz, Jr., and C. Wunsch, Preliminary field results for a mid-ocean dynamics experiment (Mode-0), Deep Sea Res., 21, 911-932, 1974.

Heinmiller, R. H., Jr., The Woods Hole buoy project moorings-1960 through 1974, Tech. Rep. 76-53, Woods Hole Oceanogr. Inst., Woods Hole, Mass., 1976.

Hogg, N. G., On spatially growing baroclinic waves in the ocean, $J$. Fluid Mech., 78, 217-235, 1976.

Hogg, N. G., Temperature maps, in Atlas of the Mid-Ocean Dynamics Experiment (Mode), edited by V. Lee and C. Wunsch, Mode-I Scientific Council, Cambridge, Mass., 1977. 
Holland, W. R., and L. B. Lin, On the generation of mesoscale eddies and their contribution to the oceanic general circulation, II, A parameter study, J. Phys. Oceanogr., 5, 658-669, 1975.

Hollister, C. D., and B. C. Heezen, Geological effects of ocean bottom currents: Western North Atlantic, in Studies in Physical Oceanography, edited by A. L. Gordon, Gordon and Breach, New York, 1972.

Hunkins, K. L., Subsurface eddies in the Arctic Ocean, Deep Sea Res., 21, 1017-1033, 1974.

Huppert, H. E., and K. Bryan, Topographically generated eddies, Deep Sea Res., 23, 655-680, 1976.

Kendall, M., and A. Stuart, The Advanced Theory of Statistics, vol. 3, 3rd ed., 585 pp., Griffin, London, 1976.

Kim, K., Instability and energetics in a baroclinic ocean, Ph.D. thesis, Mass. Inst. of Technol., Cambridge, and Woods Hole Oceanogr. Inst., Woods Hole, Mass., 1975.

Leetmaa, A., Maps from the density program, in Atlas of the MidOcean Dynamics Experiment (Mode), edited by V. Lee and C. Wunsch, Mode-I Scientific Council, Cambridge, Mass., 1977.

Liebelt, P. B., An Introduction to Optimal Estimation, 273 pp., Addison-Wesley, Reading, Mass., 1967.

Lilly, D. K., Lectures in sub-synoptic scales of motion and twodimensional turbulence, in Dynamic Meteorology, edited by $\mathrm{P}$. Morel, pp. 354-413, D. Reidel, Hingham, Mass., 1973.

Lorenz, E. A., The nature of the global circulation of the atmosphere, in The Global Circulation of the Atmosphere, edited by G. A. Corby, Royal Meteorological Society, London, 1969.

Luyten, J. R., Scales of motion in the deep Gulf Stream and across the continental rise, J. Mar. Res., 35, 49-74, 1977.

McWilliams, J. C., Maps from the Mid-Ocean Dynamics Experiment, I, Geostrophic streamfunction, J. Phys. Oceanogr., 6, 810-827. $1976 a$.

McWilliams, J. C., Maps from the Mid-Ocean Dynamics Experiment, II, Potential vorticity and its conservation, J. Phys. Oceanogr., 6 , $828-846,1976 b$

McWilliams, J. C., Streamfunction maps, in Atlas of the Mid-Ocean Dynamics Experiment (Mode), edited by V. Lee and C. Wunsch, Mode-I Scientific Council, Cambridge, Mass., 1977.

McWilliams, J. C., and G. Flierl, Optimal, quasigeostrophic wave analyses of Mode array data, Deep Sea Res., 23, 285-300, 1976.

Mofjeld, H. O., and M. R. Rattray, Jr., Barotropic Rossby waves in a zonal current, J. Phys. Oceanogr., 5, 421-429, 1975.

Müller, P., On the diffusion of momentum and mass by internal gravity waves, J. Fluid Mech., 77, 789-823, 1976.

Phillips, N. A., Large-scale eddy motions in the western Atlantic, $J$ Geophys. Res., 71, 3883-3891, 1966.

Pochapsky, T. E., Vertical structure of currents and temperature in the western Sargasso Sea, J. Phys. Oceanogr., 6, 45-56, 1976.

Rhines, P. B., The dynamics of unsteady currents, in The Sea, vol. 6 , edited by E. D. Goldberg et al., John Wiley, New York, 1976.

Richman, J. G., Kinematics and energetics of the mesoscale midocean circulation: Mode, Ph.D. thesis, 205 pp., Mass. Inst. of Tech- nol., Cambridge, and Woods Hole Oceanogr. Inst., Woods Hole, Mass., 1976.

Riser, S., Observations of mesoscale eddies over rough topography in the western North Atlantic, S.M. thesis, 118 pp., Mass. Inst. of Technol., Cambridge, 1974.

Robinson, A. R., and J. C. McWilliams, The baroclinic instability of the open ocean, J. Phys. Oceanogr., 4, 281-294, 1974.

Ruddick, B R . Observations of interaction between the internal wave field and low frequency flows in the North Atlantic, Ph.D. thesis, Mass. Inst. of Technol., Cambridge, and Woods Hole Oceanogr. Inst., Woods Hole, Mass., 1977.

Salmon, R., G. Holloway, and M. C. Hendershott, The equilibrium statistical mechanics of simple quasi-geostrophic models, J. Fluid Mech., 75, 691-703, 1976.

Sanford, T. B., Observations of the vertical structure of internal waves, J. Geophys. Res., 80, 3861-3871, 1975.

Schmitz, W. J., Jr., Eddy kinetic energy in the western North Atlantic, J. Geophys. Res., 81, 4981-4982, 1976a.

Schmitz, W. J., Jr., Observation of a new abyssal current, Geophys. Res. Lett., 3, 373-374, $1976 b$.

Schmitz, W. J., Jr., On the deep general circulation in the western North Atlantic, J. Mar. Res., 35, 21-28, 1977.

Stommel, H., The Gulf Stream: A Physical and Dynamical Description, 2nd ed., 248 pp., Cambridge University Press, New York, 1965.

Swallow, J. C., The Aries current measurements in the western North Atlantic, Phil. Trans. Roy. Soc. London, Ser. A, 270, 451-460, 1971.

Taylor, G. I., Diffusion by continuous moments, Proc. London Math. Soc., 20, 196-212, 1921.

Uchupi, E., Bathymetric atlas of the Atlantic, Caribbean and Gulf of Mexico, Rep. 71-72, 10 charts, Woods Hole Oceanogr. Inst., Woods Hole, Mass., 1971

Ulrych, T. J., and T. N. Bishop, Maximum entropy spectral analysis and autoregressive decomposition, Rev. Geophys. Space Phys., 13 183-200, 1975.

von der Haar, T. H., and A. H. Oort, New estimate of the annual poleward energy transport by northern hemisphere oceans, J. Phys. Oceanogr. 3, 169-172, 1973.

Wunsch, C., The spectrum from two years to two minutes of temperature in the main thermocline at Bermuda, Deep Sea Res., 19, 577-593, 1972

Wunsch, C.. Determining the general circulation of the oceans: A preliminary discussion, Science, 196, 871-875, 1977.

Wunsch, C., and J. Dahlen, A moored temperature and pressure recorder, Deep Sea Res., 21, 145-154, 1974.

Wyrtki, K., L. Magaard, and J. Hager, Eddy energy in the oceans, $J$. Geophys. Res., 81, 2641-2646, 1976.

(Received March 1, 1977; accepted June 15, 1977.) 


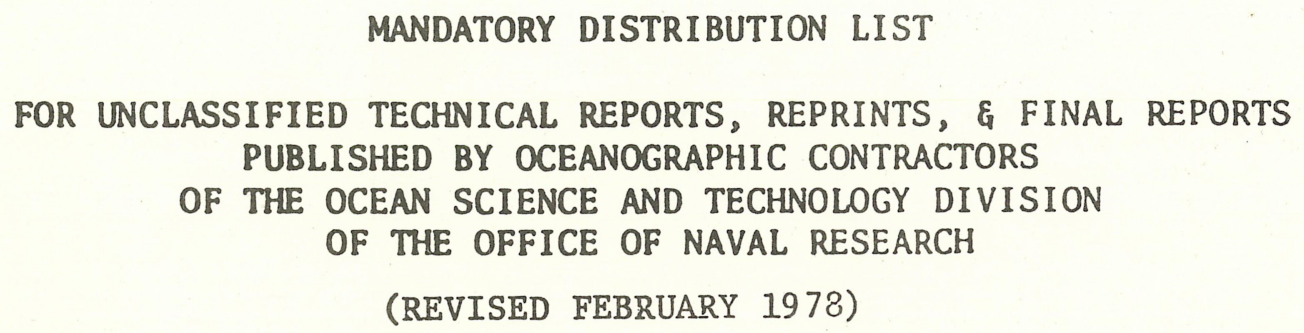

1 Director of Defense Research and Engineering Office of the Secretary of.Defense Washington, D.C. 20301 ATTN: Office Assistant Director (Research)

Office of Naval Research Arlington, VA 22217

1 ATTN: (Code 460)

1 ATTN: (Code 102-OS)

1 ATTN: (Code 200)

1 CDR J. C. Harlett, (USN) ONR Representative Woods Hole Oceanographic Inst. Woods Hole, MA 02543

1 National Oceanographic Data Center

National Oceanic \& Atmospheric Administration 330 C Whitehaven St., N.W. Washington, D.C. 20235

12 Defense Documentation Center Cameron Station Alexandria, VA 22314

Commander Naval Oceanographic Office Washington, D.C. 20373

1 ATTN: Code 1640

1 ATTN: Code 70

1 Office of Naval Research Branch Office

3 NORDA 430 495 Summer Street Boston, MA 02210 NSTL Station, MS 39529

Director Naval Research Laboratory Washington, D.C. 20375

6 ATTN: Library, Code 2620

2 CO NORDA NSTL Station, MS 39529 



\begin{tabular}{|c|c|}
\hline REPORT DOCUMENTATION PAGE & $\begin{array}{l}\text { READ INSTRUCTIONS } \\
\text { BEFORE COMPLETING FORM }\end{array}$ \\
\hline $\begin{array}{l}\text { TEEPORT NUMBER } \\
\text { WHOI-78-45 IDOE } 78-303\end{array}$ & 3. RECIPIENT'S CATALOG NUMBER \\
\hline $\begin{array}{l}4 \text { TITLE (and Subtitle) } \\
\text { SPACE AND TIME SCALES OF MESOSCALE MOTION IN THE } \\
\text { WESTERN NORTH ATLANTIC }\end{array}$ & $\begin{array}{l}\text { 5. TYPE OF REPORT A PERIOD COVEREO } \\
\text { Technical }\end{array}$ \\
\hline $\begin{array}{l}\text { 7. AUTHOR(s) } \\
\text { James G. Richman, Carl Wunsch and Nelson G. Hogg }\end{array}$ & $\begin{array}{l}\text { 8. CONTRACT OR GRANT NUMBER(O) } \\
\text { NO0014-66-C-0241; } \\
\text { N00014-74-C-0262; } \\
\text { N00014-76-C-0197; }\end{array}$ \\
\hline $\begin{array}{l}\text { 9. PERFORMING ORGANIZATION NAME AND ADDRESS } \\
\text { Woods Hole Oceanographic Institution } \\
\text { Woods Hole, MA } 02543\end{array}$ & $\begin{array}{l}\text { 10. PROGRAMELEMENT, PROJECT, TASK } \\
\text { AREA Q WORK UNIT NUMERS } \\
\text { NR } 083-004 \\
\text { NR } 083-400\end{array}$ \\
\hline $\begin{array}{l}11 \text { CONTROLLING OFFICE NAME AND ADDRESS } \\
\text { NORDA } \\
\text { National Space Technology Laboratory } \\
\text { Bay St. Louis, MS } 39529\end{array}$ & $\begin{array}{l}\text { 12. REPORT DATE } \\
\text { AugUST } 1978 \\
\text { 13. NUMBER OF PAGES }\end{array}$ \\
\hline $\begin{array}{l}\text { 14. MONITORING AGENCY NAME ADDRESS(If dllfepent lrom Confrolline Oflice) } \\
\text { *** GX-29054, GX-29034, OCE 75-03962, } \\
\text { IDO-82534 }\end{array}$ & $\begin{array}{l}\text { 15. SECURITY CLASS. (Of thI POPORE) } \\
\text { UnClaSSIFIEd } \\
\text { 15. DECLLASSIFICATION/DOWNGRADING } \\
\text { SCHEDULE }\end{array}$ \\
\hline
\end{tabular}

16. DISTRIBUTION STATEMENT (of this Report)

Approved for public release; distribution unlimited.

17. DISTRIBUTION STATEMENT (of the abetract onfored in Block 20, If difforent from Ropopt)

18. SUPPLEMENTARY NOTES

Reprinted from "Reviews of Geophysics and Space Physics, Vol. 15, No. 4, November 1977, pp. 385-420".

19. KEY WOROS (Continue on peverse alde if necensary and tdentlly by block number)

1. LoW-frequency motions

2. Mesoscale eddy field

3. MODE

20. ABSTRACT (Coninue on poverse olde if neceseary and identliy by block number)

Refer to p. 385 of reprint. 



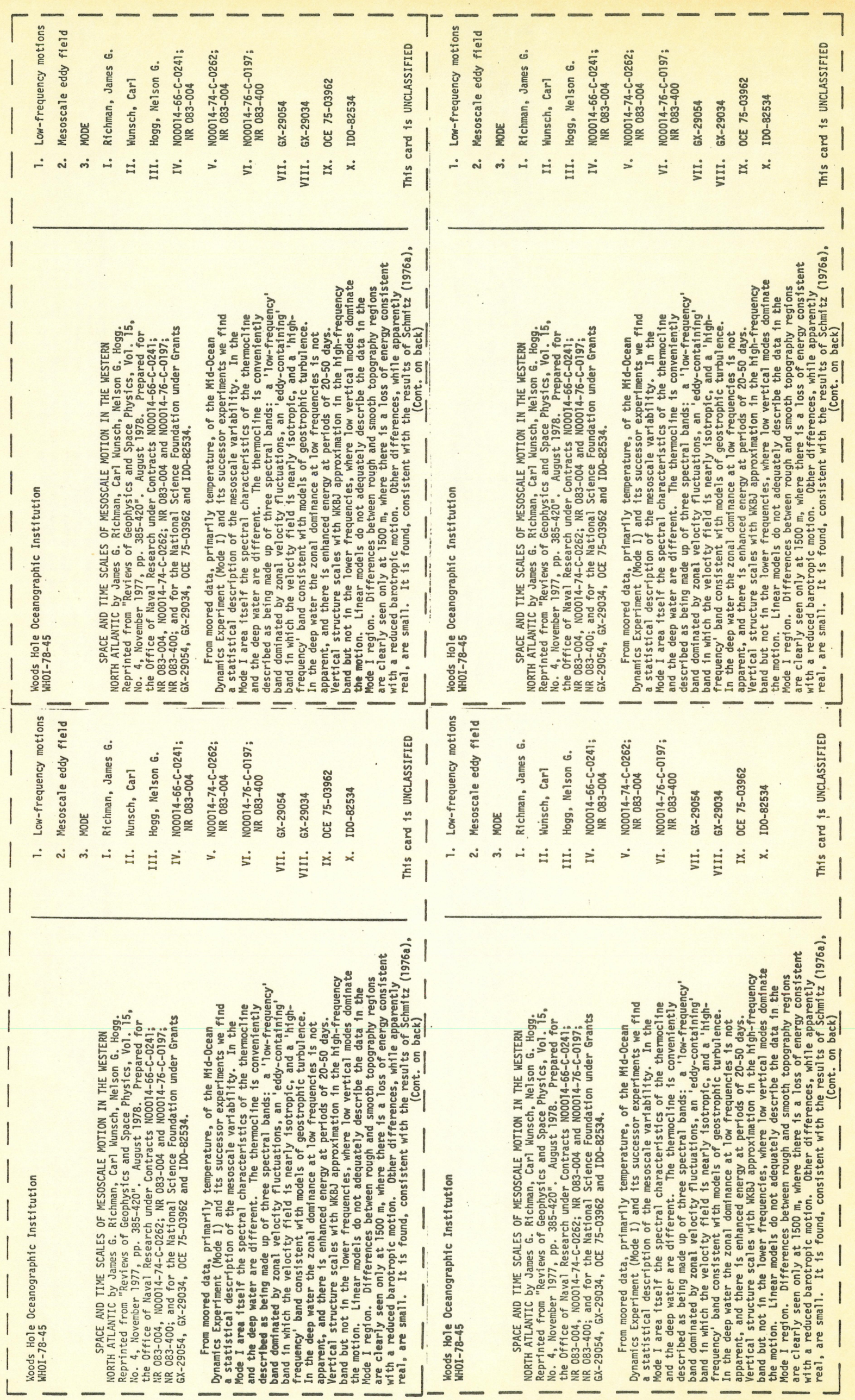



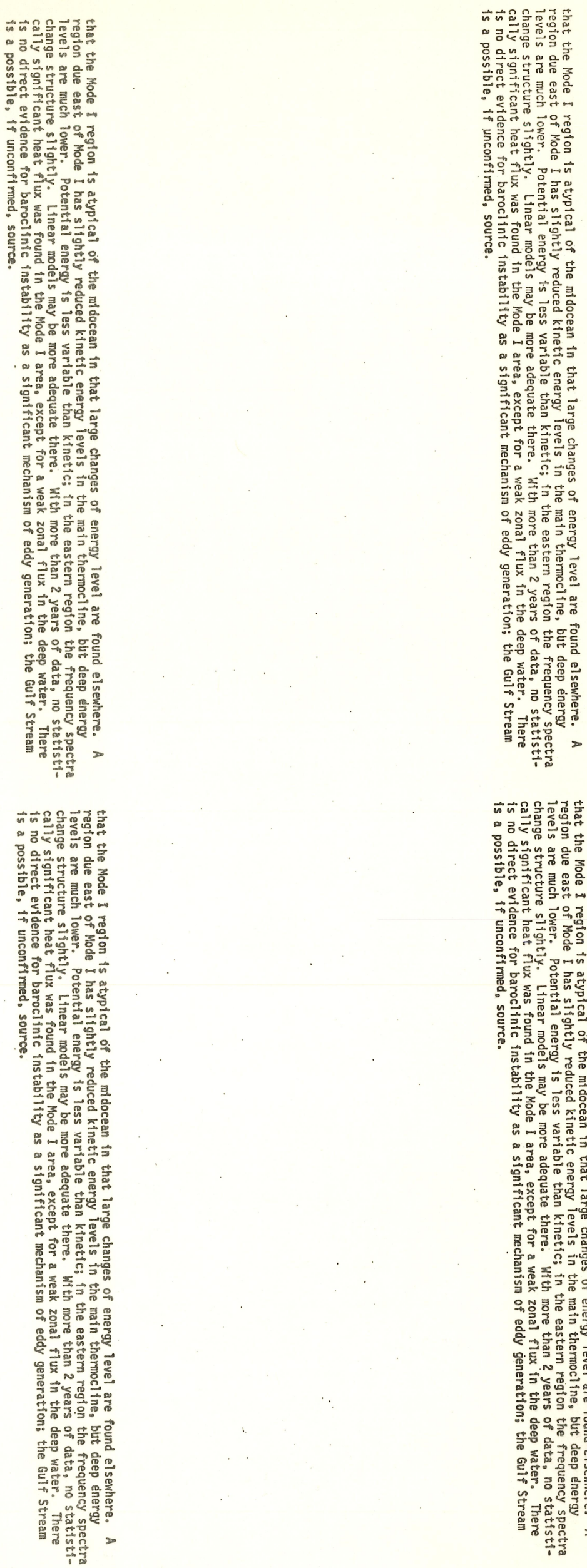

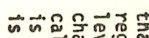

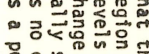

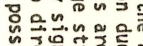

可

里过 둥

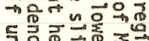

잉

욱 군무

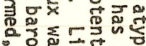

궁

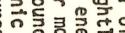

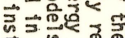

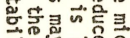

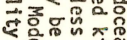

跴产

品

茨。

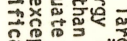

可

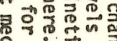

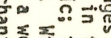

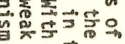

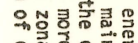

을

c.

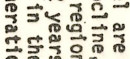

年

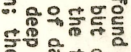

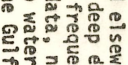

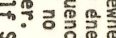

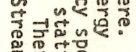

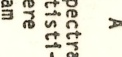

